\title{
The Impact of the Inclusive Education Strategy on the Education of Primary School Students with Disabilities in Vientiane, Lao PDR
}

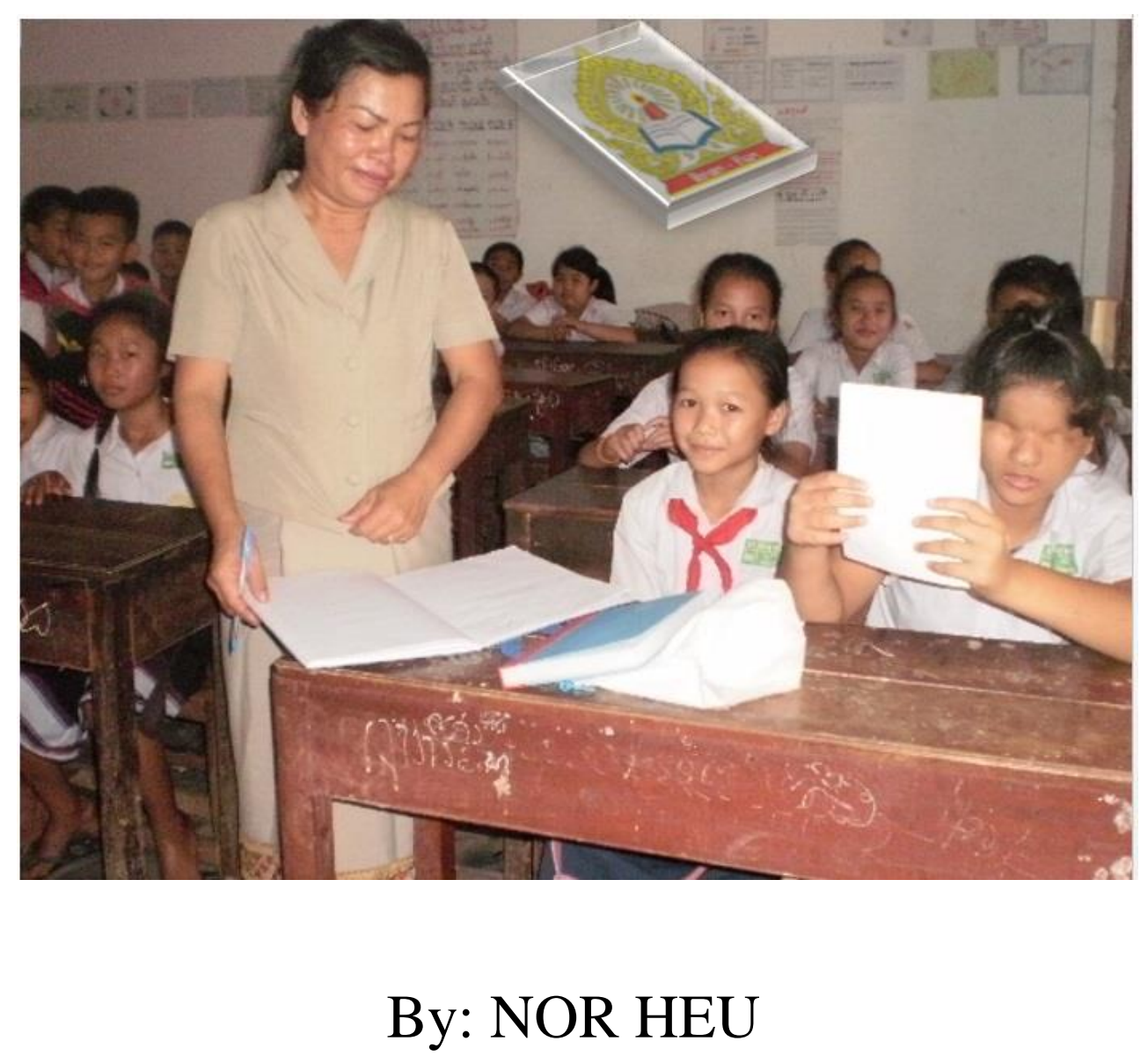

A 120-point thesis submitted to Victoria University of Wellington in partial fulfilment of the requirements for the degree of Master of Development Studies School of Geography, Environment and Earth Sciences Victoria University of Wellington 


\begin{abstract}
The inclusive education (IE) strategy promotes the inclusion of all children regardless of their abilities into mainstream schools. Little, however, is known about its impact on the inclusion of children with all sorts of disabilities at the primary school level. This study explores this issue. The main objective of this study is to analyse the impact of the Lao IE strategy in developing the public mainstream primary school system so as to be responsive to the needs of primary school students with impairments in Vientiane, Lao PDR. This is a qualitative research project which adopted semi-structured interviews, observations, and document analysis. Data was gathered from 45 participants from different backgrounds; notes recorded direct observations in primary schools; and documents such as reports and statistics were collected during the field work in Vientiane over the two month period of May and June 2015. The study established that many countries have experienced challenges in translating the IE concept into practice. Lao PDR also faces similar challenges.

The study suggests that despite the ongoing continuous improvement of the Lao IE, the principle of inclusion is not yet fully employed. Children with more complex disabilities, such as being blind, deaf, mute or having an intellectual impairment, are still restricted to studying in special schools. This practice appears to be in contradiction to the principles of inclusion, to the social model of disabilities, and to a rights-based approach to education. In addition, the lack of government funding allocated specifically to implement the IE strategy at both national and local levels indicates the current weakness of the Lao IE system. As a consequence, children with more complex impairments still cannot receive meaningful and quality education in almost all public mainstream primary schools.

Furthermore, it is evident that, although the Lao IE policy officially targets all children, in practice there has, as yet, been little impact on mainstream primary schools that are the focus of this research. Data regarding students with impairments is not collected by the relevant authorities in a consistent system. The IE policy has not been fully translated into mainstream primary school policies and development plans. The existing 'IE' schools continue to experience challenges in accessing the essential financial and technical supports they need to prepare to accept children with disabilities. Basic facilities and disabilities-related services are mostly unavailable. Importantly, the Ministry of Education and Sports (MOES) has not yet officially recognised and approved
\end{abstract}


the use of braille and sign language, even though these languages have been developed by the Ministry of Health (MOH), the Centre of Medical Rehabilitation (CMR) to teach only children with disabilities who are enrolled in the Centre. Many people have criticised MOES for not taking the lead in the provision of education for children with disabilities. Although MOES has depended on the CMR's expertise and resources to support its IE strategy, children with disabilities continuously experience obstacles in accessing and learning together with none disabled students in public mainstream primary schools that adequately meet their basic needs. This is why many people believe that children with disabilities cannot attend mainstream primary schools and the best place to learn was the CMR.

Finally, participants still retained a medical perspective regarding disabilities. The Lao government itself still translates 'disabilities' as medically defined health issues. An understanding of disabilities in terms of the more recent social model was not common among participants in this study. Given that many people hold the medical perspective, individual impairments continue to be blamed as barriers to accessing services such as education, which is opposed to the social model approach to disabilities. The present stage of development of Lao IE strategy still seems to reinforce the exclusion of children with disabilities from accessing the education that is their human right.

Key words: Inclusion, Inclusive Education; Disability, Mainstream Education, Student with disabilities. 


\section{ACKNOWLEDGEMENTS}

I would like to express my gratitude and deep honour to all the people who have contributed greatly towards the success of this thesis. Firstly, I want to thank my research supervisors, Dr. Polly Stupples and Professor John Overton. You have both contributed invaluable advice and inspired comments throughout this study. Secondly, I want to acknowledge Linsell Richards, team leader of New Zealand Aid Scholarships for assisting me by arranging financial and proof reading support for this research. Thirdly, thanks to both Steuart Henderson and Dr. Pete Howson for taking extra time and effort to proof-read and suggest edits to improve the language in all my thesis chapters. Your help has enabled me to improve my writing and to better communicate ideas in my thesis. Moreover, I wish to thank all participants in Vientiane, Lao PDR for giving up your invaluable time and knowledge to participate in this research. Without your help I would not have obtained the data to write this thesis. Lastly, I want to thank my partner, Mrs. Yermoua Palee, both for acting as my research assistant, and for doing all the family tasks such as preparing daily meals, washing, and taking care of our two children while I was absent from my husband roles. Therefore, may my Lord, Jesus Christ bless all of you who are part of my research, to succeed in your lives. 


\section{ABBREVIATIONS}

\begin{tabular}{|c|c|}
\hline ASEAN & Association of the Southeast Asia Nations \\
\hline CEECIS & $\begin{array}{l}\text { Central and Eastern Europe and the Commonwealth of Independent } \\
\text { States }\end{array}$ \\
\hline CRM & Centre of Medical Rehabilitation \\
\hline DPOs & Disabled People Organisations \\
\hline EFA & Education for All \\
\hline ESDF & Education Sector Development Framework \\
\hline ESWG & Education Sector Working Group \\
\hline GDP & Gross Domestic Product \\
\hline IE & Inclusive Education \\
\hline IEC & Inclusive Education Centre \\
\hline INGOs & International non-Government Organisations \\
\hline JICA & Japan International Cooperation Agency \\
\hline LDPA & Lao Disabled People's Association \\
\hline Lao PDR & Lao People's Democratic Republic \\
\hline MDGS & Millennium Development Goals \\
\hline MOES & Ministry of Education and Sports \\
\hline $\mathrm{MOH}$ & Ministry of Health \\
\hline MOPWT & Ministry of Public Works and Transportation \\
\hline NSC & National Statistics Centre \\
\hline OECD & Organisation for Economic Cooperation and Development \\
\hline $\mathrm{SCN}$ & Save the Children Norway \\
\hline SDESS & Saythany District Education and Sports Service \\
\hline UN & United Nations \\
\hline UNCRC & United Nations Convention on the Rights of the Child \\
\hline UNCRPD & United Nations Convention on the Rights of Persons with Disabilities \\
\hline UNDP & United Nations Development Programme \\
\hline UNESCO & United Nations Educational, Scientific, and Cultural Organisation \\
\hline UNICEF & United Nations Children’s Fund \\
\hline USCB & United States Census Bureau \\
\hline WB & The World Bank \\
\hline WHO & World Health Organisation \\
\hline
\end{tabular}




\section{TABLE OF CONTENTS}

CONTENTS

PAGE

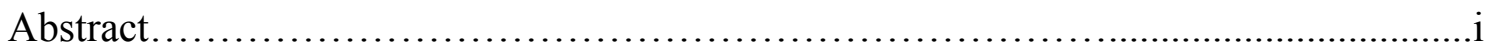

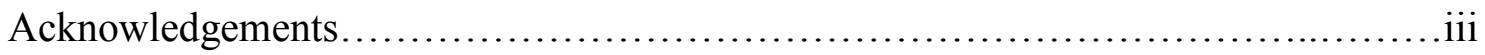

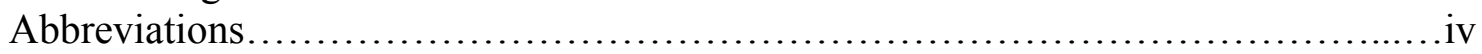

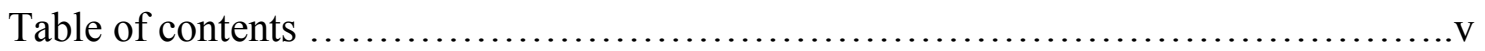

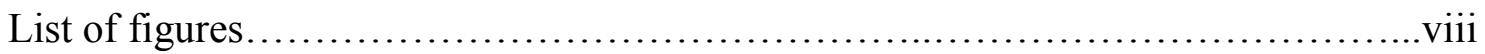

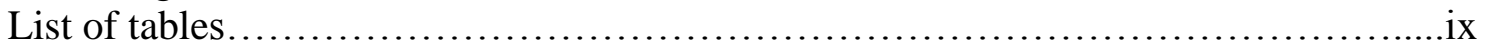

CHAPTER ONE: INTRODUCTION .......................................

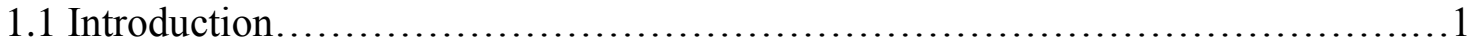

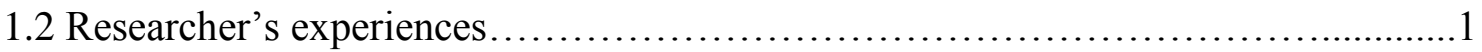

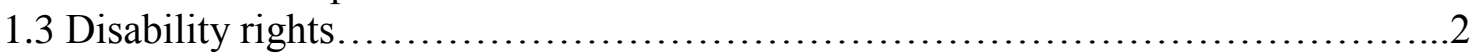

1.4 Human rights-based approach to children's development........................ 3

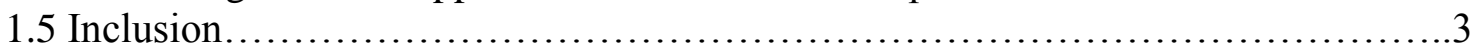

1.6 The inclusive education principles....................................... 4

1.7 Selecting children with disabilities and primary school education..................5

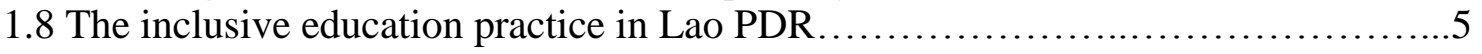

1.9 Research objectives..................................................... 7

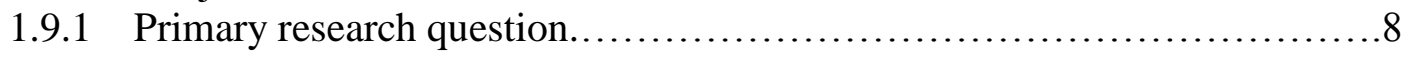

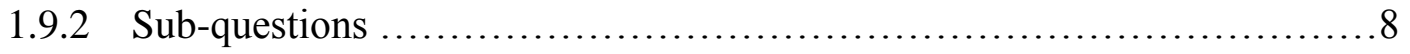

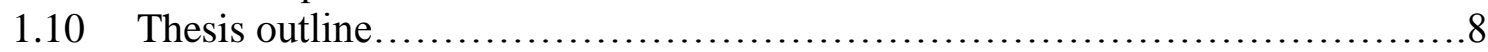

CHAPTER TWO: LITERATURES REVIEW .................................. 10

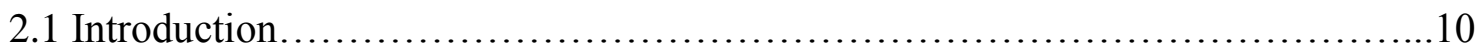

2.2 Development and Human Rights........................................... 10

2.3 Human rights based approach to development................................ 12

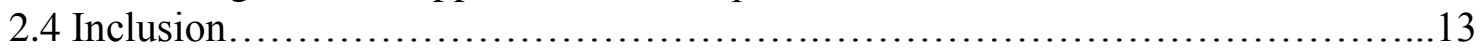

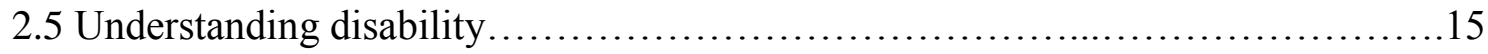

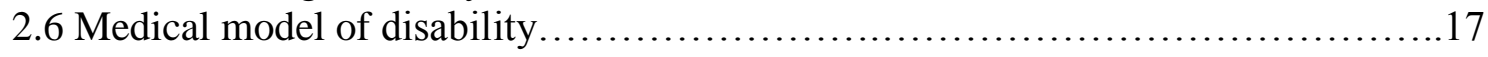

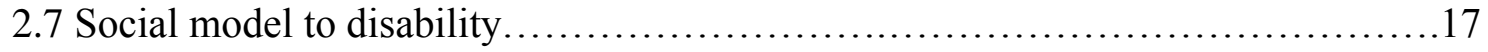

2.8 Children with disability and basic education................................... 19

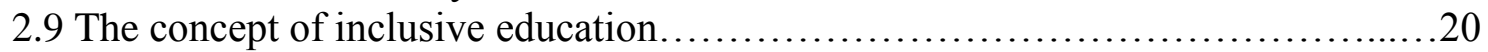

2.10 Legal frameworks of the inclusive education................................. 21

2.11 The outcomes of inclusive education practice..............................22

2.12 Other obstacles to inclusive education practice............................. 26

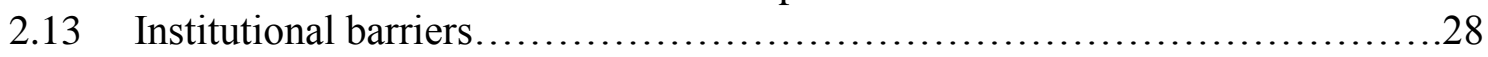

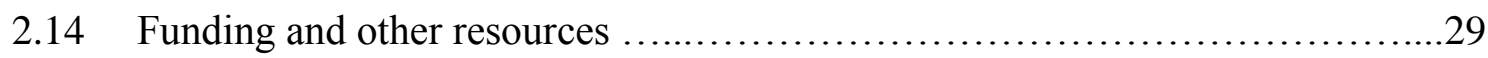

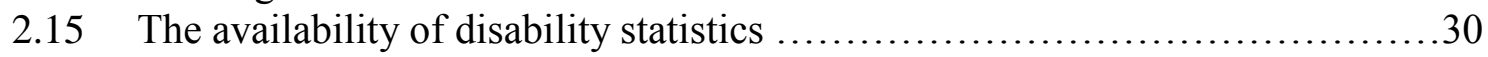

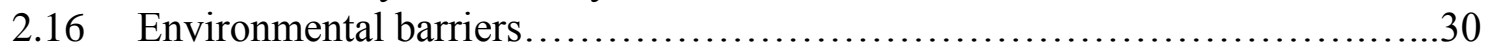

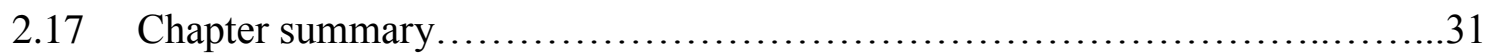

CHAPTER THREE: RESEARCH METHODOLOGY ............................ 33

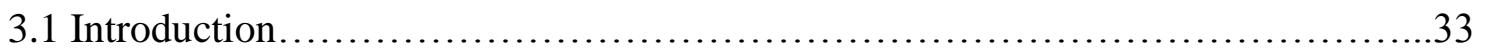

3.2 Conceptual framework of the research methodology.......................... 33

3.3 The effects of the researcher's positionality..................................... 34

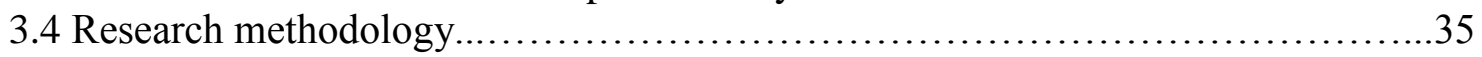

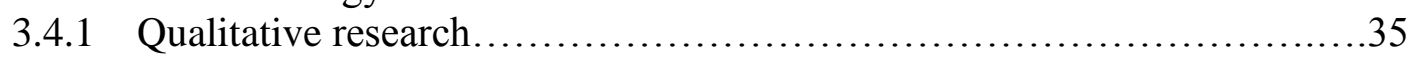

3.4 .2 Document analysis.............................................. 36 
3.4.3 Semi-structured interviews........................................... 36

3.4.4 Observations....................................................... 37

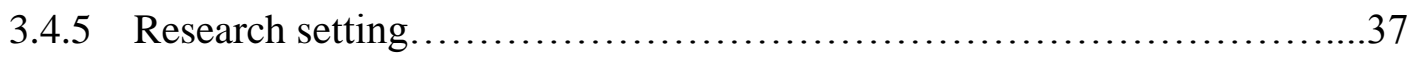

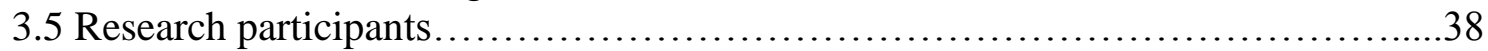

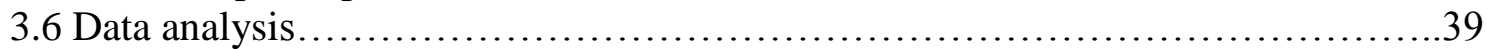

3.7 Research ethics and data collection permits................................. 40

3.8 Field research experiences................................................. 41

3.9 Chapter summary...........................................................

CHAPTER FOUR: THE CONTEXT OF THE INCLUSIVE EDUCATION

STRATEGY OF LAO PDR .................................................... 42

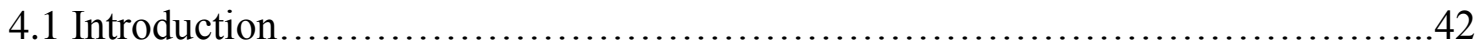

4.2 The political context...................................................43

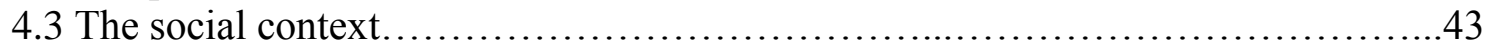

4.4 The economic context........................................................ 45

4.5 National development priorities......................................... 46

4.6 Legislation and the administration the Lao education system.....................47

4.7 The context of disability in the Lao PDR ........................................50

4.7.1 Definition of disability ............................................ 50

4.7.2 Statistics on people with disabilities ...................................50

4.8 The special education context in Lao PDR ..................................55

4.9 The Lao inclusive education concept and practices of the Ministry of Education and

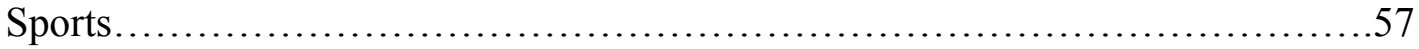

4.9.1 The establishment of the Inclusive Education Centre ....................57

4.9.2 Inclusive education principles........................................57

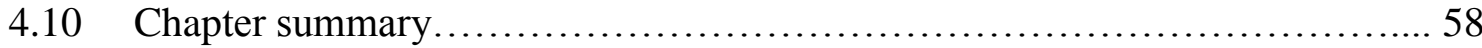

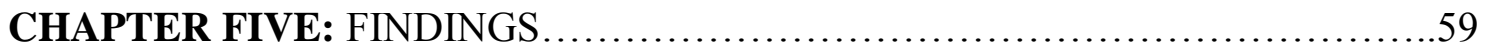

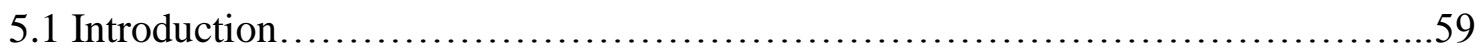

5.2 The adoption of inclusive education into national policies.......................59

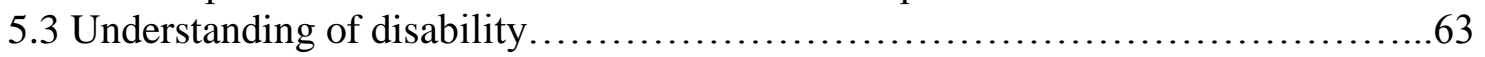

5.4 Attitudes towards children with disabilities..................................64

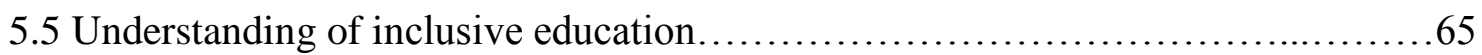

5.6 Inclusive education characteristics.........................................66

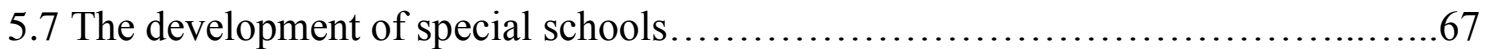

5.8 Mainstream primary schools' welfare and services policies.....................68

5.9 The education of student with disabilities....................................69

5.10 Reforming mainstream primary schools' teaching methods...................70

5.11 The prevalence of mainstream inclusive primary schools $\ldots \ldots \ldots \ldots \ldots \ldots \ldots . .71$

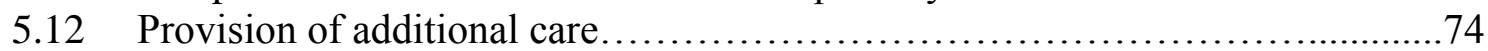

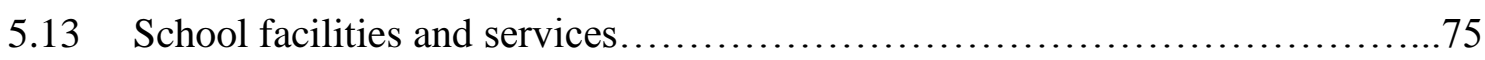

5.14 Teachers development............................................... 77

5.15 Data on primary school students with disabilities............................ 77

5.16 Educational stakeholders participation................................... 79

5.17 Primary school's inclusive education strategy............................. 80

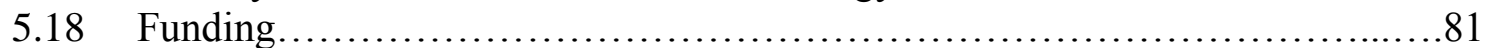

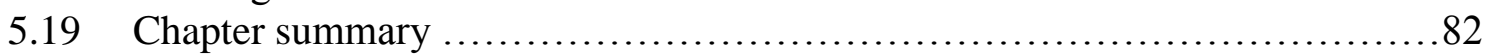




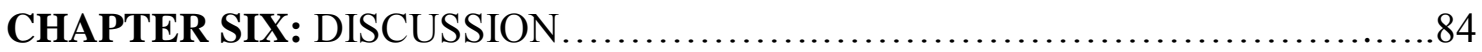

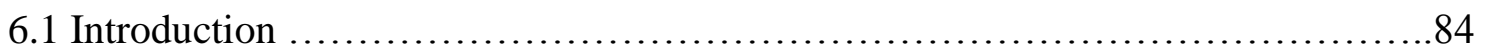

6.2 Lao inclusive education strategy ........................................ 84

6.2.1 The principle of the Lao inclusive education strategy....................84

6.2.2 Data on children with disabilities ................................... 85

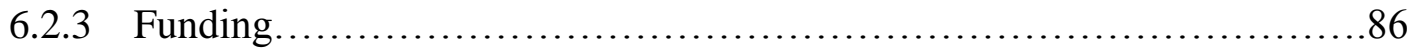

6.2.4 The development of mainstream inclusive primary schools ..............87

6.3 Participants' perceptions.................................................. 88

6.3.1 Knowledge of the inclusive education strategy............................. 88

6.3.2 Children with disabilities and their education.............................89

6.3.3 The education of children with disabilities in mainstream schools...........90

6.3.4 Perceptions on disabilities......................................90

6.4 Factors affecting the implementation of the inclusive education strategy...............92

6.4.1 Physical environmental facilities....................................92

6.4.2 Stakeholders participation..........................................92

6.4.3 The inclusive education strategy of mainstream primary schools...........93

6.5 Chapter summary............................................................ 94

CHAPTER SEVEN: CONCLUSION ......................................... 95

7.1 Introduction........................................................ 95

7.2 The inclusive education strategy and primary school students with disabilities......95

7.3 Suggestions for future research.............................................97

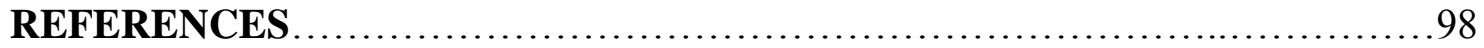

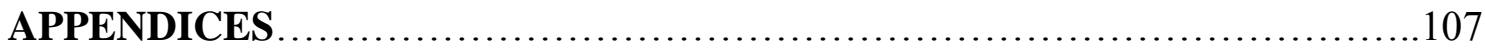

Appendix A: Ethic approval................................................. 107

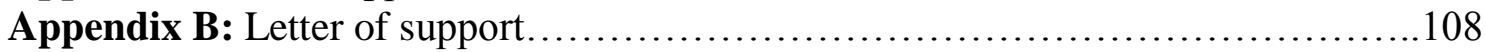

Appendix C: Participant information sheet..................................... 109

Appendix D: Semi-structured interview questions............................ 110

Appendix E: Transcriber confidentiality form ................................. 111

Appendix F: Letter of proposal........................................... 112

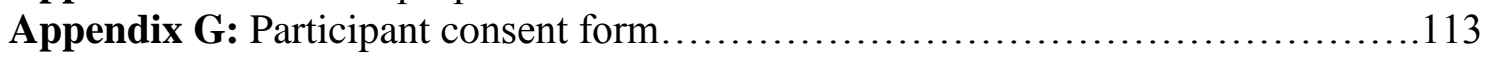




\section{LIST OF FIGURES}

Figure 1: Comparing impairment, disability and handicap........................ 16

Figure 2: Proportion of children with and without disabilities in schools in $2008 \ldots . . .19$

Figure 3: Map of Lao PDR ........................................... 43

Figure 4: Some of the key disability rights stakeholders...........................54

Figure 5: The Centre of Medical Rehabilitation...................................55

Figure 6: The entrance of the Inclusive Education Centre..........................61

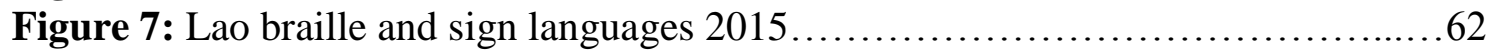

Figure 8: Student with visual impairment in Nalao mainstream primary school.........72

Figure 9: Key mainstream and special schools for blind, deaf and autistic students in

Vientiane................................................................ 73

Figure 10: Primary school students and teachers' toilet............................ 76 


\section{LIST OF TABLES}

Table 1: Comparing segregation, integration and inclusion........................ 14

Table 2: Statistics of primary school students with disabilities in Vientiane.............38

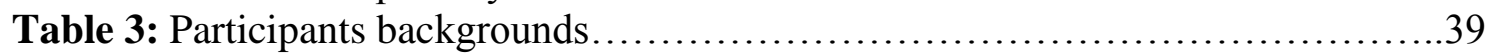

Table 4: General education system....................................... 48

Table 5: Disability questions of the Population and Housing Census 2005.............51

Table 6: Disability data of the Population and Housing Census 2005 ..................52

Table 7: Disability questions of the Population and Housing Census 2015 .............53

Table 8: Disability data form in English version of the Saythany District Education and Sports

Bureau................................................................... 78

Table 9: Disability data form in Lao version of the Saythany District Education and

Sports Bureau........................................................... 79 


\section{CHAPTER ONE \\ INTRODUCTION}

\subsection{Introduction}

This chapter explains my central motivations behind this research project. It discusses my own previous personal experiences, as well as key ideas in relation to disability rights, children's rights and inclusive primary education. It outlines the research objectives and research questions and outlines the chapters which follow.

\subsection{Researcher's experiences}

My work experience played a vital role in selecting this research topic. Since 2006, I have worked with different International Development Organisations (INGOs) such as World Vision, Mines Advisory Groups, Digital Divide Data and Handicap International in Lao PDR. These organisations gave me opportunities to experience living with impoverished people, including victims of unexploded ordnance (UXOs) and people with disabilities. I also came to realise that people with disabilities were commonly amongst the poorest people, in part because their basic rights had been ignored and forgotten by the majority.

In 2010 I worked as a Disability Rights Mainstreaming Officer with Handicap International Lao PDR. In this position, I conducted many training sessions on disability rights and equality for different development stakeholders, including development partners' staff, government officials, INGOs' staff, community members and people with disabilities themselves, across five different provinces in Lao PDR. After conducting over fifty of these training sessions, I came to realise that it was difficult to transform negative attitudes within Lao society towards people with disabilities. My experiences revealed that successfully promoting a long term positive impact on the livelihoods of people with disabilities would require ensuring that children with disabilities were able to study and continue their further education in a similar way to others within the community. This is because I found that very few children with disabilities had access to the basic education that is provided in Vientiane at special schools for the disabled. There were only three or four of these special schools for children with disabilities across the entire country. This situation made me concerned about the education of children with disabilities. 


\subsection{Disability rights}

Such issues can clearly be viewed as connected to the rights of people with disabilities. The United Nations Convention on the Rights of Persons with Disabilities (UNCRPD) which was opened for signatory and ratification in 2006 states that disability is "an evolving concept and that disability results from the interaction between persons with impairments and attitudinal and environmental barriers that hinders their full and effective participation in society on an equal basis with others" (United Nations, n.d (a), p.1). It has been recognised internationally that there is an obligation to value the lives of all people, including people with disability, and to enhance their full and effective participation in development processes (United Nations, n.d (a)). To practice this vision, one of the most important steps is for people with special needs to be educated, because being educated helps individuals to understand and exercise their basic human rights in a way that takes account of the available local opportunities.

Access to a quality education is considered a crucial part of human development, especially during the early development of a child as evidenced by the focus on education in the Millennium Development Goals (MDGs). Therefore, this study was designed to explore how disability and basic education are strongly interrelated with the agenda for personal development. Even though getting access to basic education without any barrier is a fundamental human right, and no person should be either directly or indirectly denied this, millions of children with special needs do continue to be ignored in the formal education system.

If children with disabilities remain excluded from formal mainstream educational institutions, they will face major challenges for the rest of their lives. Being educationally excluded ultimately results in being vulnerable to poverty as discussed in a report by the World Health Organisation (WHO) and The World Bank (WB) (2011). Globally, more than one billion people live with disabilities. They are the world's largest minority (WHO \& WB, 2011). People with disabilities face greater barriers to recovering from any type of disasters; they are more exposed to being victims of violence; and they have less ability than their counterparts to gain employment (ibid, p.48). Ninety per cent of children with disabilities in developing countries do not attend school, according to UNESCO (n.d., p.1). If this situation persists, children with disabilities will struggle to realise their full potentials. 


\subsection{Human rights-based approach to children's development}

The human rights-based approach to promote the rights of children with disabilities mainly depends on two international conventions. The first is The United Nations Convention on the Rights of the Child (UNCRC) 1989. This Convention functions as a guiding principle for signatory governments, to ensure that the rights of a child are not being violated, and that the right of all children to education is honoured on the basis of equal opportunity (UNICEF, 2011, p.13). The UNCRC seems to assume that all children will enjoy equal access to educational opportunities. However, in reality, for many nations, millions of children with disabilities are absentees from any formal education (UNICEF, 2014). UNCRPD is another convention that gives an assurance by all state signatories, that they will remove barriers which prevent people with disabilities from accessing their basic rights, including access to basic education (UNICEF, 2011, p.14). Lao PDR is a signatory to both conventions. It is important to note, however, the implementation of such conventions do not result in the same outcomes in all cultures and within all nations.

\subsection{Inclusion}

Inclusion has emerged as a dominant issue in development since the late 1990s (UNESCO, 2009). Inclusion is rooted in the principles of a social development model which recognizes support for those with disabilities as a development goal rather than seeing disability as an individual problem (Dyson, 2003). One of the stereotypes related to disability is that individual impairments are the cause of exclusion from social, economic or political activities. This bias has brought about the 'integration' principle, which requires persons with disabilities, including children with special needs, to adapt themselves in order to conform to mainstream norms, environments and policies (UNICEF, 2011, pp. 5-7). This idea of integration has perpetuated the view that disability used to be viewed as an individual issues rather than a social barriers (ibid). However, inclusion also recognises the need to reform and transform these negative attitudes, environments, institutions and practices to accommodate the needs of persons with disabilities. Inclusion principles also address the need to remove any barriers, and to promote safety and protection for persons with disabilities. If the mainstream education system is transformed based on the principles of inclusion, underlying values and beliefs held by all policy decision makers need to be shifted from a negative view of those with disabilities to an 
inclusive and welcoming attitude. Within the context of education, inclusion is defined as:

“...the creation of barrier-free and child-focused learning environments, including for the early years. It means providing appropriate supports to ensure that all children receive education in non-segregated local facilities and settings, whether formal or informal...involves the removal of barriers that might prevent the enjoyment of these rights, and requires the creation of appropriate supportive and protective environment [...] is not the same as 'integration', which implies bringing children with disabilities into a 'normal' mainstream or helping them to adapt to 'normal' standards" (UNICEF, 2007, p.1).

Similarly, Rafferty, et al. (2001) define inclusion as the process of providing a meaningful and appropriate educational environment that does not either directly or indirectly discriminate against children with any type of impairment in mainstream schools; these schools being the same ones these children would attend if they did not have the disability (cited in de Boer, et al., 2011).

\subsection{The inclusive education principles}

It is widely known that children with disabilities do not enjoy the same rights to education as other non-disabled children across the world. Inclusive education (IE) principles were formulated to re-emphasise a process of continuously adapting educational institutions, practices and environments on a non-discriminatory basis, regardless of student abilities (UNESCO, 2009). IE aims to promote basic human rights, an inclusive society, and efficient and effective education systems (UNESCO, 2009. IE has become one of the most significant global educational initiatives to improve education systems, so as to embrace students with diverse abilities, including children with disabilities. According to Kim (2014), many children with disabilities in developing countries are absent from school, and some of those who do attend school are enrolled in special schools, or IE schools delivering poor quality education. Kim also adds that removing the barriers to education for those with disabilities has not yet been addressed adequately, even though many countries have developed and implemented IE policies and action plans. 


\subsection{Selecting children with disabilities and primary school education}

Remedying the exclusion of millions of children with disabilities from formal education has become one of the international development priorities (UNICEF, 2011). It is estimated that within 27 countries in South Eastern Europe, Central Europe and the Commonwealth of Independent States (CEECIS), there are 1.8 million children with disabilities of primary school age who are not attending school (UNICEF, 2011, p. 8). This estimate would necessarily be much larger if it included the number of children with disabilities in other parts of the world such as Africa and Asia. Considering development priorities, we find that even though there are a number of development initiatives which attempt to improve the livelihoods of all children, such attempts have commonly overlooked the needs of children with disabilities. Children with disabilities constitute one of most vulnerable groups in society, especially children with disabilities who are also female; from an ethnic minority; from a family in poverty; or from other social, political or religious minorities.

Primary education, one of the fundamental human rights, plays a crucial role in the development of every child. Early childhood development lays the most important foundation for breaking the poverty cycle and building a prosperous life (UNDP, 2014). If children with disabilities are neglected during their early years, they are likely to remain poor and vulnerable during their later years. If the needs of children with disabilities are excluded and forgotten from development priorities, especially education development plans, millions of children with disabilities as well as their families may be unable to obtain and exercise many crucial basic human rights (UNICEF, 2007).

\subsection{The inclusive education practices in Lao PDR}

Over the past ten years, the government of Lao PDR has adopted international and regional policies in addressing the needs of persons with disabilities and promoting IE policies. Although the education system of Lao PDR appears to be poorly financed and weak in many parts, the Lao government has continuously putting efforts in improving its education policies and practices through the adoption and implementation of the Salamanca Statement and Framework for Action on Special Needs Education 1994 (United Nations Educational, Scientific and Cultural Organisation (UNESCO), 2012). At the regional level, the Asian and Pacific Decade 
of Disabled Persons (1993-2002) has also affected the development of IE in Lao PDR (Price \& Takamine, 2003).

Very importantly, in 1991, Lao PDR ratified the United Nations Convention on the Rights of the Child (UNCRC) (UNICEF, n.d.). After the government of Lao PDR ratified the UNCRC, it developed legislation to protect the rights and interests of the child, and established the National Commission for Mothers and Children to monitor and coordinate children's issues across ministries (Save the Children Norway, 2009). In addition, the government of Lao PDR ratified the UNCRPD in 2009, and established the National Commission for Disabled Persons to monitor the implementation of the Convention (United Nations, n.d (a)). However, despite the government ratifying the UNCRC and UNCRPD, and developing and approving children's rights, legislation and decrees regarding persons with disabilities, clear guidelines for implementation linked to the provision of necessary resources, including funding, have been inadequate to enable the effective and efficient implementation of these policies.

Although Lao PDR values the importance of EFA, before 1990 there was no special or IE school that provided education to children with disabilities (Grimes, et al., 2011). Special schools were initially administered by the Ministry of Health, when arguably they should be the responsibility of the Ministry of Education and Sports, but they are not. Moreover, many teachers are motivated to teach all children, including those with disabilities. Despite this, teaching and services are commonly poorly delivered (Bouthakhanh, 2013). Teaching and learning materials needed for different types of disabled student are not available, except in the special schools.

In addition, children with disabilities in Lao PDR not only experience obstacles in accessing education but they also experience cultural prejudices. One of the core values of Buddhism is the belief in reincarnation of human beings (Vorapanya and Dunlap, 2014, p. 1015). Such a value views disability as a punishment resulting from sinful acts committed in a previous life. Culturally, many Lao people still believe that disabled people are less value than other non-disabled people. Moreover, under Buddhist's karma, disability is viewed as a shameful condition. Challenging this view can be religiously and politically sensitive.

In order to reduce prejudice towards disabled people, developing mainstream schools to be inclusive has been discussed by the government of Lao PDR. Lao PDR is a signatory to many international and regional IE frameworks, and in order to 
implement these, in 2008 the MOES established the IEC and in 2012 the IEC started to play an active role in drafting IE policy and action plans, including guidelines managed by the Division of Special Education of the IEC. Within the MOES there are no clear governance or administrative structures that can facilitate the coordination of measures to address disability rights. The MOES mostly depends on external donors, and on CMR and disabled people organisations' funding and technical advice. There are only a few staff in MOES who have training and a qualification relating to supporting those with disabilities. Moreover, there is no proper system to collect statistical data regarding disability issues in Lao PDR. Consequently it is likely to be difficult for the MOES and other stakeholders to plan, implement and monitor their plans effectively.

Based on the above concerns, this research project will assess and evaluate the impacts of the MOES IE strategy under the principals of IE on the education of primary school students with disabilities. This study focuses primarily on public mainstream primary schools within one province of Lao PDR.

\subsection{Research objectives}

This research project aims to examine the level of responsiveness of the Lao PDR IE strategy under the IE principals to the needs of primary school students with disabilities in public mainstream schools in Vientiane, Lao PDR. It is intended that the findings of this project will fulfil three major aims. Firstly, it will analyse lessons learned from the implementation thus far of the IE strategy, in particular its impact on the education of primary school students with disabilities. Gathering different perspectives, this analysis will also identify ways to minimise challenges. Secondly, it will explore ways to expand the IE principles to all primary schools across the country. It will identify IE indicators that are locally appropriate in order to measure the responsiveness and quality of the education delivered within public mainstream primary schools which incorporate the complexity of a range of disabilities. Finally, this research aims to raise stakeholders' awareness of how to work better together, in order to ensure that all children with disabilities are able to complete their basic education in the public primary educational environment. To achieve these key objectives, this project will explore issues using the following guided questions: 


\subsubsection{Primary research question}

To achieve these key objectives, this project asks the following questions: To what extent is the Lao public mainstream primary school system being inclusive and responsive under the implementation of IE principals in meeting the needs of primary school students with disabilities?

\subsubsection{Sub-questions}

To clarify this broad question, the following sub-questions are also being used.

1. How well does the MOES manage its IE strategy?

2. How has the government addressed the lack of consistent adequate data regarding primary school students with disabilities across the country?

3. How are other stakeholders involved at the planning, implementation and evaluation phases in improving the effectiveness of the national strategy to foster the IE initiative?

4. What common indicators determine whether a primary school is inclusive and responsive to the needs of children with disabilities, based on the Lao context? How have such indicators been implemented?

5. Taking a holistic approach, how can the inclusion of children with impairments in public mainstream primary schools be improved?

\subsection{Thesis outline}

This thesis is organised into seven chapters. This chapter presents the researcher's primary motivations for studying IE practice and outlines the research objectives and questions. Chapter Two comprises a review of relevant literature dealing with theoretical and practical aspects of developing and implementing an IE policy in a given society. Chapter Three describes the research methodology and the researcher's decision to employ a qualitative approach for this study. It also discusses the data collection methods used. Chapter Four explores the contextual background to Lao PDR's IE policy and practice, including developmental, social, cultural, economic, political, special education and IE.

Chapter Five presents the research findings, namely the data collected from 45 (forty-five) interviewees, plus observation notes and unpublished documents from several different organisations. The results concern IE policy formulation, understanding of disabilities, attitudes towards the education of 
children with disabilities, knowledge of IE, and practical aspects at the primary school level. Chapter Six discusses and critiques three major issues derived from the results of the study in relation to the existing literature and the research questions. The first issue is the relevance of Lao IE policies to the principle of IE. The second issue concerns the participants' perceptions of disabilities, rights to education and IE policy. The last issue concerns other factors that facilitate the effective implementation of IE policy at the school level. The final chapter summarises and draws conclusions from the study, and adds some recommendations for future research. 


\section{CHAPTER TWO \\ LITERATURE REVIEW}

\subsection{Introduction}

The main objective of this study is to explore the extent to which the practice of IE improves the education of primary school students with disabilities. This chapter will discuss relevant concepts and practices of development, human rights, inclusion, disability, children's rights and IE. It consists of five issues. Firstly, it discusses what development is and why a human rights-based approach to development is particularly important to this study. Secondly, it reviews the evolution of inclusion and its practice. Thirdly, it analyses the concept of disability and two different approaches to disability: a medical approach and a social approach. This section also discusses the need to address the rights of children with disabilities to compulsory primary education. Then, it unpacks how the IE ideology promotes the rights of children with disabilities to basic education. Finally, it addresses three important factors, which are thought to strongly influence the success or failure of an IE, namely attitudes, institutions and the environment.

\subsection{Development and human rights}

Understanding the different meanings and aims of what we call 'development' is necessary in order to analyse what motivates IE practice. The term 'development' is defined in a range of ways. At least four different conventional definitions of development are discussed in the book History of Development by Rist (2002). Firstly, development can be understood as growth, progress, extension and expansion, according to the Petit Robert dictionary 1987 (cited in Rist, 2002, p.8). Such progress and growth are commonly measured by economic indicators. For example, developing countries focus on improving their economy, including the growth of their per capita Gross Domestic Product, aiming to reach the levels of North America, Western Europe and other 'developed' nations. Secondly, Rist (2002, p.8) tends to agree that development is a process that enables a person to realise their individual full potential to achieve self-esteem, self-actualisation and live their life with dignity. Thirdly, based on the Human Development Report 1991 published by the United Nations Development Programme, development is human 
development which aims to broaden choices and make activities more democratic and participatory (UNDP, 1991). This requires greater equity in accessing education, healthcare, a safe environment and employment opportunities. It includes the right to participate in community decision-making processes and enjoy political, economic and social freedoms. The fourth definition suggests that development means a group of practices which may bring about both positive and negative outcomes (Rist, 2002). The results sometimes conflict with each other. For instance, when a country generates economic growth, such a growth may be achieved based on the exploitation of the scarcity of natural environment resources.

Implementing development in terms of these definitions has raised some controversial issues. Although development theories are useful to guide human activities, history reveals that development theories have been used by elites and people in power in order to protect their own interests and make political gains. This can be seen from such 'development projects' as the second World War, the New World Order (US dominant in trade), the Cold War (battle of ideologies of capitalism vs. socialism), and indeed the invention of the concept of the developed and underdeveloped world by Harry Truman in 1949 (Rist, 2002).

Several researchers share different views towards the aim of development. One of the researchers claims that development is sustainable development (McMichael, 2011). Sen (2001, pp. 14-15) argues that development practices should not only focus on the accumulation of wealth and the growth of Gross Domestic Product and other income-related variables, but should also enhance the lives we lead and freedoms we enjoy, because a person should be a full social person able to exercise choices, interact, and influence the world in which they live. Very few development approaches emphasise the protection of fundamental rights of individuals (The World Bank \& OECD, 2013). Therefore, development should not be used only to promote wealth and political gains by people in power; human rights should be well respected too. 


\subsection{Human rights-based approach to development}

"A human rights-based approach is a conceptual framework for the process of human development that is normatively based on international human rights standards and operationally directed to promoting and protecting human rights. It seeks to analyse inequalities which lie at the heart of development problems and redress discriminatory practices and unjust distributions of power that impede development progress" (UNICEF, 2016, p. 1).

According to the definition of human rights-based approach interpreted by the UNICEF (2016, p.1), such an approach is significant to this study. Many different development approaches have been implemented to improve human rights issues, including the human rights-based approach (The World Bank \& OECD, 2013). The human rights-based approach requires development activities to respect, protect and advance human rights in both private and public spheres. This approach consists of advocacy. It links well with asset-based development (Freire, 2000) and the ideas of empowerment developed by John Friedman and Amartya Sen (Freire, 2000; Carter \& Barrett, 2006). Freire (2000) asserts that since knowledge is power, one's liberation can be achieved through conscientisation - being educated and gaining knowledge. Friedmann (1992) adds that one of the first steps to alleviate one's poverty is through gaining some form of political power. This can be achieved through being educated and gaining economic rights. Sen (2001) also sees people as poor or vulnerable because they face restrictions in what they are permitted to do. Restrictions refer to any un-freedom resulting from oppression, negative attitudes and legislation. From the perspective of asset-based development, Carter and Barrett (2006) argue that poor people do have potentials such as knowledge, resources, and ability to participate in the development process.

Another reason why this study takes the human rights-based approach to development is because this approach requires a strong commitment to systematically tackling human rights issues to achieve the transformation of institutional practice. For the United Nations, human rights are a vital part of the goals of development assistance, because they shape the way aid effectiveness is delivered and the nature of international cooperation (The World Bank \& OECD, 2013). Many bilateral agencies base their mandate and strategic policy on human 
rights because the human rights approach appears to be one of the effective development approaches to reduce poverty and promote empowerment (World Bank \& OECD, 2013). Therefore, if persons with disability are to be perceived as having equal rights rather than individual shortcomings, consciousness-raising in these terms in the education setting is needed.

There is a strong link among human rights, disability and education (Shaw, 2014). It is clear that access to education is a fundamental human right. Any exclusion from attending school based on one's disabilities is against human rights (Shaw, 2014). Children with disabilities mostly do not start schooling at the same age as other children with-out disability (World Health Organisation \& World Bank, 2011). In addition, women with disabilities experience multiple exclusions based on both their gender and disability (United Nations, n.d (b), p.1). 90 (Ninety) per cent of the children with disabilities in developing countries do not receive education; in OECD countries students with disabilities remain under-represented among those undertaking higher education; and this has led to the prevalence of unemployed disabled people -80 per cent of persons with disabilities are unemployed in many countries (ibid, p.1).

\subsection{Inclusion}

There are many reasons why the principle of inclusion was introduced in the education sector. Inclusion is a call for respect of individual differences, the promotion of non-discriminatory society as well as improvement in efficiency and cost-effectiveness of the entire education system (Eleweke \& Rodda, 2002). The concept of inclusion evolved from the dissatisfaction of special education and integration in order to promote human rights, diversity and social inclusion (UNICEF, 2005). Inclusion itself is used as a human rights discourse in promoting social justice but inclusion principles have been used in a way that lacks clarity and specification (Thomas, 2011). In order to understand the concept of inclusion, it is useful to contrast it with the concepts of segregation and integration for use in the education sector. In addition, Tremblay (2007) and UNICEF (2011) conceptualise the principle of inclusion in the same ways. Inclusion can be defined in contrast with other educational approaches as illustrated in the following table. 
Table 1: Comparing segregation, integration and inclusion

\begin{tabular}{|c|c|c|}
\hline \multicolumn{3}{|c|}{$\begin{array}{l}\text { The difference between the three different approaches to supporting the education } \\
\text { of children with disabilities. }\end{array}$} \\
\hline Segregation & Integration & Inclusion \\
\hline $\begin{array}{l}\text { Children with } \\
\text { disabilities are } \\
\text { classified according to } \\
\text { their impairments. } \\
\text { They are placed in } \\
\text { special schools that } \\
\text { respond to that } \\
\text { particular impairment. } \\
\text { Students learn with } \\
\text { other students who have } \\
\text { the same type of } \\
\text { impairment. }\end{array}$ & $\begin{array}{l}\text { Children with } \\
\text { disabilities who } \\
\text { perform well at special } \\
\text { schools are sent to a } \\
\text { special class in a } \\
\text { predefined integrated } \\
\text { regular school. Students } \\
\text { have to accommodate } \\
\text { and adapt to the } \\
\text { mainstream school } \\
\text { system and its } \\
\text { environment. }\end{array}$ & $\begin{array}{l}\text { An ongoing improvement process } \\
\text { that emphasises the transformation } \\
\text { of school's cultures, policies, } \\
\text { practices and environments to } \\
\text { embrace the diverse needs of each } \\
\text { learner. Students with disabilities } \\
\text { attend the regular class in a school } \\
\text { that is closest to their home. If } \\
\text { students with disabilities have poor } \\
\text { academic and social performance, } \\
\text { the whole school system should be } \\
\text { reformed and changed rather than } \\
\text { the disabled students. Support } \\
\text { services should be adjusted and } \\
\text { available to each student's needs. }\end{array}$ \\
\hline
\end{tabular}

(Source: compiled by the author, drawing from UNICEF, 2011 and Tremblay, 2007)

Although the definition of inclusion might be straightforward, the translation of inclusion principles into different contexts can bring about confusion. As Kavale and Forness (2000) suggest, the concept of inclusion attracts different meanings for different people in different places depending on values. These values include promoting social competence, changing values and belief systems, and achieving academic success. Both achieving academic success and improving social performance have been used by many as measures of inclusion, while others tend to measure inclusion by understanding it as the elimination of any barriers created by attitudes, environment and institutions. As shown in Table 1 above, since IE is about reforming the cultures, policies, practices and environments of all mainstream schools to meet the needs of individual students with disabilities, the existing standard curriculum which is accessible only to those without disability should be eliminated (Fuchs \& Fuchs, 1994). 
Furthermore, referring again to the definition of inclusion in Table 1 above, inclusion aims to improve both the academic and social performance of the disabled students (Tremblay, 2007; UNICEF, 2011). However, both Tremblay (2007) and UNICEF (2011) did not mention that teachers should learn languages like braille and sign that are used by students with disabilities in order to promote full and effective participation of students with disabilities in all school activities. Some teachers may favour students with vision impairment over students with hearing impairment because teachers are not familiar with sign language (Hassanein, 2015). Teachers tend to have negative attitudes towards students with disabilities because they are inexperienced and have no knowledge in teaching students with disabilities (ibid).

\subsection{Understanding disability}

Disability is a controversial term and it can be interpreted differently depending on context (Sabatello, 2013). The World Health Organisation (WHO) and the World Bank (WB) state in their World Report on Disability that disability is both a matter of human rights and development (WHO \& WB, 2011). People with disabilities tend to be oppressed, vulnerable, poor and at risks from violence and disasters (WHO \& WB, 2011). As such, disability can be a debatable and political issue through the way it is defined depending on medical or social perspectives (Singal \& Muthukrishna, 2014). Disability has been used as a socially constructed way of referring to a particular phenomenon that reflects our values, attitudes and practices towards people with disabilities (Kearney, 2009). To be specific, disability is "a restriction or inability to perform an activity in the manner or within the range considered normal for a human being, mostly resulting from the impairment" UNESCO $(2009$, p. 6). The following diagram is how $\operatorname{UNESCO}(2009$, p. 6) views disability in relation to impairment and handicap. 
Figure 1: Comparing impairment, disability and handicap
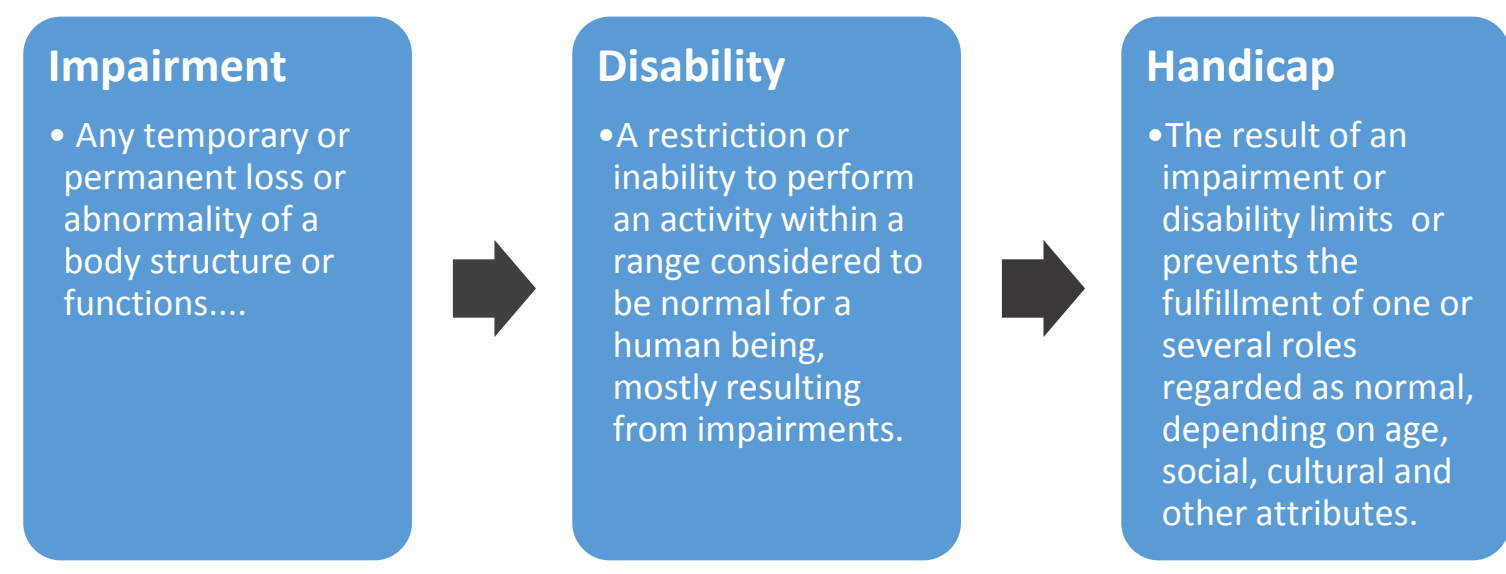

(Source: UNICEF, 2009, p.6)

Referring to the Figure 1 above, individual impairments seemed to be the cause of being excluded from social participation (Crow, 1996). However, the 2006 United Nation Convention on the Rights of Persons with Disabilities (UNCRPD) stated a slightly different definition of disability. The convention defines disability as:

"...an evolving concept and that disability results from the interaction between persons with impairments and attitudinal and environmental barriers that hinders their full and effective participation in society on an equal basis with others" (UN., n.d (a), p.2).

In other words, the definition can be interpreted to mean that if a person with any type of impairment faces no attitudinal or environmental barriers to participating in all aspects of life on an equal basis with other non-impaired people, that person does not have a disability. Disability is not a matter of health concern alone but it is multi-dimensional and contested because it refers to difficulties encountered concerning three main areas: health conditions, environment factors and participation restrictions (WHO \& WB, 2011). However, UNCRPD 2006 tends to blame social restrictions for disability more than medical conditions (UN, n.d (a)). Article 1 of the UNCRPD (2006) states that "persons with disabilities include those who have longterm physical, mental, intellectual or sensory impairments which in interaction with various barriers may hinder their full and effective participation in society on an equal basis with others" (UN., n.d (a), p. 3). Therefore, it is necessary to explore the concept of disability from both medical and social perspectives. 


\subsection{Medical model of disability}

From the perspective of the World Health Organisation, the medical model appears to be the foundation of the concept of disability (WHO \& WB, 2011). The medical approach to disability, focusing on the deficiencies of a human body rather than the abilities, plays a critical role globally in defining and responding to disabilities issues. This model assumes that the impairment of a person is the root cause of any social restrictions faced by disabled people, so these restrictions can be eliminated primarily by rehabilitation and medical treatment (Crow, 1996). Barnes (1998) points out that this model is rooted in the idea that disability concerns a sickness, biological malfunction or behaviour disorder. Agreeing with this, Shakespeare (2006) argues that the medical model encourages negative attitudes towards a disabled person because it ignores the fact that the barriers faced by a disabled person are largely posed by the surrounding society and not by the individual's physical, biological or psychological deficiency. Sabatello (2013) claims that prior to the 1960 s, people in general and especially the white middle class held the perception that 'able bodied' was 'normal', whereas 'disabled bodied' were seen as 'abnormal'. He argues that this perspective has exacerbated the root causes of exclusion and discrimination at large. The medical model of disability views 'disability' as 'inability' (UNICEF, 2011). It appears that the medical approach requires disabled persons to adapt to the functions of mainstream society rather than adapting the society to meet the needs of individual persons with disabilities.

\subsection{Social model of disability}

The social approach to disability, on the other hand, has a different focus to the medical model. As Oliver and Barnes (2010) argue, the barriers that a person with impairment(s) faces cannot be justified simply by using the medical lens alone. Consideration of social factors also need to be taken into account. Oliver and Barnes (2010) claim that social oppression, inequality, discrimination and other injustices are the main barriers faced by persons with disabilities. This means that an individual's impairment is not the principal barrier resulting in social exclusion, rather it is the social structures and institutions. Both the social model and the UNCRPD emphasise that disability is not just a matter of individual problems but a matter of broader social responsibility. Being a socially responsible community means taking account of the legal and moral rights of all members of that community. 
The legal and moral rights of one race compared to those of another race, or one group of people compared to another are not always the same. Despite difficulties in challenging diverse attitudes, religious beliefs and societal structures, the social model is a pivotal approach to empowering persons with disabilities and mobilising the disability movement across the world (Sabatello, 2013).

Despite the significance of the social model, Terzi (2004) critiques that there are three main limitations to this model. The first limitation is that it over-emphasises the society as the cause of impairment and disabilities. The second is that it overlooks the effects of impairments. The third limitation is that this model appears to reject the concept of normality, in the sense of average human functions. Therefore, he suggests that the medical model should be valued equally to the social model. These two views have both disadvantages and advantages.

Furthermore, disability issues were discussed in ways that mostly reinforce the existing inequality structures of exclusion faced by persons with disabilities. The UNCRPD 2006 for example appears to incorporate both the medical and social approaches in turn, but in ways that only strengthen the role of the state in determining what is considered to be most appropriate for a person with a disability. Almost all Articles in the UNCRPD 2006 indicate that 'state parties' have the absolute power over the decision making process in ensuring that the rights of persons with disabilities are legally protected and respected.

However, as mentioned previously, it is unlikely that government will regulate against the interest of the majority rather than the interests of minority as people with disabilities. If government personnel have not changed their attitudes and moral values towards persons with disabilities, the rights of persons with impairments and their parents can be neglected and violated (Applegate, 2013). To address this, having said that government authorities have the rights to adopt laws or policies to promote the rights of people with disabilities, government representatives should consult people with disabilities and the representative organisations of people with disabilities when developing and implementing any disability policies (WHO \& WB, 2011). The adopting of the IE principle is one of many international initiatives to promote the UNCRPD 2006 and the rights to education of people with disabilities (UNICEF, 2007). 


\subsection{Children with disabilities and basic education}

Children with disabilities form a particularly vulnerable social group because they are exposed to greater risks associated with the inequity of social relations and economic structures (WHO \& WB, 2011). Millions of children with disabilities cannot attend any formal education, and some have no choice but to attend special schools often located away from their home communities (UNESCO, 2009). According to the World Report on Disability (WHO \& WB, 2011, p.208), the proportions of children with disabilities aged 6-11 years and 12-17 years in school are lower than those without a disability in many countries (see Figure 2).

Figure 2: Proportion of children with and without disabilities in school in 2008

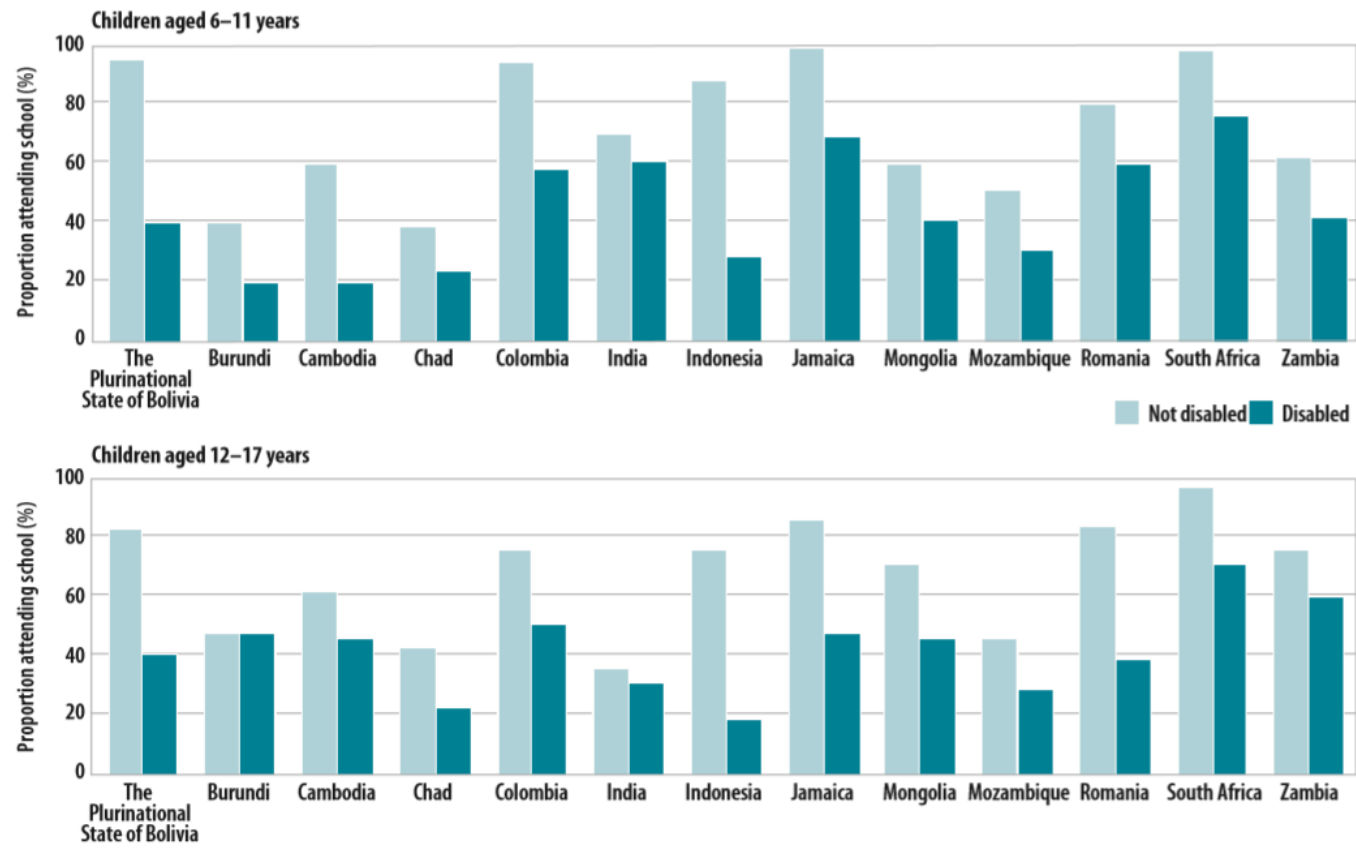

(Source: WHO \& WB, 2011)

Based on the human rights approach to development, proponents of inclusion may legitimately claim that a child should not be placed in special schools based on the child's disability (WHO \& WB, 2011). A number of laws and international development policies have promoted equal rights for children, including education for children with disabilities in regular schools together with their non-disabled peers. Such policies include UNCRC (1989), UNESCO Salamanca Statement and Framework for Action (1994), EFA (1990), Dakar Framework for Action (2000) and the MDGs (2000) (Tremblay, 2007). Despite the adoption of an international 
convention and policies, children with disabilities continue to be excluded from formal education - one of their basic human rights (Landsdown, 2013).

A number of reasons have been identified for including children with disabilities in mainstream schools (WHO \& WB, 2011). Firstly, countries that are signatories to the UNCRPD and UNCRC should fulfil their legal obligations for providing IE. Secondly, countries cannot achieve the goals of EFA and the Millennium Development Goals (MDGs) regarding universal compulsory primary education without the inclusion of children with disabilities in general education. Thirdly, there is a high social and economic cost to supporting persons with disabilities if they are excluded from formal educational and employment opportunities. Lastly, education is an integral part of human development in determining personal well-being, welfare and social status. The rights for all children to be educated continues to be the focus of high-level international initiatives, such as 'Including all children in quality learning' Regional Ministerial Education Conference, co-organised by the Government of Turkey and the UNICEF Regional Office for CEECIS (UNICEF, 2013). This event is one of many conferences that highlighted the need to promote the IE system that is responsive to the needs of all children, including children with disabilities.

\subsection{The concept of inclusive education}

IE is associated with the concepts of inclusion and disability rights (UNICEF, 2005). Mambo (2011) describes IE as contrasting with the notions of segregating and integrating. Mambo asserts that for the segregating and mainstreaming approaches, all students with disabilities should be trained in special schools, and later some students may be sent to mainstream schools. However, Mambo (2011) describes IE as the practice of students with disabilities starting their education in regular schools together with their non-disabled peers. This practice involves the ongoing adaptation of the regular school's pedagogy, practice, environment and policies in order to be a responsive system. This enables the IE concept to foster the development of a socially inclusive and academically responsive school.

Furthermore, IE is found to be the basis for the full development and participation of students with disabilities in regular schools (MacQuarrie \& LaurinBowie, 2013). Some scholars argue that the founding of the IE movement enables the abolition of special education and promotes social justice (Fuchs \& Fuchs, 1994). 
Special schools tend to rehabilitate students with disabilities so that they fit into the standard society where disabled people often feel pitied or see themselves as a burden while their potential is forgotten (Norwich, 2014). The social model of disability has challenged this practice by claiming that social issues are factors which are alterable, whereas individual disabilities or impairments are generally human conditions which can only be compensated to some degree, but not fully (Norwich, 2014). Mitchell (2010) proposes three main reasons for the development of IE. Firstly, Mitchell points out that IE is a human right, because all forms of exclusion and discrimination based on disability mean that human rights are being violated. Secondly, IE is about promoting diversity and it values individual differences. Finally, it shifts the blame from the individual student's disability as the reason for being excluded from school, to acknowledging that it is the failure of the education system as a whole.

\subsection{Legal frameworks of the inclusive education}

One of the most significant laws for supporting the inclusion of children with disabilities into mainstream schools is UNCRPD 2006. This legislation requires all parties to take responsibility in implementing IE. Article 24 of the UNCRPD states that all parties who ratified this convention shall ensure that the general education system is inclusive, free and compulsory for children with disabilities (UN. n.d (a)). The Salamanca Statement and Framework for Action adopted by the World Conference on Special Education in 1994, proclaims that education systems and educational programmes should be designed and implemented in a way that takes into account all characteristics, interests, abilities and learning needs of each child, and specifically every child with special educational needs (UN. n.d., p. viii). This statement calls for all governments and organisations to prioritise IE as a way to combat discriminatory attitudes, develop an inclusive society, achieve the goals of EFA, and improve the efficiency and cost-effectiveness of the whole education system. Therefore, any country which signed and ratified any of the above-mentioned international laws or policy frameworks is required to implement IE principles accordingly. 


\subsection{The outcomes of inclusive education practice}

The practice of IE brings both opportunities and challenges. The opportunities include the increase of professional cooperation, support to students with special educational needs, and improvements in the quality of education (Ineland, 2015). Ineland also shows that the threats involve professional ambiguity in terms of interpreting and implementing every idea of IE. Singal and Miles (2010) conducted a study on the distinction between the principle of EFA and IE. They found that EFA focuses on 'access', which introduces compulsory fee abolition, school constructions and cash transfer management. Although these commitments have been conducted to a large extent, millions of children, especially children with disabilities, are still excluded from formal education (UNESCO, 2009). Singal and Miles (2010) assert that the IE principle introduced a 'new' strategic mechanism to address the challenges faced by implementing the EFA strategy. IE is concerned with, not only academic 'access', but also 'the process' and the goal of IE. More specifically, IE targets the reform of negative values and beliefs that may be held by all stakeholders involved in the process of delivering primary education. In this sense, IE is not only looking at the education system, but also challenging the broader questions of peoples' mind-sets, values and beliefs, that shape the function of the education system.

The implementation of the concept of IE has encountered significant challenges because of context differences. A good example can be drawn from the context of Italy. The government of Italy implemented IE to transform the whole education system so as to contribute to the development of an equal and just society (D'Alessio, 2012). For Italy, its IE vision is not only about the placement of pupils with disabilities, it is also about the reform of the whole school system, including organisation structures, teaching expectations, curriculum, leadership and teachers' attitudes (D'Alessio, 2012). It is therefore rightly perceived as a challenge that requires a lot of effort to be taken, not only by the education sector, but also by the society at large.

The practice of IE in primary schools that have students with disabilities has brought a lot of challenges for both teachers and parents. Jela and Ali (2014) conducted a study on the practice and policy impacts of IE in Malaysia. They found that since the introduction of IE in 1996, the cost of providing services to children with disabilities was dependent on the responsibilities accepted by the school and the 
parents. Schools did not have sufficient funds to support in-service training for teachers. Teachers faced difficulties in supporting children with disabilities because teachers learned how to support those students only from reading text books, attending conferences and consulting psychological, physical and occupational therapists. Parents faced difficulties in providing their children with teacher assistants. Parents had to bear all the extra costs incurred in supporting their children's education (Jela \& Ali, 2.014). Furthermore, Jela and Ali concluded that Malaysian's IE policy and practice were problematic. The IE policy objectives and the programmes implemented were not coherent.

Another challenge is that the practice of IE has brought disability and religious values into conflicts. Vorapanya and Dunlap (2014) identified a range of issues faced in implementing IE in Thailand. They said that the goal of IE was still far from being reached because of the differences in the majority Thai belief system - Buddhism. One of the Buddhist principles views people with disabilities as not having an equal status in the society because of their bad Karma or actions in their previous life. Vorapanya and Dunlap found that most teachers perceived inclusive practices as a western ideology which the Thai school system has to adopt. Vorapanya and Dunlap point out that teachers and parents still bear all the costs incurred from taking a student with disabilities into a regular class even though the practice of IE in Thailand has been implemented for over two decades.

In addition, Kim (2014) identified both advantages and disadvantages with the implementation of IE in South Korea. Kim explained that those averse towards IE see the inclusion philosophy as a 'westernised' perspective. Others argue that IE is about to promote collaboration among educational stakeholders and human rights. Kim found that even though South Korea had placed the inclusion of students with special needs in their list of national education priorities since the mid-1990s, there is no successful IE practices so far. This is partly because South Korea has a history of competitive schooling practices, and diverse religious practices including Buddhism, Taoism, Confucianism and Christianity. In Kim's study (2014), there appears to be no indication whether religious diversity was a factor linked to failure of IE but Kim argues that the success of IE practice in South Korea will depend on the transformation of social, cultural, economic and political practices.

One country's success cannot be compared to that of another nation because of the differences in the nature of politics, rule of law, cultures, quality of 
infrastructure, values and beliefs (Lim \& Thaver, 2014). Although the practices of IE have brought many challenges in many countries, other countries have had quite positive experiences in implementing IE principles. In New Zealand for example, the Education Review Office (2015) found that the majority of schools (78 per cent of the total 152 schools) were identified as being 'mostly inclusive'. However, what they mean by inclusive has nothing to do with the transformation of values and belief systems. For the New Zealand context, according to the Education Review Office (2015), IE practice refers to the nature of participation and achievement by all learners. The key indicator used to determine the level of participation and achievement was a sense of belonging by children with disabilities, so that they participated in the same activities with others.

The challenge discussed above, despite contextual differences, suggests that more attention should be paid to the limitations of the IE principle. The OECD (2000) study found that many school teachers often faced hardships balancing and prioritising needs between the majority and the minority. Some parents are also concerned over the quality of support provided by teachers to non-impaired students, if students with disabilities are to be included. When embracing diversity, teachers and other non-disabled students can become the victims of physical violence by some students with disabilities. Issues of governance are also important, In Australia, federal government policy still requires the provision of special classes and special schools for some students, even though the New South Wales State has reorganised its school system and administrative structures where state and district staff are actively supporting inclusive practice (OECD, 2000).

IE should not only target changing the values and beliefs of all education stakeholders, but other factors should equally be addressed in order to minimise recurring challenges during the process of implementing IE. A study conducted by Deluca, et al. (2014) on including children with disabilities in primary schools in Mashonaland, Zimbabwe concluded that overall, parents, caregivers, teachers and school principals showed strong support for the education of children with disabilities in mainstream schools or special classes. Despite these positive attitudes, in practice, challenges remained. These included: poor school infrastructure; inadequate resources; poor sanitation; inadequate water supply; inefficient public transport; and over-crowded classes. These issues cannot be addressed only by those involved in schools such as parents, caregivers, teachers or head teachers. There is 
an imperative to work with multiple stakeholders, including community leaders, local authorities, government officials from different organisations and at different levels, donors, international non-government organisations, private enterprises and other local disabled persons organisations and others should be involved in such a study, in order to ensure that IE principles will be implemented in a more effective and efficient way. To implement the principles of IE effectively, all the stakeholders in society should be involved, because the notion of inclusion is about inclusive values, systems and practices (Poon-McBrayer \& Wong, 2013). Poon-McBrayer and Wong also assert that the core components to achieving successful IE reforms depends on the appropriateness of policies, systematic change, values building, personal training and provision of adequate resources.

There has been ongoing debate over the inconsistencies in the way that policy makers and practitioners define and interpret several key terms in IE principles, which has contributed to difficulties in identifying good examples of IE schools (Singal \& Miles, 2010). The first debated term is 'inclusion'. Some people see this as a means-to-an-end, while others see it as an ongoing process of improvement to bring about a non-discriminatory education environment. Applying inclusive principles in the education system and aiming to eliminate discrimination in either school or society seem to be different things, because even though some countries have implemented strict anti-discrimination legislation, discrimination incidents still occur in the school environment. Some people think that inclusion means the placement of all students with diverse learning abilities into mainstream schools, and that this is simply in order to reduce spending on special or segregated schools.

Another issue is that the concept of IE involves other controversial issues such as disability. There are complex impairments which contribute to disability and these impairments include sensory loss, speaking difficulties, movement problems, memory problems and behaviour problems. However, UNCRPD 2006 sees 'disability' as an encompassing concept which includes attitudinal and environmental barriers faced in the course of interaction between students with impairments, and societal attitudes and challenges posed by the environment. For instance, if a person is blind, and if this person does not face any barriers caused by attitudes and environment, this person cannot be called a 'person with a disability'. Another issue is how other people define a 'person with a disability' who is attending a formal school as a 'person with special educational needs'. This definition includes 
other types of individual characteristics, such as being a minority person, being an ethnic girl, being a student from a socially, economically or politically disadvantaged family, and other attributes. Furthermore, some people denote 'students with special education needs' as 'students with special needs', in a way that adds more groups of students, including students who are from a disadvantaged ethnic minority, migrants, isolated or living in urban slums (UNESCO, 2015).

\subsection{Other obstacles to inclusive education practice}

There are many reasons why having a positive attitudes towards children with disabilities is critical to the success and failure of IE practices in schools. Attitude refers to:

“...a psychological construct that refers to favourable or unfavourable evaluations of people, objects, places or activities. They are made up of three aspects: a cognitive component (how we think about X), an emotional component (how we feel about $X$ ), and a behavioural component (how we act towards X)” (Scior \& Werner, 2015, p.6).

In other words, attitude is an individual viewpoint towards an 'object', which may refer to a person, a principle and an idea (de Boer, et al. 2011). There are many factors that reflect personal attitudes, including personal beliefs, faiths, ritual practices, thinking, feeling, values, worldviews, knowledge, understandings and political ideologies. These shape the ways people plan and guide their motivation to perform certain tasks on a daily basis. To achieve the full inclusion of students with disabilities in mainstream schools, it is a prerequisite to address the negative attitudes that most people hold towards persons with disabilities.

In order to promote the practice of IE in schools, teachers and school administrators should have a positive attitudes towards students with disabilities. Both Forlin (2010) and Leung and Mak (2010) agree that teachers are the key people who implement IE principles because the concept of inclusion is predefined and needs to be interpreted in accordance with ideological and structural organisations within the school environment (cited in Ineland, 2015). Daveta (2009) conducted research on how teachers' attitudes affected IE practice in Fiji and concluded that significant change in the attitudes of teachers was required. This is because even though international standards state that all students have rights to study in the same 
regular school, most teachers still believe that students with disabilities should be referred to segregated or special schools. Moreover, the attitudes of mainstream primary school teachers towards the inclusion of pupils with disabilities, conducted by de Boer, et al. (2011), discovered that teachers in regular schools were more negative towards the inclusion of pupils with disabilities because they were not confident in teaching pupils with complex needs. Ineland (2015) concludes that the negative attitudes held by many teachers should be addressed in order to promote effective and full inclusion of students with disabilities.

If parents have positive attitudes towards the concept of IE, they are likely to encourage their children with disabilities in mainstreams schools. A recent study by Elkins, et al., (2003) investigated the attitudes of Australian parents who had children with disabilities attending Queensland state schools. Elkins, et al. (2003) found that if a school provides good social services and special teachers, parents favoured the inclusion of their children within the mainstream educational setting and otherwise parents favour special placement because parents fear that their children will not be treated fairly. Elkins, et al. (2003) argue that not all parents will advocate for the inclusion of their children in mainstream educational settings through concerns for the basic needs of the child rather than his/her academic performance. The success of IE also depends on when parents believe that schools have the knowledge to provide services that meet the needs of individual students with disabilities both academically and socially (Elkins, et al., 2003). In addition, Ahmmed and Mullmick (2014) investigated the major issues faced in implementing IE in primary schools in Bangladesh and they argue that effective implementing IE on children with disabilities requires an active involvement of parents of children with disabilities in order for school services to meet the needs of children with disabilities.

Inclusive schools cannot be achieved without the support of the wider society, including donors, non-government organisations, businesses, parents and individuals. If people in general still hold the perception that disabled people are not as important as the non-disabled, such a prejudice can cause exclusion which can mislead those responsible for target funding and resources distribution (Kearney, 2009). The attitudes of the wider society should support IE practice because donors, international and national non-government organisations, and other commercial enterprises are some of the key development partners with the education sector. Providing financial support, technical supervision, teaching and learning materials, 
and other assistance to both the Ministry of Education and schools may not be sufficient to achieve the goal of inclusion. The whole society should work collaboratively to break down the negative attitudes towards persons with diverse abilities, in order to bring about an inclusive school.

\subsection{Institutional barriers}

The decentralisation of IE practices is very important to this research. Based on the UNCRPD, the government is responsible for promoting the inclusion of students with disabilities in mainstream schools (UN. n.d (a)). Central government makes all decisions on the implementation of relevant international agreements, because implementing a policy requires a substantial sum of money (OECD, 2000). However, it is suggested that the implementation of IE strategy at the primary school level requires breaking down the top-down management structures to promote decentralised structures, where the local community and authorities identify their issues and seek outside help when needed (Ahmmed \& Mullick, 2014). Ahmmed and Mullick (2014) suggest that at the primary school level, the village authorities, school management committee and parents in that village should have the ultimate authority to make decisions regarding the development of teachers, teacher recruitment, teacher assistant recruitment, support services and other resources, as required to promote IE practices.

Another institutional issue is the weakness of policies and law enforcement in relation to the implementation of IE initiatives. A study conducted by Eleweke and Rodda (2002) in examining challenges of implementing IE for learners with special educational needs in many developing countries concludes that there are still weak policies and law enforcement in ensuring that appropriate services are available to be provided and the rights of children with disabilities are fully protected. Eleweke and Rodda (2002) claim that the enforcement of IE related policies and legislations had not been effective in removing challenges faced by learners with special needs who studied in mainstream schools. Eleweke and Rodda (2002) attributed the ineffective policy enforcement to the absence of clear legal guidelines, the complication of funding provision, what services to be provided and other administration issues.

Furthermore, UNESCO also highlighted that specific and clear policies are required, because specification and clarity of policies can improve the ability to reach educational targets (UNESCO, 2015). Adding to the specification and clarity 
concerns, Kratochvilova and Havel (2014) conducted a study on clarity and alignment in the perspectives of the national planning programmes and school planning. They found that the requirements of national legislations and policies are often unclear, and specify only general measures. This means that without support from experts and teachers with long experience teaching students with disabilities, each school may develop their own inclusive environment which might not comply with the principles of inclusion. According to a study from Turkey, conducted by Sakiz and Woods (2015) on achieving inclusion of students with disabilities, found that what adds further confusion to the implementation of IE programmes is the fact that there is a lack of clear structural arrangement from the ministry to the school levels. Sakiz and Woods (2015) argue that the confusing organisational structure results from the fact that laws and policies concerning IE do not have an explicit aim and have very little impact on schools' regulations and policies.

\subsection{Funding and other resources}

A sustainable and well-structured funding arrangement is one of the indicators determining the success of IE practice in schools (Eleweke \& Rodda, 2002). Eleweke and Rodda (2002) assert that although the Salamanca Statement and Framework for Action on Special Needs Education adopted at the World Conference on Special Needs Education reaffirmed the commitment of states to give a high budgetary priority to implement IE principles in schools, for many developing nations, the provision of financial support to improve inclusive schools remain weak. Effective IE policy translation, planning, implementation, monitoring and evaluation requires adequate financial resources (World Health Organisation \& the World Bank, 2011). Mambo (2011), argues that there should be ongoing availability of additional money for children with special needs, as well as standard funding for the school's other activities, in case they need to purchase special assistive devices such as hearing aids and other necessary materials. Mambo (2011) gives as an example that, if a school has a blind student, the school should be given money to buy a Braille printing machine that can produce handouts and others texts for this student.

If variety of funding sources are available and accessible for schools that have students with disabilities, the inclusion of such students in mainstream schools are more likely to be successful. The Education Review Office of New Zealand (2015) found that the majority of New Zealand schools were mostly inclusive because of the 
availability of government funding and private resources. This report showed that the Ministry of Education spent around $\$ 500$ million on special education services annually, and provided specialist support to about 35,000 children and young people with special education needs. This Review Office also indicates that 900 resource teachers and an additional Special Education Grant were available to support schools.

However, for many developing countries, the availability of funding is far behind New Zealand. Opoku, et al. (2015) conducted a study by assessing the IE programme piloted in Ghana's Ashanti and BrongAhafo regions. Opoku, et al. (2015) found that financial shortage was one of the critical issues faced by Ghana's education sector as there was almost no funding available for the Ghanaian District Special Education Coordinator and Resource Teachers. They claimed that such a shortage has had a negative effect on both the school administration and teaching under the IE programme that targets students with disabilities. To be specific, Opoku, et al. (2015) conclude that the lack of funding has deteriorated IE activities including conducting school visits, monitoring and supervision; training existing teachers; hiring qualified teachers; purchasing teaching and learning materials; and improving the accessibility of school physical environment.

\subsection{The availability of disability statistics}

Many reports show that it is still difficult to obtain accurate data regarding persons with disabilities across the world. Disability is a complex phenomenon. Despite efforts being initiated by many countries, a comprehensive understanding of disabilities across regions still cannot be determined (WHO \& WB, 2011). This hinders the efforts of governments and development partners to address the complex needs of people with disabilities at large (ibid). UNICEF even claims that there is no official number of children with disabilities across regions (UNICEF, 2011). The only figures available are through estimations. Therefore, without clear statistics, implementing IE strategy will face many challenges, and such challenges will remain repeatedly unaddressed.

\subsection{Environmental barriers}

The last barriers faced by students with disabilities relate to the environment, including the humanly constructed environment and the natural environment. Unlike attitudinal and institutional barriers, the environmental barriers are physical and can 
be identified more easily. Many researchers assess accessibility within the school environment by students with disabilities, and take account of things such as ramps, walk-ways, toilets, elevators, classroom assistive devices, and other facilities within the school (Kim, 2014; Vorapanya \& Dunlap, 2014; Woods \& Sakiz, 2015). However, none I have identified assess the wider environment within that community, such as the pedestrian walking paths, public transport, as well as all the objects hindering a disabled student moving between their house and the school. Many articles report a generally positive attitude towards the idea of IE, but truly positive attitudes should also be determined by the continuous improvement of accessibility by those with disabilities. Some of the key indicators that should be measured in assessing environmental aspects are the accessibility to constructed infrastructures, including accommodation and transport systems, information provision in braille and sign languages, assistive devices such as adjustable wheelchairs, crutches and voice readers, as well as study resources such as text books in Braille. The EFA reports that the improvement of rural infrastructures including roads, electricity, clean water supply and other public transport networks would definitely improve school access (UNESCO, 2015). The accessibility needed by disabled persons in the school, home and society at large should be carefully planned and continuously improved, to ensure an inclusive society as well as inclusive schools.

\subsection{Chapter summary}

This review has explored the concept of development, human rights, inclusion, and disability in order to better understand the concept and practice of IE, and to explain the relevance of this piece of research. It found that despite the support of international, national and regional legislations for IE principles, the implementation of an IE philosophy has always been challenging, due to the need for clarity of definition, and issues with specification. Taking a rights-based approach to development, inclusion has become a common development goal, which aims to bring about social justice, an inclusive society, and the creation of a barrier-free environment for people from all walks of life. However, affirming the principle of IE has often become more about accommodating all children in a similar educational environment than about really addressing the rights of persons with disabilities so that they can enjoy their education in mainstream schools. In addition, the 
development of the social approach to disabilities has challenged the medical model of disabilities, which has emphasised the IE strategy by reducing segregated and integrated education practices.

The IE philosophy aims to address the causes of the exclusion of millions of children with disabilities from attending school seems to be a promising goal for many, however, empirical evidence suggests that there are still many issues hindering the way governments translate IE ideology into their own country educational systems. Specifically, there is inadequate literature taking a holistic approach to evaluate how the primary school education system has been challenged by the adoption of the concept of IE. Given that the successful implementation of IE varies depending on educational, but also broader socio-economic and cultural systems, this study fills a gap in the literature by explaining how IE practices will impact on the education of primary schools students with disabilities in some of the least developed countries such as Lao PDR. 


\section{CHAPTER THREE RESEARCH METHODOLOGY}

\subsection{Introduction}

This chapter explains the research methodology used in this study. It begins with a discussion of the conceptual framework that gives rise to the methodology adopted, then describes that methodology and the methods used to conduct the research. Reasons for selecting Vientiane - the capital of Lao PDR - as the research setting and of selecting participants is also discussed. Finally, the chapter presents some ethical concerns and reflects on the researcher's experience in the process of data collection.

\subsection{Conceptual framework of the research methodology}

Epistemology describes how we come to know about the world, and explores how knowledge is created and disseminated (Cresswell, 2013). The first element to consider in the research processes is epistemology because it helps to inform the types of methodology and methods that a research will undertake (Crotty, 1998, cited in Kearney, 2009). Kearney (2009) explains that epistemology, depends on two different perspectives: objectivism and subjectivism. The first is based on the belief that there is a knowledge to be discovered in which the subjects and contexts are irrelevant whereas the latter is based on an understanding that knowledge is derived from the perspectives of subjects on objects (Kuhn \& Dean, 2004 cited in Kearney, 2009).

Referring to the aims of the study, both objective and subjective epistemologies are insufficient on their own to provide answers to the research inquiry because disability and inclusion, the main concerns of the study, are socially constructed discourses that affect the outcomes of the IE principles. This study found that constructivism is one of the most relevant epistemological worldviews to inform this study. Constructivists assert that researchers are part of knowledge creation and that phenomena cannot be fully understood in isolation of both subjectivity and objectivity (Crotty, 1998 cited in Kearney, 2009). Constructivism acknowledges the fact that the researcher has to interpret the results of any study in which a qualitative approach to research is used (Cresswell, 2013). Under the constructivist research, researchers also have to use broad and general questions including open-ended questions to gather opinions and ideas that they then interpret (Cresswell, 2013). 


\subsection{The effects of the researcher's positionality}

Positionality is an important aspect that can affect the process of the research and data interpretation. Referring to one of the aspects of constructionism, Crotty (1998) points out that researchers' backgrounds and experiences inevitably have an effect on the result's interpretation (cited in Cresswell, 2014). Chacko (2004) suggests that a researcher who wants to conduct field-based research should acknowledge his or her positionality, which potentially includes all aspects of a person's identity. Being aware of my positionality helps to understand the power dynamics between myself and other participants, and it helps me to create opportunities for informants to feel free in expressing their views. In my case, I reminded participants of my role as a researcher and that there were no rights or wrong answers. As a student, I had no intention to criticise their views or report their view to their bosses. Many participants seemed happy to share their honest perspectives without fears.

Another aspect of my positionality that has an effect on the process of my field work is the fact that my ethnicity is Hmong and I had some disability rights and equality advocacy experiences prior to this research. My identity and experiences posed some limitations in approaching some government officials. Being a Hmong person who has never served as a civil servant, some government officials asked me why I chose to focus on disability. I tried to arrange meetings with senior officials or policy makers but some of them rejected my requests for an appointment. My assumption was that since I was not on the government staff and held no important role in government, the senior officials saw little value in meeting with me. Some senior officials refused by saying that the issue of disability was not their responsibility.

However, at the school level, my position has changed from seeing as a disability advocate to an 'outsider' researcher. This gave me more of a neutral position as a researcher. Many teachers valued my research because they claimed that this research will enable their voices to be heard in order to improve the educational system to meet the needs of disabled students. This change brought me a stronger relationship with participants. Interviews went smoothly. Some allowed time for lengthy discussions and anticipated that my research might bring positive change into their school and improve the education of disabled children.

Furthermore, as a Hmong person, there were some issues I had to avoid. Some people within Lao PDR seem to mistrust the Hmong ethnicity because some Hmong 
were perceived as opposition to the government. Hmong have a long history of fighting for freedom. Some Hmong groups were recruited by foreign aggressors to fight against the Pathet Lao and North Viet Nam during the Viet Nam War in the 1960s (Hamilton-Merritt, 1993). After the Pathet Lao took power and overthrew the monarchy government in 1975, some Hmong fled as refugees to Thailand and a small number of Hmong people continued facing conflicts in assimilating to the Pathet Lao government (Conquergood, 1988). Although some Hmong people joined and served the Pathet Lao government, Hmong in general are still perceived to be one of the government's opponents. Therefore, doing research in the context of Lao PDR, a Hmong researcher may encounter some issues in accessing information. For example, one of the Hmong officials told me that he did not want to be involved in the interview because he is a Hmong. He was afraid of being accused by non-Hmong colleagues of leaking information. He recommended that I should interview his colleagues instead. However, apart from this example, I do not consider my research to have been affected by being Hmong. This is because my own religion and beliefs inspired me to conduct this research confidently and remind me to treat all participants in equally respectful ways.

\subsection{Research methodology}

\subsubsection{Qualitative research}

This project has been undertaken as qualitative research because it is believed that a qualitative approach will allow me to gain in-depth information from participants by asking follow-up questions (Kearney, 2009; Mambo, 2011). Qualitative research is an approach used to understand the meanings that are considered to be important to an individual or group of people while the relations between social and human issues are also interpreted (Creswell, 2009). The key issue in this study is the attitudes of a range of different stakeholders towards an IE strategy aimed at improving the education of children with disabilities. In it, I focus on all types of disabilities including physical, sensory, hearing, mobility and cognitive impairments. This is because the principal of inclusion is that all children regardless of their abilities, backgrounds, races, religion, political and socio-economic disadvantaged should not experience any discrimination in school.

In addition, a qualitative approach is one of the most common approaches used in research. A study conducted by Kearney (2009) on barriers to inclusion 
within New Zealand schools to inclusion employed a qualitative approach. Kearney considered the qualitative approach to be useful in examining participants' perceptions the cause of exclusion of children with disabilities from mainstream schools. Furthermore, in case there is inadequate secondary data, employing a qualitative approach is beneficial (Creswell, 2009). In regards to this study, I employed the qualitative approach as there is limited secondary information in Lao PDR concerning disability and primary school education. Most data is only available in hard copy. For this study some of the key methods of qualitative research will be used, including document review, semi-structured interviews and observations.

\subsubsection{Document analysis}

Document analysis is a systematic procedure used to assess both printed and electronic documents, and is also an established qualitative research method (Bowen, 2009). Bowen (2009) asserts that document analysis offers more benefits than limitations, and is often used in combination with other qualitative approaches such as interviews and observations of participants. Some of the documents collected contained the most recent reports, development plans, training resources, project documents, national policies and decrees concerning disability, disabilities statistics and other pamphlets that are available at all interviewed organisations from Ministries, provincial offices, district offices to school offices as well as nongovernmental organisations (See Appendix H).

\subsubsection{Semi-structured interviews}

"Semi-structured interviews incorporate both open-ended and more theoretically driven questions, eliciting data grounded in the experience of the participant as well as data guided by existing constructs in the particular discipline within which one is conducting research (Cross, 2013, p.45)”.

Semi-structured interviews involve giving sufficient time for the interviewees to share their experiences and raise questions, creating a comfortable environment and promoting two-way communication (Polonsky \& Waller, 2011). Applying the notion of semi-structured interviews to my research, I developed a set of semistructured interview questions (See Appendix D). By allowing the interview to take the shape of an open conversation, I also made sure that I included the main areas where I wanted to ask as the conversation continues. This study will explore 
participants' perceptions towards the concept of IE approach relating disabilities, disability, key indicators of being responsive to the needs of disabled students, and suggestions to improve IE practices. Semi-structured interview questions allow great flexibility, promote follow-up questions, as well as encouraging interviewees to further extend the ideas conveyed or eliminated possible misconceptions (Creswell, 2013).

\subsubsection{Observations}

Observation is a qualitative research tool which focuses on the actions rather than the perceptions of the researched participants (Silverman, 2001). During observations, the researcher gets first-hand experience of the participants, and records information as it occurs (Cresswell, 2013). During the field work, the author conducted observation in eight geographically different mainstream primary schools. The observation emphasised the availability of the school IE policy, teachers' attitudes towards disabilities, school's infrastructure, teaching and learning materials and the students' behaviour in class time and outside class time. These observation indicators allowed to understand how IE principles are being practiced at the public mainstream primary schools. In addition, I observed all the key ministry offices, public roads and other public places to check how different groups within society have facilitated the education of children with all kinds of disabilities.

\subsubsection{Research settings}

This study targeted the key stakeholders residing within four different districts, namely Sikhotabond, Chanthabury, Saysetha and Saythany Districts within the capital city of Vientiane, Lao PDR. These were selected for a number of reasons which include the concentration of children with disabilities in public mainstream primary schools, and the researcher's familiarity with them, and the availability of resources. According to the statistics available from the Vientiane Capital Education and Sports Bureau (2014), four out of the nine districts in Vientiane were chosen because they have the highest number of student with disabilities in Vientiane. These districts includes Saythany, Saysetha, Chanthaboury and Sikhotabong (See Table 2 below). 
Table 2: Statistics of primary school students with disabilities in Vientiane 2014-2015

\begin{tabular}{|c|c|c|c|c|c|c|c|c|}
\hline \multirow[b]{2}{*}{ No. } & \multirow[b]{2}{*}{ Name of District } & \multirow{2}{*}{\begin{tabular}{|c|} 
Types of \\
school
\end{tabular}} & \multirow{2}{*}{$\begin{array}{l}\text { Buddhist } \\
\text { Schools }\end{array}$} & \multirow{2}{*}{$\begin{array}{l}\text { Completed } \\
\text { Schools }\end{array}$} & \multicolumn{2}{|c|}{ Total students (Grade 1 -5) } & \multicolumn{2}{|c|}{ Special Students (Students with disabilities) } \\
\hline & & & & & Total students & Female & Total Students with disability & Female \\
\hline \multirow[t]{2}{*}{1} & \multirow[t]{2}{*}{ Sisattanak } & \begin{tabular}{|l|} 
Public \\
\end{tabular} & 0 & 22 & 2238 & 1092 & 33 & 15 \\
\hline & & Private & 0 & 19 & 3419 & 1626 & 2 & 0 \\
\hline \multirow[t]{2}{*}{2} & \multirow[t]{2}{*}{ Sikhotabond } & Public & 2 & 38 & 4976 & 2445 & 73 & 23 \\
\hline & & Private & 3 & 17 & 4778 & 2275 & 16 & 4 \\
\hline \multirow[t]{2}{*}{3} & \multirow[t]{2}{*}{ Chanthaboury } & Public & 2 & 17 & 1620 & 784 & 63 & 22 \\
\hline & & Private & 2 & 17 & 6251 & 3122 & 7 & 1 \\
\hline \multirow[t]{2}{*}{4} & \multirow[t]{2}{*}{ Saysetha } & Public & 2 & 38 & 3888 & 1841 & 82 & 20 \\
\hline & & Private & 2 & 27 & 4586 & 2262 & 9 & 2 \\
\hline \multirow[t]{2}{*}{5} & \multirow[t]{2}{*}{ Hatxayfong } & Public & 3 & 46 & 4707 & 2186 & 54 & 17 \\
\hline & & Private & 0 & 9 & 2295 & 1093 & 9 & 3 \\
\hline \multirow[t]{2}{*}{6} & \multirow[t]{2}{*}{ Naxaythong } & Public & 4 & 40 & 6766 & 3181 & 25 & 9 \\
\hline & & \begin{tabular}{|l|} 
Private \\
\end{tabular} & 0 & 4 & 996 & 445 & 0 & 0 \\
\hline \multirow[t]{2}{*}{7} & \multirow[t]{2}{*}{ Saythany } & Public & 8 & 84 & 13287 & 6349 & 214 & 89 \\
\hline & & Private & 0 & 23 & 4112 & 1929 & 0 & 0 \\
\hline \multirow[t]{2}{*}{8} & \multirow[t]{2}{*}{ Santhong } & Public & 3 & 31 & 3278 & 1594 & 0 & 0 \\
\hline & & Private & 0 & 0 & 0 & 0 & 0 & 0 \\
\hline \multirow[t]{3}{*}{9} & \multirow[t]{2}{*}{ Pakngeum } & Public & 5 & 41 & 4677 & 2258 & 25 & 16 \\
\hline & & Private & 0 & 0 & 0 & 0 & 0 & 0 \\
\hline & & & & & & Total $=$ & 612 & 221 \\
\hline
\end{tabular}

(Source: Vientiane Capital Education and Sports Bureau, 2014)

\subsection{Research participants}

I selected participants based on their perceived relevance, considering the aims of this study were to gain diverse perspectives on how to improve school environments, practices and to understand people's attitudes to promoting the education of children with disabilities through IE. The key participants, therefore, include concerned parties both outside and inside the education sector, such as concerned government ministries, provincial and district education bureau offices, development partners or donors, international non-government organisations, local organisations representing people with disabilities, and parents of children with disabilities. It should be understood, however, that this study presents the opinions of individual participants whose personal ideas may or may not represent the views of their organisations. Only one participant per organisation participated in the semistructured interviews because I wanted to approach as many as possible participants from different professional backgrounds.

As shown in the Table 3 below, I want to point out that this thesis attempted to collect data from a range of sources and interview participants from diverse backgrounds. The participant selection is based on the nomination of the organisation. A letter was sent to the selected organisation requesting the head of the organisation to voluntary nominate a person to participate. 
Table 3: Participants

\begin{tabular}{|c|l|c|}
\hline No. & Participants & Number of participants \\
\hline 1 & Staff of relevant government departments & 6 \\
\hline 2 & Development donors & 2 \\
\hline 3 & Adult disabled people & 1 \\
\hline 4 & Disabled students' teachers & 4 \\
\hline 5 & District education bureaus & 5 \\
\hline 6 & Disabled people organisations & 4 \\
\hline 7 & Non-disabled people & 2 \\
\hline 8 & General mainstream primary schools & 3 \\
\hline 9 & Staff of inclusive mainstream primary schools & 5 \\
\hline 10 & International non-government organisations & 1 \\
\hline 11 & Ministries & 2 \\
\hline 12 & Parents of children with disabilities & 1 \\
\hline 13 & Private primary schools & 2 \\
\hline 14 & Provincial education bureau & 2 \\
\hline 15 & Special schools & \\
\hline 16 & Village authorities & 3 \\
\hline & & \\
\hline
\end{tabular}

\subsection{Data analysis}

Data collected was analysed manually. All information gathered, either from the semi-structured interviews, or documents and researcher observation notes was firstly translated into English by the researcher. All information then was summarised into themes. The common themes that emerged from all responses. It was difficult to identify themes as opinion were diverse. The major themes include information about the IE policy development at the national level; knowledge and attitudes towards disabilities and the practical aspects of IE practices to ensure that all mainstream primary schools are responsive to the needs of children with of impairments including movement, seeing, speaking, hearing and learning difficulties.

The assurance of data validity and trustworthiness is dependent on the researcher continuously taking a reflexive approach to minimise researcher's bias, which in turn influences the interpretation of the data. Information was cross-checked across three sources of data: interview results, document analysis and researcher observations. Responses that support each theme based on these sources of data were used in order to enable readers to understand an issue from different perspectives. 


\subsection{Research ethics and data collection permits}

Ethics plays an important role in any research that involves human subjects. Going through the ethics approval process of the Human Ethics Committee of the Victoria University of Wellington has helped me to reflect on my own ethical approach and challenges that this thesis may present. An Ethics Approval application was filed and submitted to the Human Ethics Committee in according with the Human Ethics Policy of the Victoria University of Wellington, and was approved prior to fieldwork.

For getting additional permission to collect secondary data that are available from different organisations and permission to conduct interviews, a number of documents needed to be available in both English and Lao prior to consultation with key informants. These documents included a standard letter of request, participant information sheet, the semi-structured questionnaire, transcriber's confidentiality agreement, ethics approval, consent form and University support letter.

A standard letter of request was edited to suit individual informants. I had to deliver the request letter to each organisation. A week after delivering the letter, I followed up with each organisation. A number of follow-up phone calls were made until I could get a confirmation of participation or refusal. Some organisations decided who should participate in this project on their behalf. Some organisations requested a consultation meeting before agreeing on the interview date. The most effective way to progress this was that I had to visit each targeted organisation in person and discuss my research, and propose suitable participants for interview with the organisation. Otherwise participants were more likely to send no signal as to whether they agreed to participate or not.

For participants with speaking and hearing impairments, but not also visual impairments, the letter of proposal, information sheet, consent form and interview questions did not need to be translated or interpreted into braille. Assistance for the interviews was organised with the relevant organisations. After getting permission from relevant authorities and schools, the schools appointed a teacher fluent in braille and sign languages to give me assistance as appropriate. Confidentiality of the information provided by participants was clearly explained to both the assistants and participants before interviewing.

Concerning teachers and parents, I spoke with school principals and requested permission to approach relevant teachers, school administrative staff and parents. 
After the first meeting with the school principal, I followed up with phone calls and met in person several times until an interview could be conducted.

Everyone I approached was informed about the confidentiality of the information provided, and they were aware that none of the participant's personal information would be used in the report.

\subsection{Field research experiences}

The majority of participants were willing to give up their time for the interview, and share their views and relevant documents. Despite this largely positive response, I still experienced difficulties in accessing information from many international non-government organisations. The majority of participants who refused to participate in the research were non-governmental organisations. Since I had interviewed a few important INGOs, it was sufficient to have a general understanding on the issue being researched. However, overall, I had quite positive experiences from approaching all participants. The majority of the research target participants showed a welcoming attitude to sharing their experiences, knowledge and information that were all relevant and useful to my research questions.

\subsection{Chapter summary}

This chapter explained the qualitative approach taken in this research thesis. This approach involved the employment of document analysis, semi-structured interview questions and observations. Even though some organisations refused to participate, the 45 research participants are a good representation of all crucial mainstream primary schools stakeholders in Vientiane. Ethical concerns have been considered and permission to interview and collect data were sought appropriately. Confidentiality was maintained throughout the study. No major issues were experienced preventing the completion of the data collection phase of the project. 


\section{CHAPTER FOUR THE CONTEXT FOR INCLUSIVE EDUCATION PRACTICE IN LAO PDR}

\subsection{Introduction}

This chapter explores the context of this research, focusing initially on demographics, political, social, economic, and development priorities of the Lao People's Democratic Republic, hereafter called Lao PDR. It then describes and discusses the system in Lao PDR for identifying and supporting those with a disability; and the Lao PDR education system, including special education and IE that are important frameworks for supporting learners with disabilities. These factors will determine, shape and limit the responsiveness of Lao society to create an effective and IE system for students with disabilities.

Lao PDR is a landlocked and mountainous country located in Southeast Asia. It shares borders with five other countries: China in the north, Myanmar in the North West, Thailand in the west, and Cambodia in the South and Viet Nam in the east. Lao PDR is divided into 17 provinces, 147 districts, and 8,615 villages (Lao PDR, 2013, p.11). According to the Lao Statistics Bureau (2014) the total population is about 6.8 million people, 3.4 million of whom are female. The population is very young: more than half of the population is aged under 25 (Lao PDR, 2013, p.12). The total area of Lao PDR is 236,800 square kilometres, and the majority of people live in rural areas. (see Figure 3). 
Figure 3: Map of Lao PDR

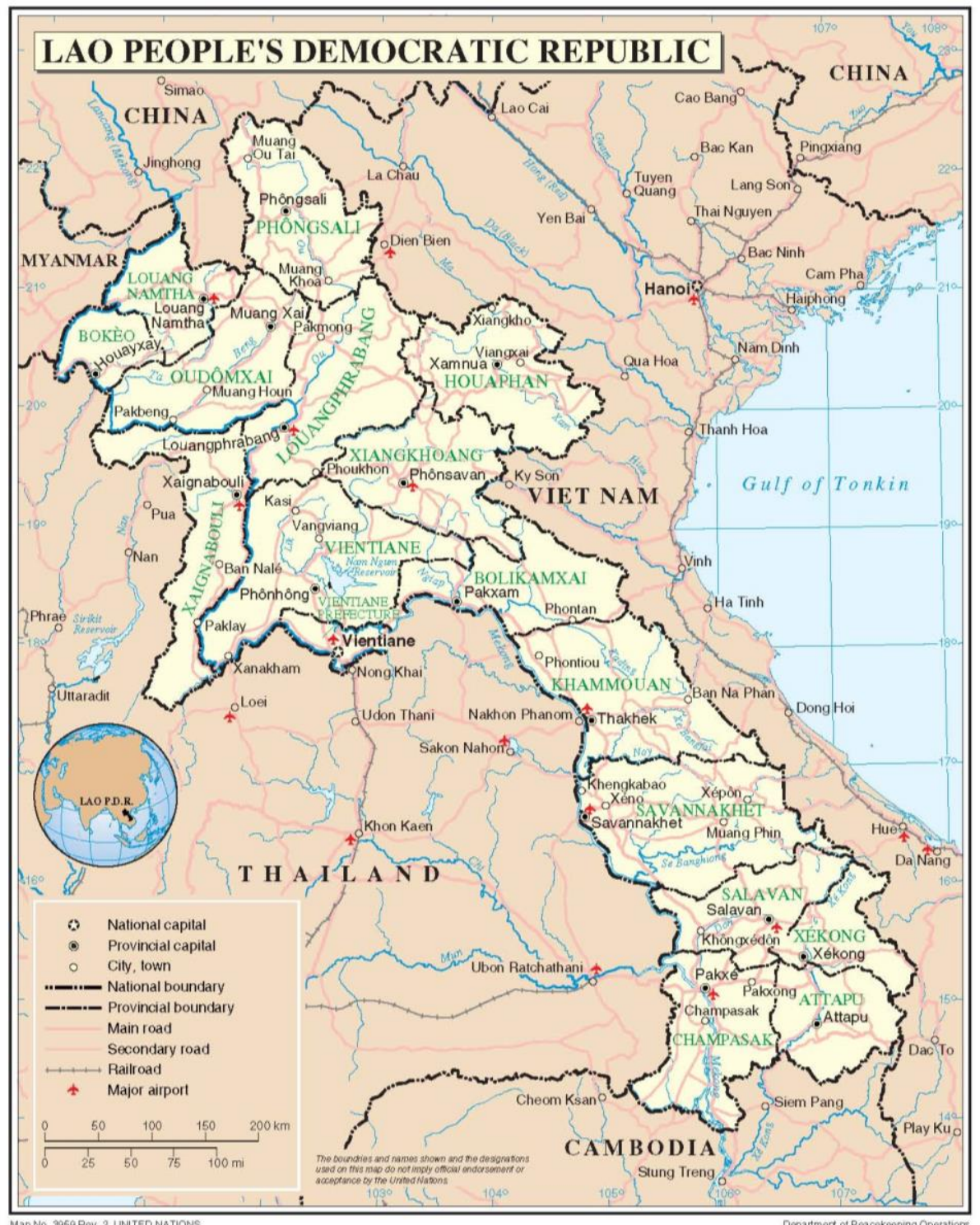

(Source: Retrieved 29 July 2015, from http://www.un.org/Depts/Cartographic/map/profile/laos.pdf)

The adult literacy rate is 74 per cent (ibid). The 2014 Human Development Report ranked Lao PDR as 139 out of 187 countries. Gross Domestic Product (GDP) per capita is low at US $\$ 1,628$. However, the rate of GDP growth is fairly high at eight per cent $(8 \%)$. This growth is primarily driven by foreign investments and overseas development assistance. Lao PDR experiences many challenges. Firstly, common natural disasters are flooding and drought. In 2009, Typhoon Kesatna hit five southern provinces of Lao PDR and affected hundred thousands of people (Global Facility for Disaster Reduction Recovery, 2014). Secondly, Unexploded Ordnance (UXO) has continuously threatened the development process of Lao PDR. Lao PDR is one of the most UXO-affected countries (UNDP, n.d.). According to the National Regulatory Authority (n.d.) for mines/UXOs action sector, Lao PDR is one of the most heavily bombed countries in the 
world per capita. Over two million tonnes of ordnance have been deployed across the country; about $30 \%$ of which failed to explode as intended (National Regulatory Authority, n.d., p.1). This continues to bring about death and injury with approximately 300 UXO-related accidents occurring every year (ibid). Furthermore, poor road access and poor communication infrastructure in many remote regions cause major difficulties for rural people and persons with disabilities in accessing quality education services, healthcare and information.

\subsection{The political context}

The Lao People's Revolutionary Party (the Party) came into power in 1975 and the Party renamed 'Laos' as 'Lao PDR'. Any reform of the economic, social and political policies requires the political support from the key political party members because of the centralised leadership and decision-making.

Lao PDR is a single party state. All state organisations, including the national assembly, ministries, and public service organisations are required to follow the centralised administration and be led by Party members. The Central Politburo Committee is made up of political party members, and the Party Congress is held every five years to determine national development policy goals and other socio-economic and political directions. As recorded by the National Assembly of Lao PDR (2011a), the 9th Party Congress was held in Vientiane, Lao PDR during 17-21 March 2011. This Congress involved 576 Party delegates representing 191,780 party members. The Congress determined political rules, and the progress to be achieved through the Fifth National Socio-Economic Development Plan (2011-2015). Therefore, to effectively implement and translate any plans into practice, it is essential to get the full support from all political party members among the central level because central party members have more power in all IE policies decision making than others.

\subsection{The social context}

Lao PDR encompasses many diverse cultures, yet little attention has been paid to cultural development and the language of many ethnic groups despite the rights of all ethnic groups being protected by Article 3 of the Lao constitution. There are 49 officially recognised different ethnic groups in Lao PDR. These ethnic groups are categorised into four different linguistic groups: the Lao-Tai, the Mon-Khmer, the Tibeto-Burman and the Hmong-Mien (UNESCO, 2012). Within these four groups, there are many sub-ethnic 
groups. Each ethnic group and each clan has its own beliefs, values and practice systems. More than half of the total population of Lao PDR is the Lao Loum speaking group which is under the Lao-Tai linguistic group. Lao Loum speaking people generally follow animistic Buddhism. Around 60 per cent of the total population of Lao PDR practices Buddhism. Many other minority groups practice spirit worship, Christianity and other religions. These religions can have a powerful impact on people's perceptions and attitudes towards persons with disabilities as mentioned previously. How different religions interpret disability will be discussed in more detail in the discussion chapter.

In addition, little effort has been given to promoting the inclusion of many ethnic people in Lao society through acknowledging their individual group languages. According to the amended constitution of Lao PDR, article 89, the Lao language and Lao script is the only official language. The government of Lao PDR classifies ethnic groups on the basis of language, but the written and spoken languages of many ethnic groups can be used in informal situations only. So far, the Lao government has not adopted any plan or strategy to develop and recognize the written and spoken language of any other ethnic group, as part of its cultural promotion policy. Since language carries power, ethnic groups whose first language is not Lao, or other foreign languages, are often politically, socially, and economically disadvantaged, compared to the Lao Loum majority population

Lao PDR culture is generally focussed on the community and extended family more than individuals. Parents need the assistance of their children, and adult children have to take care of their parents. Lao families tend to be more extended, with support often coming from relatives, cousins and brothers or sisters in-law.

\subsection{The economic context}

Lao PDR has achieved remarkable economic development outcomes but such outcomes do not benefit all people equally. According to the Asian Development Bank Outlook (2015), the Lao PDR Gross Domestic Product is at seven per cent in 2015, and is expected to reach 7.2 per cent in 2016, which is higher than the average GDP growth rate among Asian countries (6.3 per cent). The national poverty rate has decreased about half from 46 per cent in 1992 to 23 per cent in 2013 (ibid). This growth might be the result of increased foreign aid and investments in hydropower, minerals and other services (National Assembly of Lao PDR, 2011a). However, persons with disabilities do not enjoy the same opportunities that derive from such growth. Accurate and comprehensive 
information on the employment rate and access to education among persons with disabilities remains unknown or unavailable, even though the Ministry of Labour and Social Welfare of Lao PDR is responsible for facilitating the employment of persons with disabilities (Asia-Pacific Development Centre on Disabilities, 2014). Despite the above progress, inequalities between the rich and the poor, and between urban and rural people, remain challenging, because the benefits from development initiatives have not been allocated in an equitable and balanced way.

Lao PDR has made a number of achievements in integrating into both the regional and global economy. Lao PDR became a member of the Association of the Southeast Asian Nations (ASEAN) in 1997 and ASEAN Economic Community in 2015 (UNDP, n.d.). In 2013 Lao PDR became a member of the World Trade Organisation, and in 2011 Lao PDR became a lower middle income country (World Bank, 2015). This thesis argues that these economic development opportunities should not only benefit the wealthy, the benefits should also reach persons with disabilities, especially those with severe impairments, and including children with disabilities.

\subsection{National development priorities}

Based on the human rights-based approach that emphasises the state's responsibilities to protect the human rights of its citizens, the Lao People's Revolutionary Party (The Party) and the government (the administrative arm of the Party) play a crucial role in developing national development policies and strategies to protect the rights of all ethnic groups including people with disabilities. According to the National Policy on IE, one of the country's national development priorities is to progress Lao PDR to become a modern industrialised country (MOES, 2011). In this policy, one specific priority is that by 2020 Lao PDR will graduate from the list of least developed countries. At the same time the government is seeking to promote socio-economic development, environmental sustainability, and political stability, and to preserve cultural diversity. To accomplish these priorities, the government has developed and implemented a number of development strategies including the National Growth and Poverty Eradication Strategy 2020, National Socio-Economic Development Plan and MDGs (ibid). Lao PDR has already achieved universal access and gender equity to primary education in 2015 (UNDP, 2013). It would be interesting to explore how applicable this achievement is to children with disabilities. 
Overall, the education situation in Lao PDR has been improving over the last 15 years while disparities of attendance in schooling remain prevalent. The second of the MDG's goals is to achieve universal primary education. School enrolment rate and net survival rate, (the percentage of students who study continuously from grade 1 to grade 5), are used as indicators to determine whether this goal has been achieved. However, these indicators are insufficient. Lao PDR almost achieves its net school enrolment rate, with a recorded rate of 98 per cent (UNESCO, 2014, p.14). The survival rate has improved from 48\% in 1992 to 70\% in 2012 (UN, 2010). However, these figures do not provide any indication of the quality of the process of education service delivery, as some students might be attending without effective learning. In addition, Goal Two did not specify reforming the general education standards to cater for the needs of children with disabilities. To achieve the above indicators, the EFA strategy focuses on the abolition of school fees, school construction, a food programme for education, financial transfer and other factors. However, the EFA strategy should also address other social issues if they really want to achieve EFA. A report attributes disparities in education in Lao PDR to low socio-economic status, rural or isolated settings, and gender, ethnic, and cultural differences (UNESCO, 2012). In 2008, the difference in the net primary school enrolment rate for males (84 percent) was higher than for females (81 percent) (UNESCO, 2012, p.5). For persons with disabilities age over 6 years old, there is a higher rate of never attending any school where there is no road access (76.5 percent for females and 53,6 percent for males) than for those who live in areas with good road conditions ( 67.7 percent for females and 40.6 percent for males).

\subsection{Legislation and the administration of the Lao education system}

Although the Party and government of Lao PDR emphasise in all their policy documents that education tends to be one of the most important development priorities and a basic human right for the development of the nation, there tends to be weak support in implementing basic education. The Lao constitution was adopted in 1991 and amended in 2003. Article 22 of the amended constitution states that the purpose of compulsory education is to build good citizens and develop revolutionary competence, knowledge and abilities (National Assembly of Lao PDR, 2011b). It adds that both the state and society should create opportunities and a favourable educational environment for all Lao people including disadvantaged children. The term 'disadvantaged children' includes many types of children and not only children with disabilities. 
Since Lao language is the only language instructed in the Lao educational system, people who use other languages experience difficulties in learning (Chounlamany, 2014). The Lao PDR education legislation amended in 2007 is consistent with the constitution in that it emphasises compulsory and free primary education without discrimination based on individual student's backgrounds. However, languages like braille and sign especially, have recently been developed by the ministry of health and other non-profit organisations over the last 10 years. Therefore, children with disabilities still face difficulty in adapting to the mainstream education system.

Since there is no special educational system for people with disabilities in Lao PDR, they have to comply with the mainstream education system. The early or general level of education consists of four levels of study. The first level is preschool which includes children up to two years. The second level is kindergarten school, taking children aged from three to five. The third level is primary school, taking children age from six to ten. The last level is secondary school taking children aged from 11 to 17 (McLaughlin, 2011 , p. 7). The form of education generally involves teaching based on textbooks and memorising learning with reproduced tests. This study focuses on primary school education. The education system overview can be understood as shown in Table 4 below:

Tables 4: General education system

\section{Education System Overviey'}

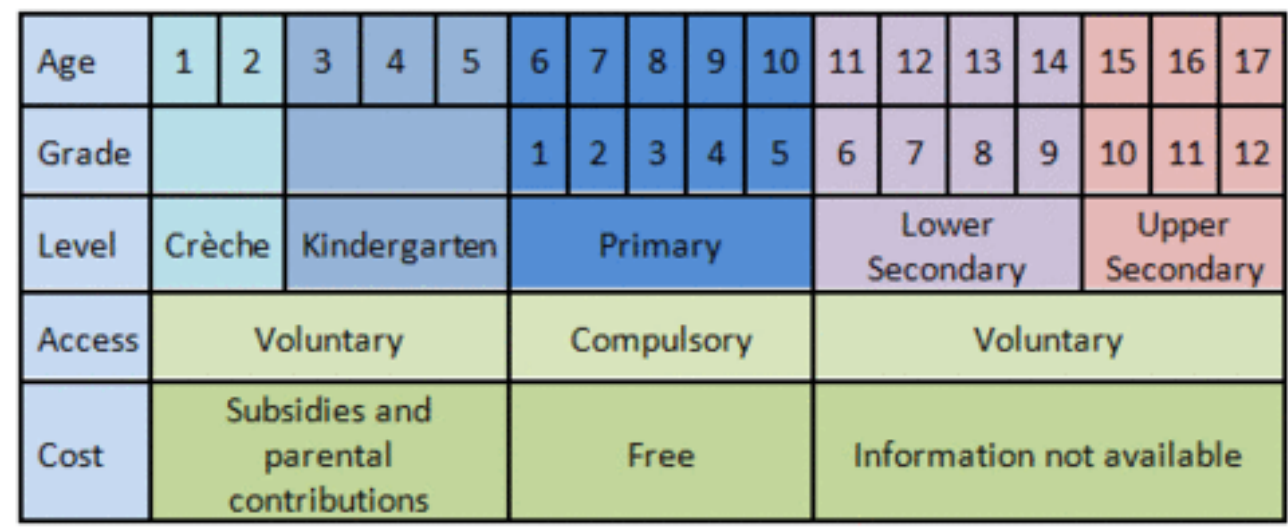

(Source: Retrieved 31 July 2015 from

http://www.unescobkk.org/education/resources/resources/education-system-profiles/laopdr/education-sector-overview/)

The administration and management of education services which consists of three levels: central, provincial and district, is centralised. At the central level, the Ministry of Education and Sports (MOES) is in charge of education nationwide and acts as a 
secretariat for the government. MOES determines and finalises all education policy development, planning, implementation, monitoring and evaluation (UNESCO, n.d.). At the provincial level, Provincial Education and Sports Services is responsible for secondary schools and technical and vocational schools. At the third district level, District Education and Sports is in charge of preschools, primary schools and other non-formal education institutions within the district catchment area. Based on democratic centralism, the provincial and district levels are required to implement policies and guidelines as directed by the central level, and report their implementation to the central level.

In addition, the implementation of any national policy reforms faced challenges in practice despite the support of international organisations. UNESCO plays an active role as a member of the Education Sector Working Group (ESWG). This group was formed under the Vientiane Declaration on Aid Effectiveness in 2006. The MOES, UNICEF and Australian Aid chair the working group, and meet regularly to discuss education policies and implementation with other development partners such as the Asian Development Bank, the World Bank, the European Commission and the World Food Program (UNESCO, 2012). Many of these changes happen only at the national level and have not addressed the repetitive challenges faced by the implementation of policies at the local level.

Moreover, if the government depends on external support, it will be difficult to ensure that the implementation of any educational plan of action and related policies benefit children with disabilities. According to a draft Report on the implementation of the Inclusive Education Development Plan 2014-2015, one of the challenges faced by the special education unit is that there is limited financial support to implement the special education development plan (MOES, 2014). In the report, almost none of the staff working in the MOES at any level have specialist training in disability education. Due to the fact that decision makers and the society at large have a limited understanding regarding the education of students with disabilities. 


\subsection{The context of disability in Lao PDR}

\subsubsection{Definition of disability}

Lao PDR adapted the definition of disabilities from the United Nations Convention on the Rights of Persons with Disabilities 2006. According to the Decree on Persons with Disabilities No. 137, Article 3, disability refers to the physical, mental or intellectual anomaly including visual, hearing and speaking impairment (Government, 2014). In article 2 of the same Decree, it defines 'persons with disabilities' as persons who "irrespective of the cause of disability, are persons who have long term physical, mental or intellectual anomalies or defects including visual, hearing and speaking impairments, which hinder their daily activities and full participation in social activities". Both the Lao Decree and the UNCRPD share the same definition of 'persons with disabilities', namely those with obstacles that hinder full participation in daily activities. However, they tend to define 'disabilities' differently. The UNCRPD seems to identify negative attitudes on the part of others in society and a negative environment as causal factors that hinder a person with any impairment from full participation in normal daily life; while the Lao Decree appears to define 'disability' as a person's physical or medical anomaly . If consistent definitions cannot be achieved, gathering meaningful comparative data on persons with disabilities will be difficult.

\subsubsection{Statistics on people with disabilities}

Lao PDR is still in the early stages of collecting disability data and has been trying to use different methods to achieve this. According to a recent report on the implementation of the Vocational Training for Persons with Disabilities Project Phase Three (9 September 2009 - 31 May 2014), the Centre for Medical Rehabilitation (2014) points out that in 2009 the Economic and Social Commission for Asia and the Pacific organisation reported that there are 8 per cent or about 400,000 persons with disabilities out the total population of five million people. Since persons with disabilities face different challenges, concrete nationwide disabilities information needs to be available, segregated by age, gender, race, types of disabilities, and severity of disabilities. Yet, this information is currently unavailable. To support this statement, Save the Children Norway (2009) evaluated its Lao PDR Inclusive Education Project in 2009, and found that there are only estimated statistics on persons with disabilities. This evaluation adds that despite many initiatives attempting to improve the livelihoods of disabled persons, the government of Lao PDR does not have the relevant data and does not have the capacity 
to continuously identify the profile of school aged children with disabilities across the country.

There have been many attempts to collect statistical data regarding persons with disabilities. Chanthalanouvong (2010) presented disabilities information on the Measurement of Gender Dimensions of persons with Disabilities in Lao PDR during the third Global Forum on Gender Statistics in Philippines, Manila. Chanthalanouvong shows that prior to 1990, there was no census on disabilities. In 1994, the government conducted a survey on social indicators and found that about 7 (seven) per cent out the total population were disabled persons. In 2005, the third Population and Housing Census adopted three questions, including whether there was a person with disabilities in the family or not, and attempted to identify the types and causes of disability based on physical appearance. Please see the following Table 5 and 6 below for the questions used to collect disability data and its results. According to the National Statistics Centre (2011), this 2005 Census counted the total number of persons with disability across the country to be 56,727 people (61.1 percent male and 38.9 percent female).

Table 5: Disability questions from the Population and Housing Census 2005

Population and Housing Census 2005 - Questions used in disability data collection

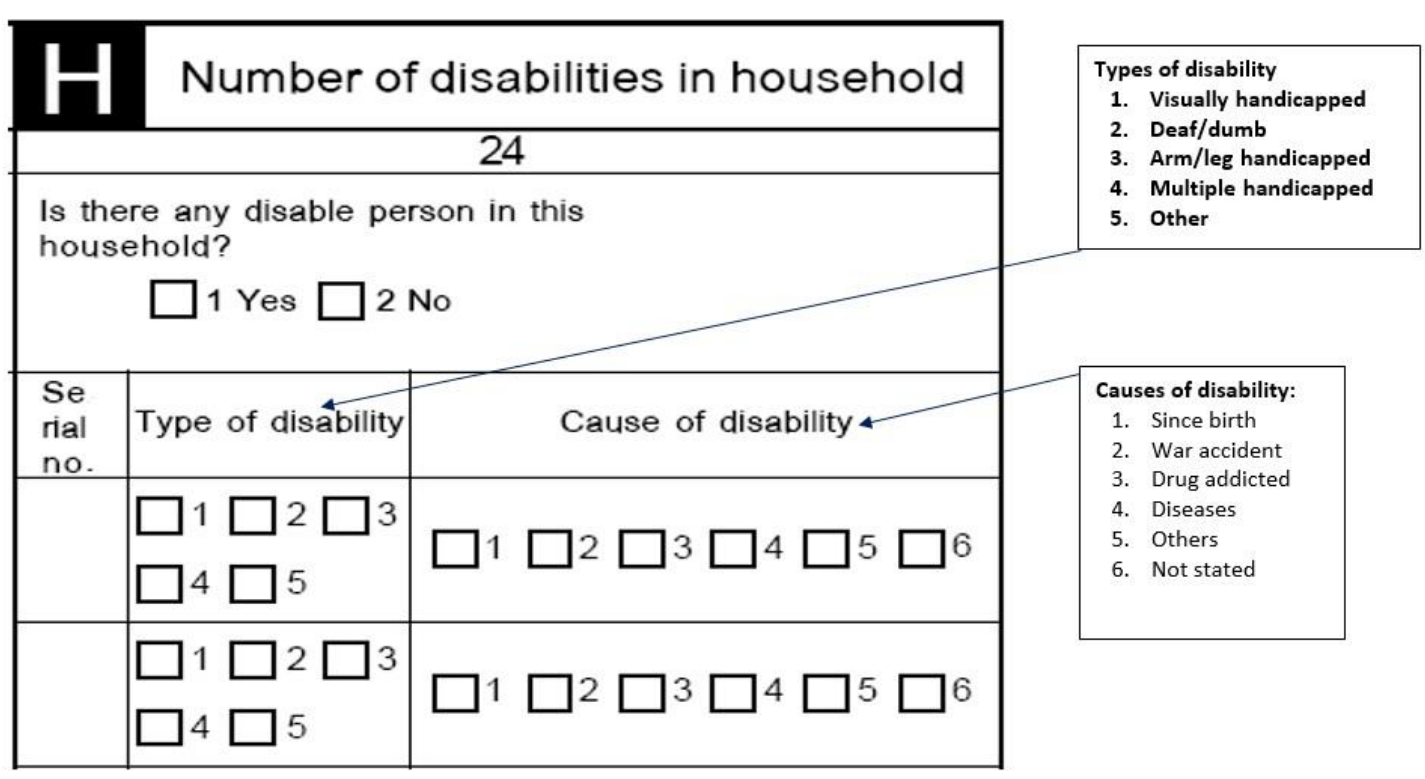

(Source: National Statistics Centre (2011)) 
Table 6: Disability data of the Population and Housing Census 2005

\section{Table 5: Percentage distribution of disable persons by cause and type of disability and sex , 2005}

\begin{tabular}{|c|c|c|c|c|c|c|c|c|c|c|c|c|c|c|}
\hline \multirow{3}{*}{$\begin{array}{l}\text { Cause of } \\
\text { Disability }\end{array}$} & \multicolumn{14}{|c|}{ Type of Disability } \\
\hline & \multicolumn{2}{|c|}{ Visual } & \multicolumn{2}{|c|}{ Deaf/Dumb } & \multicolumn{2}{|c|}{$\mathrm{Arm} / \mathrm{Leg}$} & \multicolumn{2}{|c|}{ Multiple } & \multicolumn{2}{|c|}{ Others } & \multicolumn{2}{|c|}{ Not Stated } & \multicolumn{2}{|c|}{ Total } \\
\hline & Female & Male & Female & Male & Female & Male & Female & Male & Female & Male & Female & Male & Female & Male \\
\hline Since birth & 28.5 & 26.3 & 67.4 & 60.8 & 32.4 & 19.6 & 44.2 & 37.3 & 38.2 & 35.2 & 22.9 & 20.5 & 43.7 & 33.4 \\
\hline War accident & 2.7 & 11.7 & 3.0 & 8.6 & 4.4 & 22.5 & 1.4 & 9.9 & 1.2 & 4.7 & 7.1 & 11.3 & 3.1 & 14.6 \\
\hline Accident & 12.3 & 25.2 & 3.0 & 4.2 & 21.0 & 28.5 & 3.8 & 7.3 & 2.7 & 5.1 & 9.6 & 12.5 & 10.6 & 18.2 \\
\hline Drug addicted & 1.1 & 1.3 & 0.6 & 0.5 & 0.7 & 0.7 & 2.7 & 3.8 & 0.5 & 3.3 & 2.5 & 2.7 & 0.9 & 1.2 \\
\hline Diseases & 44.4 & 25.7 & 19.4 & 18.9 & 35.2 & 23.5 & 41.3 & 34.3 & 38.4 & 32.3 & 15.8 & 15.5 & 32.7 & 24.3 \\
\hline Others & 6.4 & 4.9 & 3.3 & 3.3 & 3.5 & 2.8 & 3.2 & 3.1 & 15.0 & 15.8 & 10.4 & 8.0 & 5.3 & 4.6 \\
\hline Not Stated & 4.6 & 4.8 & 3.3 & 3.7 & 2.8 & 2.4 & 3.5 & 4.2 & 3.9 & 3.6 & 31.7 & 29.5 & 3.7 & 3.6 \\
\hline Total, percent & 100 & 100 & 100 & 100 & 100 & 100 & 100 & 100 & 100 & 100 & 100 & 100 & 100 & 100 \\
\hline Number (persons) & 3517 & 5744 & 6539 & 8399 & 7374 & 14497 & 1730 & 2397 & 2651 & 3303 & 240 & 336 & 22051 & 34676 \\
\hline
\end{tabular}

(Source: Chanthalanouvong $(2010$, p.16))

In addition, people with disabilities in Lao PDR are amongst the most vulnerable in terms of education. The 2005 Census showed that more that 50 percent of all people with disabilities had never attended any school, followed by 39.23 percent who dropped out in their primary school age (NSC, 2011, pp.18-20). For the people with disabilities aged over 6 years old (54,761 people, 33,601 are male and 21,160 are female), the Census points out that 65.2 percent of females with disabilities had never attended any school while 39.8 percent of males with disabilities had never attended any school (ibid).

The 2005 Census has some weaknesses. The first is that it classified disability types in limited ways that did not account for people who have mental, memory, cognitive and other less visible forms of impairments. The second issue is that in the education statistics, the Census did not classify age specific groups of those who had never attended school beyond 6 years old. This appears to be too broad as a basis for planning IE initiatives.

Due to the limitations of the 2005 Census in 2015 the Lao Statistics Bureau conducted its fourth Population and Housing Census 2015, using questions regarding six disability types, including: vision difficulty, hearing difficulty, ambulatory difficulty, cognitive difficulty, self-care difficulty, and speaking or communication difficulty (see Table 7 below). Unfortunately, the results of this survey were not available at the time of 
writing, but it would be expected that the national numbers of disabled people would increase with the inclusion of these broader categories.

Table 7: Disability questions from the Population and Housing Census 2015 (Translated from the Lao version of the Fourth Population and Housing Census 2015 Lao PDR).

\begin{tabular}{|c|c|c|c|c|c|c|c|}
\hline $\begin{array}{l}\text { Question } \\
4\end{array}$ & $\begin{array}{l}\text { Question } \\
11\end{array}$ & \begin{tabular}{|l|} 
Question \\
12 \\
\end{tabular} & $\begin{array}{l}\text { Question } \\
13\end{array}$ & Question 14 & $\begin{array}{l}\text { Question } \\
15\end{array}$ & Question 16 & Question 17 \\
\hline \multirow{3}{*}{$\begin{array}{l}\text { Sex type: } \\
\text { 1. Male } \\
\text { 2. Female }\end{array}$} & \multicolumn{6}{|c|}{ Do you face difficulty in the following matters? } & \multirow{3}{*}{$\begin{array}{l}\text { Main causes of the difficulty (for the questions } 11-16 \\
\text { only) } \\
\text { 1. Birth } \\
\text { 2. War } \\
\text { 3. Accident } \\
\text { 4. Unexploded ordnance } \\
\text { 5. Diseases } \\
\text { 6. Others }\end{array}$} \\
\hline & \multicolumn{6}{|c|}{$\begin{array}{l}\text { 1. No difficulty } \\
\text { 2. Minor difficulty } \\
\text { 3. High difficulty } \\
\text { 4. No ability to anything }\end{array}$} & \\
\hline & Vision & Hearing & $\begin{array}{l}\text { Walking } \\
\text { or } \\
\text { mobility }\end{array}$ & Remembering & Self-care & $\begin{array}{l}\text { Speaking or } \\
\text { communication }\end{array}$ & \\
\hline $\begin{array}{l}1 \ldots \\
2 \ldots\end{array}$ & $\begin{array}{l}1 \ldots, 3 \ldots . . \\
2 \ldots ., 4 \ldots . .\end{array}$ & $\begin{array}{l}1 \ldots ., 3 \ldots . . \\
2 \ldots ., 4 \ldots . .\end{array}$ & $\begin{array}{l}1 \ldots, 3 \ldots . . \\
2 \ldots ., 4 \ldots . .\end{array}$ & $\begin{array}{l}1 \ldots ., 3 \ldots . . \\
2 . ., 4 \ldots \ldots\end{array}$ & $\begin{array}{l}1 \ldots ., 3 \ldots . . \\
2 \ldots ., 4 \ldots .\end{array}$ & $\begin{array}{l}1 \ldots ., 3 \ldots . . \\
2 \ldots, 4 \ldots . .\end{array}$ & $1 \ldots ., 2 \ldots, 3 \ldots, 4 \ldots, 5 \ldots, 6 \ldots \ldots$ \\
\hline
\end{tabular}

(Source: NSC, 2015)

Little information about the education of students with disabilities at primary school level is available. It is estimated that as many as $16 \%$ of the total disabled people in Loa are children under the age of 15 (National Statistics Centre, 2011, p.7). MOES (2011, p. 3) indicates that there were 4,569 children with disabilities in 2008 and only 4 (four) per cent of them were enrolled in preschools, primary and secondary education where trained teachers are provided.

Many organizations in Lao PDR have taken part in attempting to promote disability rights. The National Committee for the Rights of Persons with Disabilities oversees the translation and interpretation of the UNCRPD into policies. Maout (2014) explains that there are many stakeholders contributing to the development of IE in Lao PDR (see Figure 4 below). The Ministry of Labour and Social Welfare (MOLSW) is responsible for vocational training, employment, social welfare and protection. The Ministry of Health $(\mathrm{MOH})$ is in charge of physical and mental rehabilitation and disability prevention. The Ministry of Education and Sports is responsible for IE and the special education of persons with disabilities. There are many international non-profit organisations working with government key ministries to promote disability rights, including the Catholic Relief Service, Handicap International and other civil society organisations. There are many active local civil society organisations advocating for persons with disabilities in Lao PDR. An overview of these stakeholders' roles and relationships are summarised in the following diagram (see Figure 4): 
Figure 4: Some of the key disability rights stakeholders

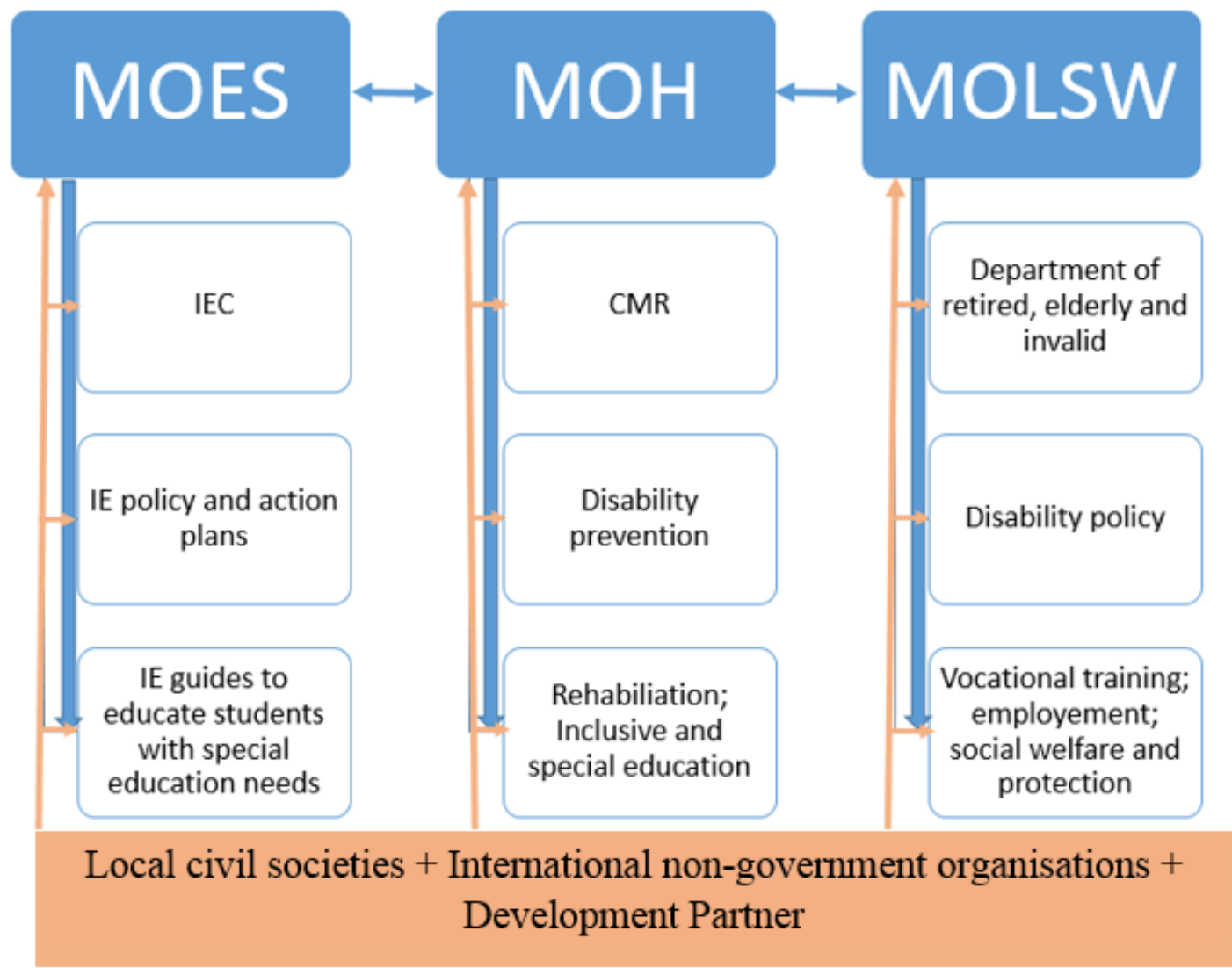

(Source: Compiled by the author)

Seven out of the 43 registered local associations within the Ministry of Home Affairs are working on disability related issues. In addressing disability rights and equality, Maout (2014), found that seven local disabled people organisations have been established to coordinate with the Lao government and other international organisations. Many of the local disabled people organisations was actively participated in promoting disability rights. Some of these organisations include:

1. Lao Disabled People's Association (LDPA) was officially established in 2011 to improve and promote the rights of people with disabilities.

2. Association for Autism was established in 2012. Their work covers education, health, labour and social welfare. It has a centre caring for and educating autistic children.

3. Vocational Development for Blind Association was established in 2012, working in the areas of labour and social welfare.

4. Aid Children with Disability Association was established in 2013, working in the areas of education, health, labour and social welfare, information, culture and tourism. 
5. Association for the Deaf was established in 2013 working in the areas of health, labour and social welfare.

6. Association for Patients with Epilepsy was established in 2013 working in the area of health.

7. Association of the Blind was established in 2014 working in the area of social security, training and vocational development.

\subsection{The special education context in Lao PDR}

Special education or a special school is a legal requirement to improve the education of children with disabilities in Lao PDR. Even though there are no clear guidelines to implement the Decree on Persons with Disabilities No. 137 (2014), Articles 21 and 22 of this Decree states that educational institutions shall try their best to promote effective learning by all students with a disability in all state-run schools, based on the actual conditions and capacity of each school (Government, 2014). If learners with mental, visual, hearing, speech or other complex disabilities cannot attend the state-run 'inclusive schools', they will be referred to special schools. This Decree's points out that there is a need to support special schools for disabled students. Figure 5 below shows that special schools was initially carried out by the $\mathrm{MOH}$.

Figure 5: The Centre of Medical Rehabilitation

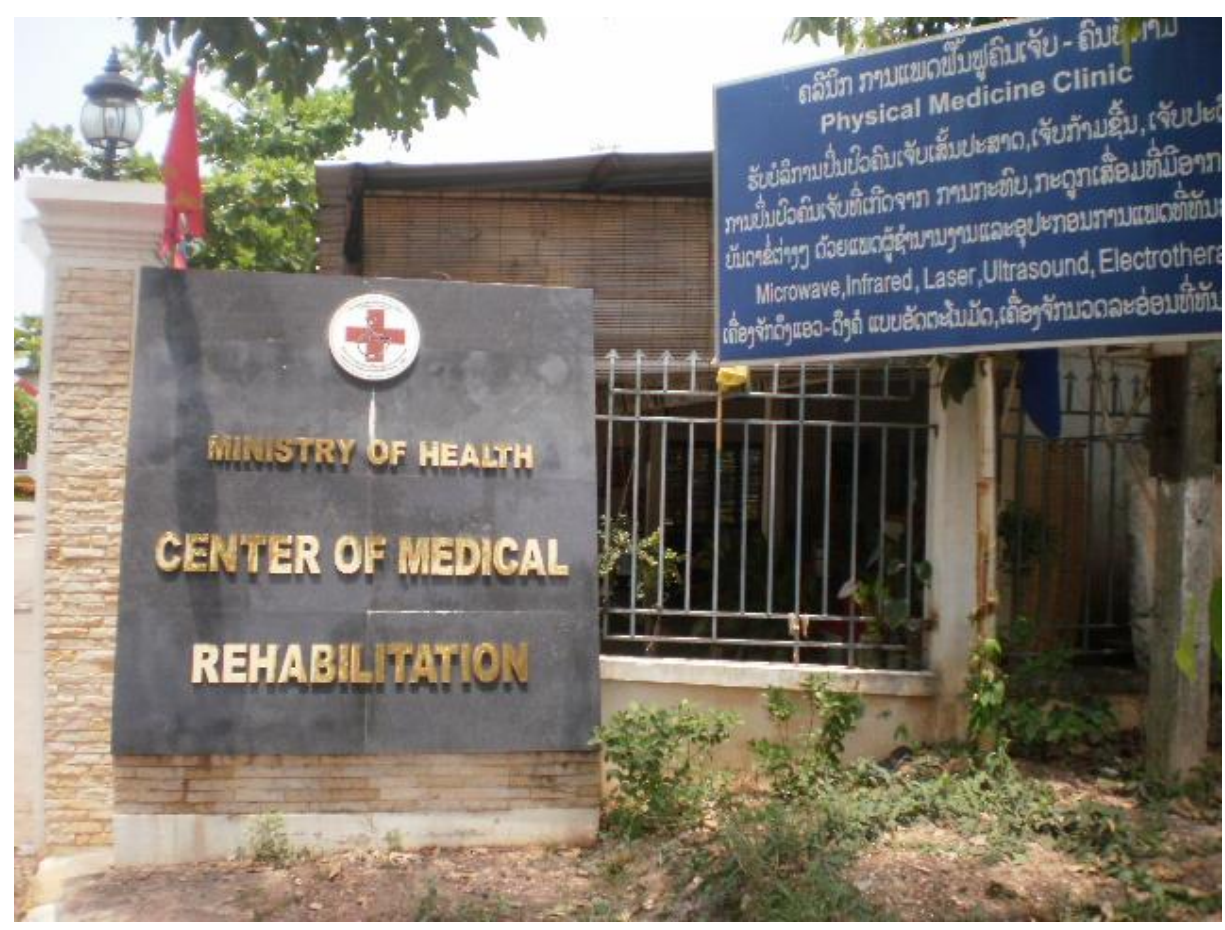

(Source: Taken by the author) 
Lao special education historically reflects the medical model for disability, where persons with disabilities are required to be rehabilitated to fit the functions of the society. According to an Approval of the Implementation and Organisation of the CMR 241, dated 04 August 2011, the CMR is under the responsibility of the Ministry of Health. This Centre is the first and only organisation to provide special education and rehabilitation for persons with disabilities (MOH, 2011). Various organisations, both public and private, have supported this Centre to provide disability services, including developing Lao braille and sign language teaching schools, providing wheelchair devices, artificial prostheses and orthoses, and other rehabilitation activities. 4 out of 17 provinces have a branch of CMR. These provincial branches are not able themselves to provide special education for children, and the Centre headquarters is the only place since 1992 that has started to teach children with visual and speech impairments. In 2013 there were 97 in-patients (30 blind, 67 deaf), and 34 out-patients with mental disabilities. The Internal Final Evaluation Report 2009 on the Lao PDR Inclusive Education Project, conducted by Save the Children Norway (2009), found that prior to 1992 there was no special school within the country. The Japanese International Cooperation Agency Planning and Evaluation Department conducted a study (JICA, 2002) on the Lao PDR country profile of disabilities. The study found that the CMR was founded in 1962, and started to provide disabilities-related services in 1975 . The CMR provided no education to persons with disabilities.

The development of informal special education curriculum was initially supported by external donors. There were no Lao sign and braille languages before 1993. Between 1993 and 2009, Save the Children supported the Ministry of Education and Sports to conduct a pilot IE project to establish two to three inclusive schools per district to promote disabled children to study alongside their peers. However, since the project ended in 2009, the principles of inclusive schooling have not yet been understood and used in all public education institutions. In practice, all the IE primary and secondary schools still follow integration principles emphasising the placement of students with disabilities in a special class or in project schools. 


\subsection{The Lao inclusive education concept and practices of the Ministry of Education and Sports}

\subsubsection{The establishment of the Inclusive Education Centre}

The Inclusive Education Centre (IEC) was created in 2002 to enable all children especially children with disabilities, girls and children of minorities to have opportunities to learn in all schools and all subjects (Maout, 2014). In 2008, IEC was first established as the Centre for education for girls, ethnic groups and disabled persons as well as students who were socio-economically disadvantaged. In 2012, the IEC became a unit under the Department of Preschool and Primary Education. Maout points out that IEC is a centre for coordination among foods for study programme, gender mainstreaming and children with special educational needs.

\subsubsection{Inclusive education principles}

The adoption of the term 'IE' by the MOES has started to shift the focus of the Lao PDR education strategy (MOES, 2011). In the past, all students attending schools had to conform and assimilate to the same 'universal standards' (Grimes, 2009). Prior to 1993, diversity and differences generally were not tolerated and valued, because there has been no concrete policy or action plans to embrace the diverse backgrounds of students (Grimes, 2009). However, since MOES has adapted the IE definition from the 48th International Conference on Inclusive Education in 2008, there were some new policies adopted to promote the inclusion of all students learning together in the same mainstream schools (MOES, 2011). In 2010, the MOES approved its Decree on the endorsement and promulgation of the national policy on IE. It has also started to implement the National Strategy and Plan of Action on Inclusive Education 2011-2015 (Maout, 2014). According to the National Policy on Inclusive Education and the National Strategy and Action Plan on Inclusive Education 2011-2015, MOES (2011) views IE as an ongoing improvement process of providing quality education tailored to the diverse needs of individual students.

This definition may imply that any barriers faced by individual students should be removed in order to promote effective learning by all students. In other words, individual problems will no longer be viewed as educational barriers, while the school environment and educational institution should be adjusted to the needs of its students. In relation to the diverse needs of students with disabilities, IE should be constantly responsive to changing needs. It does not specify whether the government will reduce the number of special schools or promote students with disabilities into mainstream schools. The term 
IE seems to imply a holistic approach and includes a wide range of people, not only persons with disabilities. Maout (2014) conducted a situation analysis report for Handicap International on disability-IE in Lao PDR. Maout (2014) explains that IE in Lao PDR means the inclusion of girls, children from ethnic minorities and children with disabilities into general schools.

In practice, in Lao PDR, the implementation of IE principles has not been successful (Grimes, 2009). Save the Children Norway conducted an internal final evaluation on the Lao PDR Inclusive Education Project in 2009 (Grimes, 2009). Grimes (2009) pointed out that this project has created opportunities for some mainstream primary and secondary schools to enrol children with disabilities to study together with other non-disabled students in the same class. However, Grimes concluded that despite this effort, students with disabilities continued to experienced difficulty in adapting to the mainstream norms, general educational system and school environments, which is contradicting to the principles of IE. This is because the main point of IE is that the education system should be adapted to meet the needs of individual students rather than the students.

\subsection{Chapter summary}

Taking a holistic approach in understanding the Lao PDR context, it can be seen that reforming the educational institutions alone cannot achieve effective learning by students with disabilities, unless other political, social and economic institutions in the society, are also reformed so that they are all aligned for a common purpose. Historically, the rights of persons with disabilities in Lao PDR have not been addressed adequately, which has brought about limited disability resources to support the implementation of education policies. However, recently, the government's key ministries and civil society organisations in Lao PDR have brought the inclusion of persons with disabilities in into development programs. Even though national policies and action plans continued to be developed and implemented, challenges to promoting inclusive practice in the Lao school system were poorly unaddressed. It is found that the implementation of IE principles has not yet been implemented widely. Responses to disability rights are still based on the medical model. Data on disability is inconsistent and unreliable. Many development priorities have not emphasised disability needs adequately. The promotion of IE in mainstream primary schools is far from successful for various reasons based on its context. 


\section{CHAPTER FIVE \\ FINDINGS}

\subsection{Introduction}

This chapter presents the results of this study. It concerns the extent of inclusion of the Lao public mainstream primary school system, under the principle of IE in promoting the primary education of children with disabilities. Data was gathered using a qualitative methodology. All observation notes and documents collected werr analysed manually and used to supplement the information gathered from the semistructured interviews. Four major themes were discovered in relation to the main research findings. These themes are: the adoption of the IE strategy into national education policies; the understanding of disabilities, attitudes towards children with disabilities; the understanding of the IE concept and its practical impacts on mainstream primary schools in Vientiane, Lao PDR.

\subsection{The adoption of inclusive education into national policies}

Finding reveals that the government of Lao PDR has a positive attitudes towards the principle of IE. Many senior officials of the MOES pointed out that the need to include children with disabilities into all mainstream schools is one of the top priorities under the IE policy development and the establishment of the IEC (MOES, 2015). Document analysis found that the principles of IE have been incorporated into the MOES strategy and policies, even though there is limited funding and resources to support the implementation of such policies at both the national and local levels. One of the latest policies is the (draft) Plan of Action on Education for Learners with Disabilities 2016-2020, which was developed by the IEC (MOES, 2015). This Plan of Action drafts work plans, action areas, indicators, activity timelines, an estimated budgets for each priority, and responsibilities of concerned stakeholders for the next 5 years. This is the second Plan of Action. It was developed from the lessons learned from the previous National Strategy and Action Plan on Inclusive Education 20112015. Importantly, the Draft Plan of Action 2016-2020 shows more concrete priority areas and indicators and activities for each indicator, whereas the previous one did not. The development of these action plans signifies positive attitudes towards 
children with disabilities and their education from the government, specifically the MOES.

The development of this Plan of Action is one of the major achievements in terms of a broader policy development programme that includes a number of other legislative and educational policies concerning the rights to education of children with disabilities. These legislative and educational policies include: the United Nations Convention on the Rights of Persons with Disabilities which Lao PDR ratified in 2009; the United Nations Convention of the Rights of the Child which Lao PDR ratified in 1991; and the Lao PDR Decree on Persons with Disabilities 2014. In addition, according to the MOES (2015) other legal documents that support this Plan of Action comprise: the Constitution 2003; National Education Law 2007; National Strategic Plan for Reforming the System of Education 2006-2015; National Implementation Plan for Education for All (2003-2015); Education Sector Development Framework (ESDF) 2009-2015; Education Sector Development Plan 2011-2015; National Policy for Inclusive Education 2010; National Strategy and Plan of Action on Inclusive Education 2011-2015; and the Mid Term Review of the 5 year plan ESDP 2013.

Despite the development of the above strategies and policies, the observation and interview results indicate that the MOES is still far from being a responsive ministry to cater for the needs of persons with disabilities. One of the INGOs staff attributed such a failure to the inadequate resources and weak organisational structure of the organisation that is responsible for disability advocacy under the IE strategy. She further commented that most MOES's donors appeared to under value the education of disabled students especially primary school students with disabilities. This is proven by the poor physical environment of the MOES. Per observation, the premises of both the ministry and the IEC have no ramp, no lift and no information available in braille and sign languages (see Figure 6 below). Figure 6 reveals that IEC has not yet prioritised the need to improve its premises to promote a barrier-free environment and this may make it difficult for them to challenge all mainstream primary schools to improve their environment. 
Figure 6: The entrance to the Inclusive Education Centre 2015

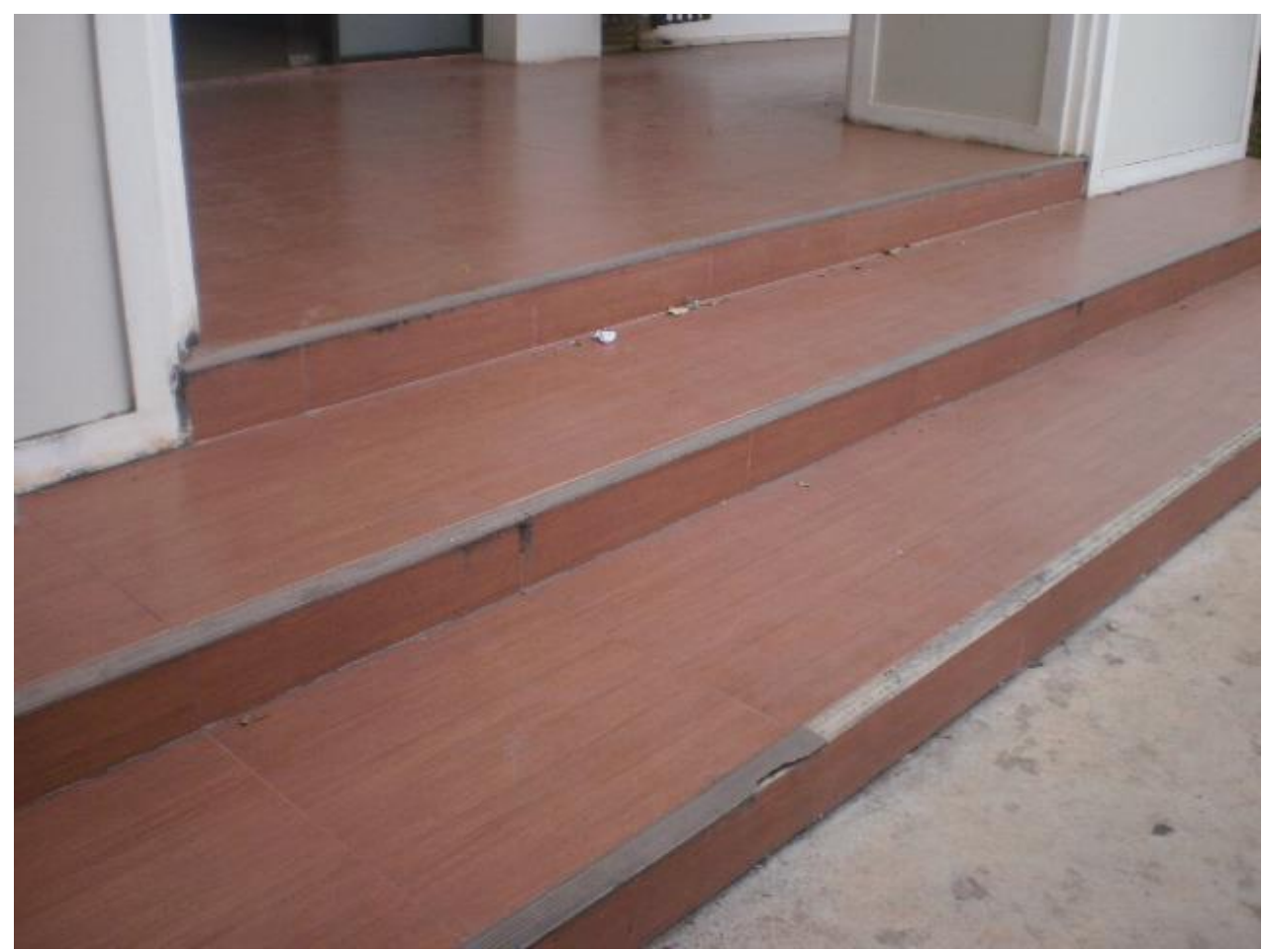

(Source: Photo taken by the author)

In terms of knowledge about disability rights, finding reveals that only a few people who are directly involved in the disability projects have full knowledge and correct understanding on the disability rights. From the interview, one government official explained that only some of the staff who are directly involved in the special education division within the IEC are aware that disability is an issue to be prioritised while the rest of the MOES senior official have limited knowledge about disability rights. This is because they have never attended any disability rights. A key issue identified from analysing documents, is that only a few activities are included that concern persons with disabilities or students with special educational needs in the MOES's national policy. This appeared to be why the Action Plan developed by the IEC was largely dependent on support from the financial contributions of external organisations including Disabled People Organisations, International NonGovernmental Organisations and Development Partners (Donors). 
Figure 7: Lao braille and sign languages 2015

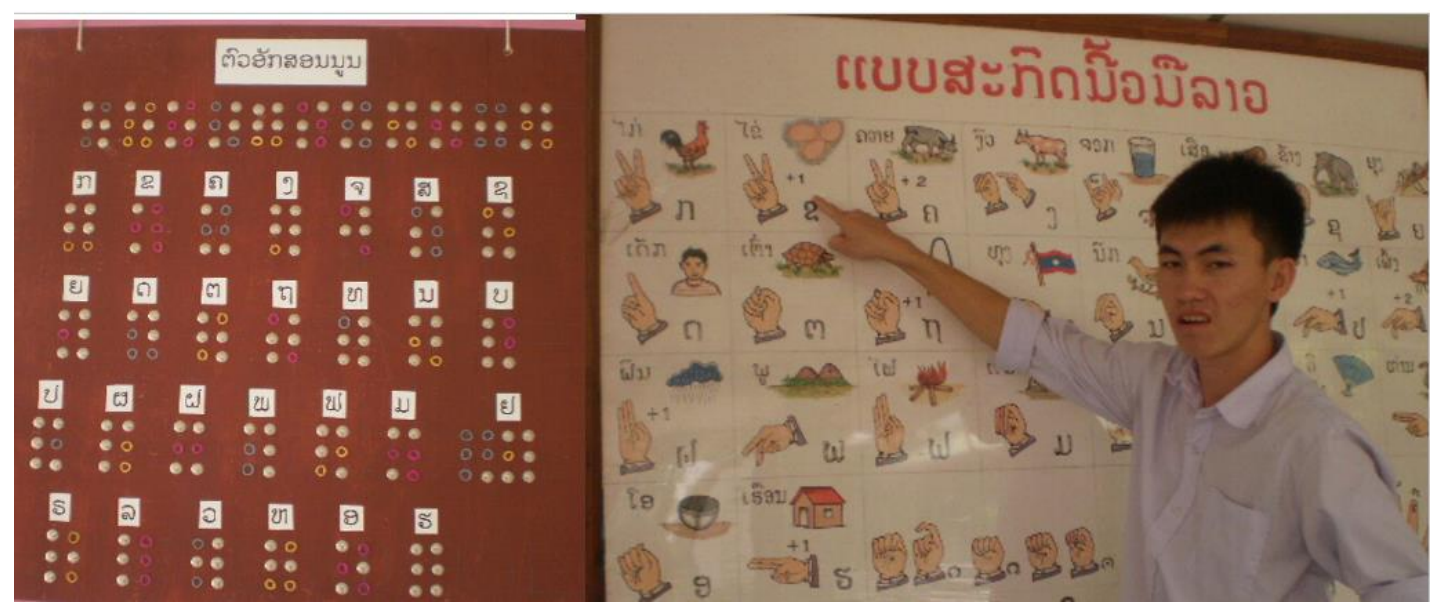

(Source: Photo taken by the author)

Many school teachers agreed that even though the Lao braille and sign languages have been developed by many organisations, such languages were not yet approved as official languages by the MOES (see Figure 7 Above). From my observation, the usage of these languages appeared to be still limited as only a few people in some special schools and disability representative organisations are capable in communicating these languages.

For the level of IE practice in all public mainstream primary schools, it is generally weak because of the weak leadership of the IEC. IEC is the only division within the MOES that has responsibility for the education of students with special education needs. It will be difficult for IEC alone to address barriers faced by learners with disabilities. Concerning IEC's funding capability, even though the IEC's financial documents were not available for review, some of MOES staff claimed that IEC did not receive adequate funding to implement IE activities for learners with special educational needs. Furthermore, interview results found that despite the fact that they had attended some IE related trainings, the majority of IEC staff had poor knowledge on how the IE education should be like as most of the IEC staff did not have any specific qualifications related to the education of children with disabilities. Furthermore, most interviewees representing DPOs, primary school teachers and staff of IEC, agreed that there was a problem with the structure of the IEC. They claimed that IEC is organisationally weak in IE projects activities decision making process because its role was largely depending on the Department of Pre and Primary Education. In fact, some IEC staff suggested that IEC should have an equal role as a department and should be an independent department. 
One interviewees represented MOES asserted that

"IEC should have an autonomous role and structure rather than being directed by the Department of Pre-and Primary Education of MOES to be able to influence the MOES budget allocation on the education of students with disabilities".

Primary school staff claimed that IEC is a small and weak division in promoting the education of students with disabilities. Overall interview results revealed that IEC should not exist under the Department of Pre and Primary Education. It should be established as an independent department in order to have an equal power to persuade other departments in promoting the education of students with disabilities across the entire education system.

\subsection{Understanding disability}

The interview results indicated that the majority of participants had limited knowledge of disabilities, probably due to the fact that they had not attended any disabilities training and had not been involved personally with children with disabilities. Most participants referred disability to the malfunction or failure of one or many parts of the body. None of the participants were able to relate disability to the dysfunctional interactions within society because of negative attitudes, environmental barriers and institutional failure. Participants described persons with disabilities using many different negative words such as physically weak person, pity and incomplete body and disabled body. Most non-disabled participants and INGOs staff agreed that children with disabilities should attend rehabilitation and be trained to adjust to the standard rules of society if they wanted to be included in it.

Moreover, when asked participants opinion on the meaning of disability, those participants who have never participated in any disability rights activities, refers 'disability' to being physically unhealthy. The term 'disability' in Lao language is known as '๒ึราบ'. Almost half of the interviewees expressed that it is impolite and disrespectful to categorise as 'ழ่ากบ' because this term has more negative connotations than positive. One of the participants pointed out that she prefers to categorise students with disabilities as students with special educational needs instead because this is a more respectful way of referring to a person who has some sort of impairments. 
On the other hand, only a few school teachers and participants represented disabled people organisations, notably those who had attended one of the disability rights training sessions, were able to explain the wider issues. They argued that disability is not a physical, mental or intellectual impairment of a person, but is a barrier faced by people who have impairments, due to the negative attitudes, unfriendly environments and unsupportive legal institutions, as these impact on daily activities considered normal to people without an impairment. Interview results revealed that only those who had any experience in contacting with people with disabilities or attended disability trainings had a more positive attitude to children with disabilities.

\subsection{Attitudes towards children with disabilities}

When participants were asked about attitudes towards children with disabilities and their rights to basic education, they expressed different opinions. The majority of participants expressed positive attitudes towards children with disabilities because they believed that these children should be treated fairly and receive equal opportunities in access to education. They pointed out that children with disabilities should be encouraged by their parents, community and teachers to attend school.

Other participants gave reasons why children with disabilities did not receive equal opportunities to be educated as their counter parts. Some responses from village authorities indicated that although there is a Village Development Committee to encourage parents to send their children to school and to work with primary schools, such a committee focuses on general children rather than children with special needs. Furthermore, many parents who have children with disabilities claimed that there is a very limited number of schools that accept children with complex disabilities, and these are often too far from their child's home.

Over half of the whole respondents indicated that all schools are willing to accept children with disabilities, but many schools' facilities and activities were not appropriately arranged to serve children with complicated disabilities. One parents of children with disabilities asserted that currently children with hearing and speaking impairments face numerous difficulties in learning alongside other non-disabled students, because services, learning materials, and teachers and school staff are not capable of helping them. 
Interview results revealed that children with different types of disabilities are being educated in differently environment. Most primary school teachers believe that children with disabilities have different characteristics, and their body parts are incomplete compared to 'normal' students, so they should be treated differently. Many school teachers pointed out that deaf students, for instance, should be separated from non-disabled students, because many school teachers in each grade do not have any understanding of sign language. Whereas some teachers asserted that blind students were regarded as exceptions who could study together with normally sighted children, because the teacher can read to blind students.

\subsection{Understanding of inclusive education}

There are different views towards what IE constitutes based on both the results of document analysis and interviews. Based on the National Policy on Inclusive Education No. 1170, the Lao government acknowledged that there were still many people remained out of public mainstream schools even though the government has implemented the EFA, the National Education System Reform Strategy and the Education Sector Development Framework (MOES, 2011). The development and implementation of IE is to drive and strengthen the existing MOES's education policies in a coherent way (MOES, 2011). IE is not only about accommodating children with disabilities into formal education system but it includes children with other backgrounds: ethnicity, race, languages, religion, sex, age, socio-economic status and other differences in abilities (MOES, 2011). In the documents review, 'IE' refers to the process of continuously providing quality education that is applicable to the diverse needs of all students. The aim of this process is to promote barrier-free education by creating friendly, safe, protective environments, and encouraging all learners, parents, and communities to be involved effectively in the process (MOES, 2011).

In addition, from the national legislation perspective, the Decree on Persons with Disabilities of Lao PDR, Article 21 states that IE for persons with disabilities means that "persons with disabilities have the rights to access every state-run education institution on the basis of actual conditions and abilities" (Government, 2014, p.8). It also adds that education institutions should be equipped to accommodate persons with disabilities. This means having a suitable classroom and educational premises; providing a suitable learning and teaching curriculum for each type of 
disability; and promoting research on appropriate teaching and learning materials to develop effective teachers and caretakers for students with disabilities.

In practice, when participants were asked to define IE and explain its objectives, their understanding of IE were varied depending on participants' IE experiences. Many participants including school teachers, non-disabled people, none profit organisations and government officials, who had neither worked with the IEC nor disabilities section were not able to explain concretely of what the MOES's IE policy was about. For some participants, even though they had never seen any IE documents, they agreed that IE creates equal opportunities for educating all children regardless of abilities, religion, ethnicity and abilities. A few teachers and parents with children with disabilities described that if a school does not include children with disabilities, such a school cannot be called an inclusive school.

\subsection{Inclusive education characteristics}

Participants were asked to describe the nature of inclusive schools. More than half the responses pointed out at least one characteristic of an inclusive school. Most primary school principals stated that the nature of inclusive schools depends on the policy of the Ministry of Education and Sports. Furthermore, school principals specified that at least one or two teachers per school should be specialised in one or two types of disability, as well as becoming fluent in both braille and sign languages. However, from the interview with parents of children with disabilities, most parents think that emphasis of IE should be making sure that all teachers are trained and have knowledge on the psychological characteristics of each person with disabilities. They added that a few teachers have the compassion and a loving attitude towards persons with disabilities. For the perception of village authority representatives, the built environment of villages and primary schools are still far from being responsive, supportive and adapted to meet the evolving needs of disabled students. From my perspective, most public facilities such as school buildings, public roads between student's home and schools and buses did not meet the needs of children with disabilities.

Many primary school teachers did not know what indicators determine inclusive practice in a school, especially when it comes to children with severe disabilities who cannot conform to normal standards within the school setting. In the past, when children with complicated impairments came to a state primary school, 
they were referred to the Centre for Medical Rehabilitation. Both primary school principals and parents claimed that teachers had not been well prepared in terms of attitudes, knowledge and skills to support the education of children with disabilities. Where school administrative staff and teachers were not ready, children with disabilities were rejected from enrolling in mainstream schools.

Only a few private schools accept children with disabilities. A private primary school teacher expressed that she does not know what could describe an inclusive school even though her school accepted children with disabilities and trained her teachers to cater such students. She said:

"In our school, we take disabled students. Now we have two disabled students. One has difficulty in movement and another one has difficulty in speaking. I know that many private schools do not take disabled children. For our school, we sent our teachers to train in Thailand in teaching children with disabilities. We do this voluntarily by our own capacity".

\subsection{The development of special schools}

A common finding from both government documents and interview results was that students with significant impairments were not welcome in attending mainstream schools. The government (2014) states in the Decree of Person with Disability that learners with mental, visual, hearing and speech disabilities are advised to attend special schools. Likewise, most participants including INGOs staff, ministry departments and communities agreed that children with complex impairments cannot study together with other non-disabled children in mainstream schools because almost all mainstream schools do not have the skilful teachers, support services and facilities that meet the needs of children with complex needs. In addition, interestingly, all teachers expressed that students with complex impairments are not learning if they attend mainstream schools because they need a special curriculum and specialised teaching methods, and they require specialised teachers.

When participants were asked to describe the education received by children with complex needs, a common view is that children with complex needs should be placed in special classes and special schools. Based on a new special education guide drafted by the IEC, special schools can be organised in two ways (MOES, 2015). The first is that students can attend a special class in the mainstream school while still socialising with other non-disabled students during the break or after class. Another way is that special schools can be constructed where accommodation, foods and other services are provided for disabled children who are from a distant village. 
The finding revealed that there is not a consistent way to manage all the special schools in Lao PDR in providing the education for children with disabilities. According to the interview with staff representing MOES, there were three regional special schools in three different provinces: Luangprabang, Vientiane and Savannakhet. These schools are under different jurisdictions. The special school in Luangprabang is managed by the Luangprabang Provincial Education and Sports, while the other 2 (two) are under the jurisdiction of the Ministry of Health. IEC staff representatives stated that there will be more regional special schools built to cater for more children with complex impairments across the country.

\subsection{Mainstream primary schools' welfare and services policies}

The finding revealed that there is an absence of any specific welfare policy within schools themselves for students with disabilities specifically, which was a common concern for all participants. Ideally, the Decree on Persons with Disabilities 2014, Article 23 states that students with disabilities shall receive either the reduction or exemption of school fees and other expenses when studying within a state education institution, in accordance with the relevant policies and regulations (Government, 2014). When asked, school principals and teachers stated that there was no formal written policy to offer free education for students with disabilities. Moreover, all district education representatives were aware of the Decree on Person with Disabilities 2014 and the Inclusive Education Strategy of the IEC, but they pointed out that many conditions in these policies have not been fully enforced at all state mainstream primary schools yet.

In addition, it is evident that only several primary schools were equipped to teach children with disabilities while the majority of researched primary schools were not informed to take children with disabilities. From the researcher's observations, many primary schools have never had students with disabilities which implied that those schools did not have any existing disability services. As mentioned by one primary teacher, every mainstream primary school generally targeted non-disabled children, except for the special schools and inclusive schools supervised by the CMR). There is no proper procedure to address deficiencies in a school that does not have policies on students with disabilities.

The findings revealed that the disability services and welfare policies of special schools are far better than that of public mainstream primary schools. For 
special primary schools that were managed and supervised by the CMR, students with disabilities studying in these schools mostly receive living allowance, free accommodation, foods and other medical supports. These services were not mentioned by any participants from public mainstream primary schools. All participants from CMR explained that for children with disabilities who are from wealthy families, their parents bear every expense including transportation, food and the cost of extra care. All the researched participants also agreed that other mainstream primary schools that are not under the management of CMR, free accommodation and other allowance were not available. One parent stated that there was no tendency for all mainstream primary schools to provide accommodation and other disability services.

Furthermore, it was not clear how mainstream primary schools charged students with disabilities. All primary school principals explained that the normal school fee per year for schooling is 110,000 Kip per student annually. Some parents of disabled students paid higher fees and other non-school fees if the child required intensive support for eating, changing clothes, escorting to and using the toilet. In such cases, some parents paid up to 150,000 Kip per person per year.

\subsection{The education of students with disabilities}

When asking how responsive mainstream primary schools are in taking children with complex impairments, results identified that the acceptance of a child with disabilities into a primary school is claimed to depend on many factors: the actual school conditions and teacher's abilities, and the severity of the child's disabilities. None of the mainstream schools researched was designed to accommodate a child with disability, unless the child with a disability had been trained to follow the normal standards for non-disabled children. Other children with disabilities who have difficulty in adapting to the normal system will be referred to special schools or be required to stay at home.

It is still optional whether schools accept a child with a disability into the school. This depended on the number of students in the class. The majority of teachers and parents asserted that many mainstream schools take too many students per class already, more than 30 students per class and this was more than the ratio determined by MOES of 25 students per class per teacher. Moreover, some parents stated that their children had been declined from attending mainstream schools because school 
principals reasoned that there were no supporting resources, and no teachers who were able to communicate with the child. Thus, some parents who participated in this research decided to leave their children with disabilities at home while other wealthier parents sent their child to private care centres.

The interviews also found that students with disabilities mostly could not continue their education beyond primary or secondary levels because there were limited schools that accept student with severe impairments at those higher levels. The interviews with special school and mainstream school teachers found that the majority of blind and mute or deaf students only complete primary school grade 5 . From interviews with representatives of government departments and teachers, it was found that there was only one upper secondary school in the country, Phiawat Secondary School, which offers secondary education for disabled students who have completed primary school. There is only one college in the country, Dongkhamxang College, which offers education for the blind. Some participants stated that only a few students who are mute or have a hearing impairment complete upper secondary school and some decided to continue job training at a vocational training centre.

Students' academic progress assessment was of the issues affected the quality of learning of disabled students. As stated by many teachers, different assessments and examination questions are created for students with disabilities. All the primary school teachers in this research agreed that there is a policy which requires that these students pass to the next grade each year, no matter whether they are learning or not. Some slow learning students or students with poor academic results are required to spend an hour after normal school hours studying a subject in which they had poor results.

\subsection{Reforming mainstream primary schools' teaching methods}

With regard to teaching methods, documents indicate that the IEC (MOES, 2014) promotes opportunities for disabled students to participate in learning with the other non-disabled students as much as possible, depending on the severity and type of disabilities. Students with disabilities can either participate in all subjects, undertake only some subjects, or participate in all subjects with a special teacher assistant. The Lao Disabled People's Association (2011), conducted a project with the Unit for the Deaf to develop a Lao sign language handbook. The Unit developed this handbook with the Sota Vientiane School at the Centre for Medical 
Rehabilitation. This handbook was produced in both hard copy and compact discs, and was disseminated to 3 (three) provinces: Luangprabang, Vientiane and Savannakhet. This project was started in 2011 and funded by Lao and Thai artists and the Direct Aid Program of the Australian embassy. The interviews with key staff from this project, found that the project produced more than 1,000 Sign language words and these words were put into 4,000 CDs and 2,500 printed books. No participants mentioned whether these sign languages were either used in mainstream primary schools' teaching methods or if they are useful in learning.

A common response is that there is inadequate and low quality of learning materials for children with disabilities. Respondents from INGOs, teachers and staff of CMR, agreed that CMR is the main organisation that provides training to teachers, plus teaching materials and learning materials for students. At most public primary schools, general handbooks are provided for Grade 1 and 2 students, plus teaching materials and study monitoring books for each school. Many respondents representing MOES and primary school teachers claimed that there were no subject related disabilities, and insufficient learning and teaching materials for each primary schools. Some companies and INGOs provided recycled used papers for students with visual impairment. One disabled students said that handbooks for many subjects are not available in braille.

\subsection{The prevalence of mainstream inclusive primary schools}

Findings revealed that not every mainstream primary schools is equipped to teach children with disabilities. All participants believed that students with mild levels of impairment can attend any mainstream primary schools, but those with severe impairments have to attend special schools and special classes in selected mainstream schools. Participants who represented DPOS and primary school principals added that there were limited number of public mainstream schools that children with severe disabilities including those who are deaf, blind, behaviour disorder, memory loss, cerebral palsy and psychological disorder. These participants argued that if public mainstream schools enrol students with these characteristics, such students may disturb the class environment. In addition, regular school teachers and the parents of such students do not know how to include them into the mainstream class. Many participants who worked for different organisations other than schools asserted that 
children with disabilities were better in attending special schools because special schools offer more appropriate services including psychological therapy.

The figure 8 below was taken during my observations in a 'mainstream' primary school. One of the students has a vision impairment sitting in the front table and is being assisted by her non-disabled peer. Only a few mainstream schools took their own initiative in the placement of students with disabilities into mainstream schools (see Figure 8).

Figure 8: Student with visual impairment in Nalao mainstream primary school

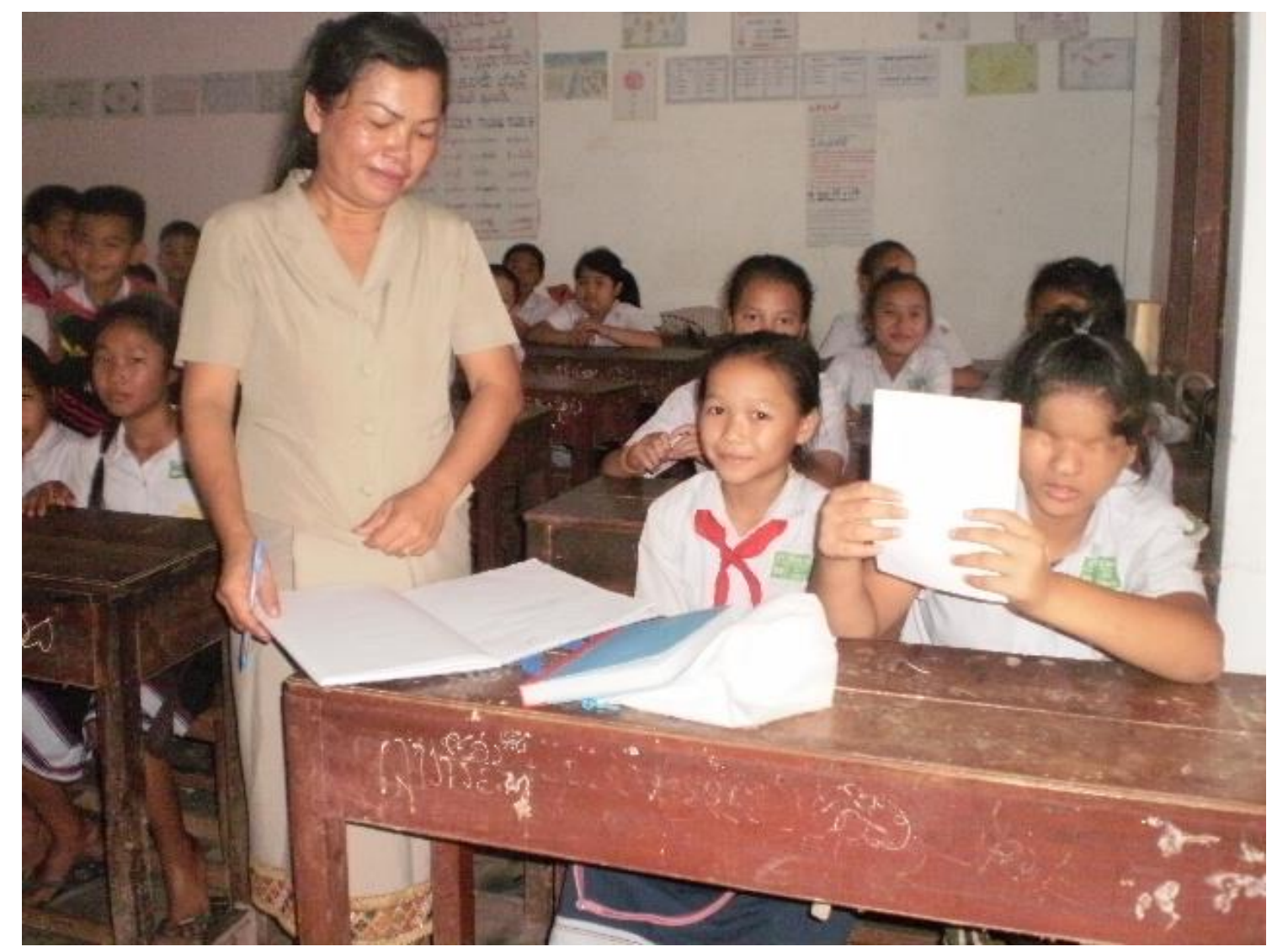

(Source: Photal taken by the author)

This figure 9 below shows the relationship among special schools and mainstream schools in teaching learners with disabilities especially students who are blind, deaf and autistic. The stars represent schools and the arrows represents how the educational routes for such students continuing their study from primary school level to college level. Arrows with dots imply that not many students with disabilities were able to pass from one grade to another. This figure indicates that schools other than these shown in the figure were not commonly known by many participants because even though these 9 schools were considered by some interviewees as the most wellknown ones within the researched area. Therefore, this figure has shown the limited 
educational opportunities for students with disabilities who resides in a long distance from these schools (see Figure 9).

Figure 9: Key mainstream and special schools for blind, deaf and autistic students in Vientiane

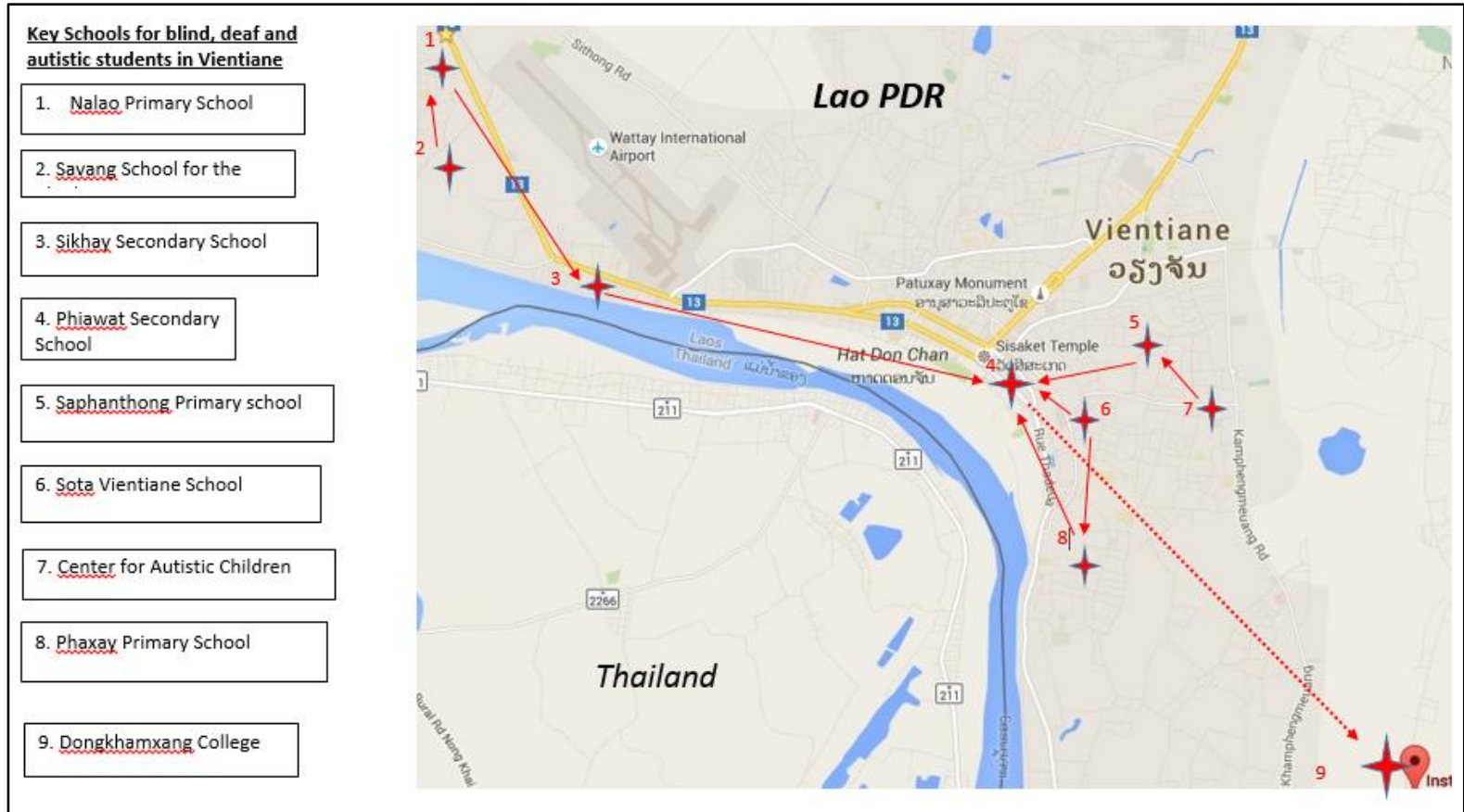

(Source: Mapping by the author)

Challenges for students with severe disabilities result not only because of the limited number of schools that will accept them, but also because there are a lot of built environmental barriers including the distances between the student's accommodation and the school. As one of the blind students asserted, this is particularly difficult for blind students, who if possible need accommodation at the school, but only three schools offer accommodation for students with disabilities, particularly blind students. These schools are Savang School for the Blind, Sota Vientiane School and Dongkhamxang College.

From the interviews with staff at the CMR, I found that the Centre plays an important role in determining whether students with disabilities in special schools can enrol in mainstream schools in Vientiane or not. Approximately 15 to 20 students with disabilities from all around the country come each year to register with and live in the Centre. The Centre, however, cannot take them all because of limited funding and insufficient available accommodation. In 2015, there were 67 students living at the CMR, CMR staff said. 
Findings revealed a limited educational choice for students with visual impairments. For instance, the Savang School for the Blind. This School prepares students with reading and writing skills in the braille language. This special school will assess and select students to attend an IE nominated mainstream primary school. This targeted mainstream school will send one or two teachers to the special school for braille language training, usually undertaken during the school holidays. The special school provides teaching and learning materials to the school teachers and students. The mainstream school teachers will then coordinate with other non-profit organisations for further assistance both internationally and from local disabled people organisations. There are three public mainstream primary schools offering education for the blind including Nalao Primary School, Mixay Primary School and Phaxay Primary School within the researched areas.

\subsection{Provision of additional care}

None of the researched primary schools provided an additional carer, nor were responsible for bearing the additional costs incurred due to the special care required by children with disabilities. All participants agreed that for mainstream primary schools, there is no organisational structure in place to provide mobile teachers or special teaching assistants to students with disabilities. Many documents emphasise the role of the Village Education Development Committee and school principals as the main people who are in charge of primary school management. The school principal is in charge of the whole primary school, and responsibility for improvement of the school environment lies with the village authority, while the school human resources and teachers' salaries are the responsibility of the District Education and Sports Bureau. It is therefore the responsibility of the District Education and Sports Office to make sure those students with disabilities or with learning difficulties are provided with appropriate teaching assistants.

However, in reality, mobile teachers or teacher assistants are not referred to in any school policies within the researched schools. Participants claimed that it is common for non-disabled students to be relied on to provide assistance to other students with disabilities. The problem is that none of these students without disabilities has been trained in braille or sign languages, or how to provide support to those with other types of disability such as cerebral palsy, autism, or intellectual 
disability. Some parents expressed concern that such untrained students could impose extra problems on the disabled students.

\subsection{School facilities and services}

The majority of public school facilities and services delivery were unequipped to serve the needs of students with disabilities. Even though the Decree on Persons with Disabilities of Lao PDR, Articles 31 and 32 states that any public places shall provide reasonable convenient facilities such as ramps, rails, lifts, toilets, and appropriate signs, only a few special schools that were constructed for the students with disabilities specifically were more equipped to train students with disability than others. As claimed by one teacher that:

"In our school, we do not take student with disability because our school are not equipped to meet their needs especially our facilities and services were initially organized to meet the needs of non-disabled students. I would suggest parents of children with disabilities to send their children to special schools because they have the trained teachers and appropriate school facilities or services".

For school construction, the Division of Design and Construction Management of the Ministry of Education and Sports developed School Construction Guidelines 2009 (MOES, 2009). These Guidelines require all stakeholders, from the community level up to the ministry level, and all involved agencies and donors, to pay careful attention to each step of the school's construction. The guidelines aim to promote good quality, inclusive, child-friendly education, and a safe school for all students (MOES, 2009). However, this document includes no guidelines specifying how the school is required to be responsive to the needs of students with disabilities. It only requires future schools to be compliant with the Guidelines. It mainly focuses on minimising risks in case of a disaster, rather than promoting a barrier-free school environment. Even though this guide is available in both Lao and English languages, there appear to be no legal obligations for enforcement. As ascertained in interviews, some government staff pointed out that in practice such a School Construction Guideline is still optional tool used by school constructors. As such, it is observed that almost all observed primary schools have never considered their ability to provide safe and convenient facilities student with disabilities especially students who use wheelchairs (see Figure 10 below). 
Figure 10: Primary school students and teachers toilet

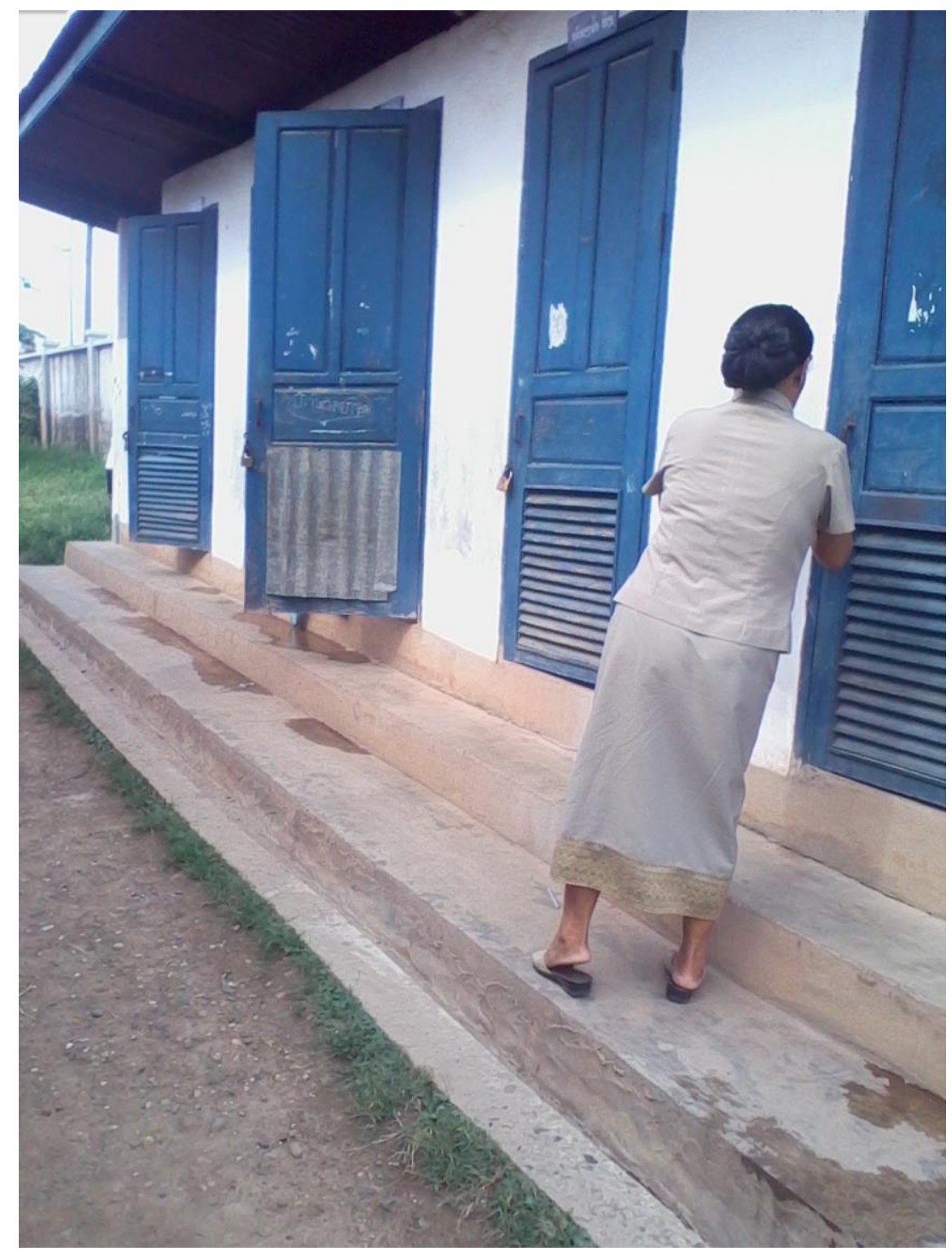

(Source: Photo taken by the author)

In the findings, a common response is that almost all researched mainstream primary schools were really aware of the needs to adjust its physical environment to individuals' needs. Improving a primary school's infrastructure depends on the contribution of the community, especially the village authority where the school is located. For schools that had more than two floors, the schools did locate the class to be attended by a student with mobility impairment on the ground floor, but most toilets of all primary schools had still not been constructed in a supportive way with stairs instead of ramps. Non-disabled students still had to guide and carry the students with disabilities to use the toilet. 


\subsection{Teachers development}

Document reviews revealed that none of the district education office reports indicated any provision of professional development in disabilities training for primary school teachers. For example, the Saythany District Education and Sports Service (SDESS) recent report (2014-2015) showed that one teacher attended computer training at the Provincial Education and Sports Bureau office (SDESS, 2015). Even though in Saythany District, it has the highest number of students with disabilities, many teachers were asked at other times to attend training updating the political views of the Party, and training in foreign languages and other skills, while training related to supporting students with disabilities was not included.

However, if there were children with disabilities in a mainstream school, some teachers in that school often received training each year related to disabilities. An IEC staff explained that MOES encouraged teachers from mainstream schools to attend braille language training. Participants from special disability schools mentioned that some teachers from the National University of Lao PDR have recently been invited to braille language trainings, because in the future the special schools will send blind students to the National University of Lao PDR.

\subsection{Data on primary school students with disabilities}

Overall, it was evident that data on children with disabilities is either lacking or inconsistent, despite the efforts undertaken by the MOES, National Statistics Centre, and other non-government organisations. One of the staff from MOES explained that MOES used the Education Management Information System as a tool to collect education data of all students from all schools. However, other participants argued that this tool does not have specific questions concerning students with disabilities. Some mainstream primary school teachers collected data on students with disabilities in hard copy, and shared this data with the District Education and Sports Bureau. Some District Education and Sports Bureau staff agreed that data on students was mostly general and such data consists merely of student names age, gender, parents' names and contact details, and the general type of disability. Furthermore, none of the participants from either MOES, donors, INGOs or communities were aware of data on students with disabilities. Only staff from IEC, CMR and disabled people organisations had participated in data collection of students with disabilities. 
Therefore, data on students with disabilities at mainstream primary schools used to be collected in many inconsistent ways.

There is an inconsistent ways of collecting and reporting of data on primary school students with disabilities. One of the IEC staff mentioned that in the IEC used to conduct a nationwide survey to collect data on children with disabilities from the eight Northern provinces but this survey did not specifically focus on primary school students with disabilities as it included all children from the community. Another inconsistency is that IEC and the Vientiane Provincial Education and Sports Bureau produced two annual data sets showing different indicators and results because they used different forms. The IEC version determines disabilities on a visual basis. Information collected includes province, district, number of children with disabilities (sex aggregated), types of disability, linguistic background, and educational status. In sharp contrast, the provincial form has only one question; this is regarding the total number of special children (sex aggregated). Many indicators that appear in the IEC form do not appear in the provincial form. Both the IEC and Provincial Education and Sports Division data collect form determined the types of disabilities based on the physical appearance of the child. Data regarding mental impairment was limited.

The table 8 below translates the headings of the table 9 from Lao language to English. The table 9 shows that data of students with disabilities were inconsistent and inadequate to understand the needs of students with disabilities. This is because disabilities were reported in the form of physical appearance such as hand, mouth, mental, ears, limb, mute, deaf, joint or feet problem, low vision, body, difficulty in speaking, disability of both hands and feet, disabled of whole body, leg, unclear voice, eyes and unequal development of the body parts.

Table 8: Disability data form in English version of the Saythany District

Education and Sports Bureau

\begin{tabular}{|l|l|l|l|l|l|l|}
\hline No. & Student & Grade & Age & $\begin{array}{l}\text { Characteristic } \\
\text { of disabilities }\end{array}$ & $\begin{array}{l}\text { School } \\
\text { name }\end{array}$ & $\begin{array}{l}\text { School } \\
\text { principal } \\
\text { Phone } \\
\text { number }\end{array}$ \\
\hline & & & & & & \\
\hline
\end{tabular}


Table 9: Disability data form in Lao version of the Saythany District Education and Sports Bureau

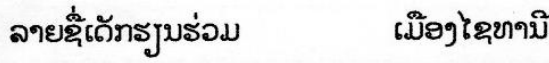

\begin{tabular}{|c|c|c|c|c|c|c|}
\hline ล/ด & ฉ และ บขบสะรุบ & ขำ & ฮๆยุ & ขึราบลัๆบ & ไราฐ & $\begin{array}{l}\text { เขิโขผู้อำบอย } \\
\text { ภาบ }\end{array}$ \\
\hline 1 & บ.รอบเซัด & & & i & U.ท వెอిไล & 55602778 \\
\hline 2 & บ.ตุ้มล่า & & & ริบ & U.ท విอొไล & 55602778 \\
\hline 3 & บ.จ่ฮย & & & వะชมతి & U.ท 401 & 55762305 \\
\hline 4 & ย.จาบ์รัสัก & 5 & & จะชมภ9 & บ.ท มิบา & 55695162 \\
\hline 5 & ย.อ็บระบะ & 4 & & నะชుతి & บ.ท มิบ? & 55695162 \\
\hline 6 & ย.ถิมฐับ & & & ๒ู & บ.ท จ้วตช์อบ่ & 56771979 \\
\hline 7 & ย.กุ้ว & & & 29รุด & U.ท వิมవะขัอบ & 0309291636 \\
\hline 8 & บ.ชูมา ล่อับไล & & & บารท็ก & U.ท వิมవะยัวบ & 0309291636 \\
\hline 9 & บ.ฐุบาบิ อ์่อ่าccฐร & & & ตูอบอก,บารทิก & U.ท వิมవะเัวบ & 0309291636 \\
\hline 10 & ท.ढิบ & & & ฐะชมภร & U.ท ริมฐะขัอบ & \\
\hline 11 & ท.บุบลู & & & వะชుత9 & U.ท వิมฐะยัวบ & \\
\hline 12 & ท.จุ้อ & & & వะชมภ9 & บ.ท నิมฐะยัวบ & \\
\hline 13 & ท.บุบฐ์ & & & อ่ติบบิล2เบ็จง & บ.ท ชิอ2รง & 58899100 \\
\hline 14 & ท.ฐิวา & & & వะชుత9 & บ.ฤ ช์อลรว & 58899100 \\
\hline 15 & ข.ถองล็ & & & వะชมతి & บ.ท ช์อะรง & 58899100 \\
\hline 16 & บ.จุ้ว๒ือา & & & వะบมอง & U.ท ชิอ2ร9 & 58899100 \\
\hline 17 & บ.ปี่อ่า วากవะผ์ & 5 & & cсรวตารับ & บ.ท ชังรวอรวอ่า & 22012231 \\
\hline 18 & ท.บะcฐิก & 5 & & వะชมుత? & U.ฤ ชัรวอรวอ่า & 22012231 \\
\hline 19 & บ.จับฐะยมงฮบ & $r$ & & cc2n & บ.ฤบบจรอรวอ่า & \\
\hline 20 & ท.อ็บัด & 5 & & వะชుతి & U.ท อృรศรว้อ & 22426650 \\
\hline 21 & บ.ล่าบวบ & 4 & & వะชมภ9 & U.ท อรগсcร้อ & 22426650 \\
\hline 22 & ท.ฮ้าอ & 3 & & จายการับ & U.ท อรগccรัo & 22426650 \\
\hline 23 & บ.ถาลาอับ & 3 & & వะชมఠత & U.ฤ อృรศร้อ & 22426650 \\
\hline 24 & ท.บูบ & 2 & & ธ่างราย & U.ท อรราcรัอ & 22426650 \\
\hline 25 & ท.ภยวจา & 4 & & ปั & U.ฤ อรรсcรัo & 22426650 \\
\hline 26 & ข.ฮิปะไเ & 1 & & వะชుత & บ.ฤ อรรธcรัอ & 22426650 \\
\hline 27 & บ.Cม & 2 & & వะชมวง & U.ท อรรсcรัอ & \\
\hline 28 & ข.ข้า & & & వะชుతి & U.ฤ อรэсcร้อ & \\
\hline
\end{tabular}

(Source: SDESB, 2015)

\subsection{Educational stakeholders participation}

Despite the lack of consistent data on primary school students with disabilities, there is a growing trend in coordination among all educational stakeholders to work on IE initiatives. The majority of participants including donors, INGOs, government departments, village authorities and other primary school teachers asserted the education of students with disabilities has become a national development concern especially to the MOES. A good example of this is the multi-stakeholder funding 
engagements focused on students with autism. According to an Annual Report of the Association for Autism (AFA) 2015, staff of the Association attended workshops organised by the IEC, and commented on the guidelines on IE teaching (Association for Autism, 2015). In 2014, the Centre for Autism in Vientiane provided education for 38 students, and 15 of these students were able to attend mainstream primary and secondary schools in Vientiane capital (AFA, 2015). The Association's main funding sources at the time of this report in 2015 were from the Catholic Relief Service, supporting the Rights to Learn project, and the United Nations Democracy Fund supporting the Autistic Children Rights project.

There is strong coordination among ministries at the national level to develop policies and strategies to address the needs of persons with disabilities in general and especially children with disabilities. The main ministries of those actively involved in disabilities were Ministry of Health (MOH), MOES, Ministry of Labour and Social Welfare. $\mathrm{MOH}$ is responsible for prevention, treatment and rehabilitation of disabilities. MOES is in charge of the education sector. Ministry of Labour and Social Welfare is responsible for employment and welfare for all people with disabilities. Above the researched ministries, the role of the $\mathrm{MOH}$ is far more important than others because it is taking a lead in providing special education through the establishment of CMR.

\subsection{Primary schools' inclusive education strategy}

Participants were asked about how the IE strategy and action plans have been incorporated or translated into the District Education Action Plans and primary school development plans. Since many participants had not seen or read the MOES's IE policy documents, the majority were unable to answer this question. Further questioning elicited the response from one participant of the provincial education bureau that the planning and statistics staff at both provincial and district education office levels are in charge, so whether the government IE plan is translated to provincial, district and school development plans really depends on them.

Document reviews revealed that the strategies of the District Education and Sports Services are general, and not specific to the requirement to be responsive to the needs of students with disabilities. . The Report of the Education Development Plan 2014-2015 and the Future Development Plan 2015-2016 of four districts were examined to see how IE principles have been adopted into localised educational plans. 
This revealed that there are no specific directives or activities in their development plans targeting each category of children with disabilities under the requirement of the National Policy on Inclusive Education and National Strategy and Action Plan on Inclusive Education 2011-2015 (MOES, 2011). The quality assurance of the primary schools was mentioned, but it focused only on: distributing student handbooks to pre and primary schools; teacher development based on the new curriculum; providing incentives to teachers; monitoring and evaluating; creating model schools, promoting green school environments; and ensuring freedom from activity by criminals and drug traffickers. The District Education Development Plans do not specify how each District Education Bureau will coordinate and address the IE principle that all students with different types of disability should be incorporated into mainstream primary schools.

\subsection{Funding}

Many primary schools appeared to experience continuous underfunding, shortage of class materials, inadequate service provision, and ineffective monitoring and evaluation systems. According to all the District Education Development Plan implementation reports for 2014-2015, there was no budget clearly specified for supporting the needs of children with disabilities in mainstream primary schools. Budgeting to provide quality education for such students depends on the actual local conditions and capacity of the school, largely because although MOES has a national policy and plan, such an IE national plan of action has not as yet been owned, translated and incorporated into local school level development plans. One donor staff said that:

"Most of the donors' fund were used in conducting trainings, organising workshops, hiring consultants and not many fund goes to policy implementation such as the IE policy because disability is still a debatable issue. Some organisations used to provide funding to special schools but the project monitoring and evaluation process were weak".

Participants' main responses indicated that the main sources of funding for primary schools are from the collection of school activities fees from all students, plus in-kind contributions from the parents, community, shops and projects. They stated that this is because requesting funding from the government is difficult and time 
consuming. Some participants explained that for the mainstream primary school budget, the government provides a block grant of 50,000 Kip annually per primary school student: 20,000 Kip is paid at the beginning of the year and 30,000 Kip is paid in mid-year. Mainstream schools require all students to pay a non-school fee or enrolment fee: 100,000 Kip for primary school students, 120,000 Kip for lower secondary school students, and 150,000 Kip for upper secondary school students, even though compulsory education is 'free' for all students. The non-school fee is double the block grant given by the government. Many schools request and accept this extra school fee as an in-kind contribution. Some primary school principals claimed that the government block grant and other contributions from students and their parents were regarded as insufficient to improve the school environment and improve its services to meet the needs of students with disabilities.

\subsection{Chapter summary}

This chapter has summarised the key findings from the study as this study initially aimed to review the level of response by the mainstream primary school system from different perspectives. Findings identified many critical issues but some of the most important ones can be briefly summarised as follows. The first issues involves the existence of major policies and legislations which support the principles of IE. The results revealed that IE principles were incorporated at the national level into many MOES strategies and policies and there is a growing tendency of corporation among disability stakeholders to promote IE at the national levels.

The second major finding concerns participants' attitudes towards the concept of disabilities and the education of children with disabilities. Mostly participants still perceived disability as functional deficiency of the body and health issues rather than social barriers. Such beliefs contributed to the limited educational opportunities and support services that were available in supporting the education of children with disabilities at primary school level. The third issue is that the majority of the participants understand that the concept of IE is about accommodating all children which does not specifically focus on children with disabilities into regular school instead of seeing IE as an ongoing reform process of the education system to meet the needs of children with disabilities. Findings revealed that only participants who had experienced in IE activities expressed IE as a believe that the education system should 
be reformed in one or other ways to effectively promote the full and active participation of children with disabilities rather than the individual students.

Finally, the implementation of the IE concept from national to school levels is far from being successful because of many reasons. The findings show that there are many issues faced by the implementation of IE policy at both national and local levels, including the lack of comprehensive data regarding children with disabilities, funding limitations and the absence of legal enforcements. Thus, the focus of the next chapter will discuss these major concerns in relation to the literature review. 


\section{CHAPTER SIX \\ DISCUSSION}

\subsection{Introduction}

This study aims to explore the level of inclusiveness, under the principles of IE, of public mainstream primary schools in Lao PDR for children with all sorts of disabilities. This chapter discusses some of the key issues which have emerged from the interviews, observations and documents in relation to the literature reviewed in Chapter 2. This discussion focuses primarily on the impact of the IE strategy. Some of the most critical indicators of policy impacts that this study uses include policy development, participants' perceptions and the physical environment of primary schools. The data was gathered from a range of participants representing diverse backgrounds in an effort to reveal diverse perspectives. A further three major themes which emerged from the research will be discussed: the relevance of the Lao IE policies to the principles of IE generally; participants' understandings of the concept of IE; and other factors that could affect the implementation of IE strategies within the public mainstream primary schools in Vientiane.

\subsection{Lao inclusive education strategy}

\subsubsection{The principle of the Lao inclusive education strategy}

Taking a human rights-based approach, since 1992, Lao PDR has continuously improved its education policies in line with international IE policies, promoting the inclusion of children with disabilities in mainstream schools. The findings revealed that the Lao PDR's education policies do generally follow international human rights agreements and relevant legislation enacted in other countries. Lao PDR has reformed its own institutions and policies to support the rights to education of children with disabilities (World Health Organisation, 2011). Even before Lao PDR ratified the United Nations Convention on the Rights of Persons with Disabilities in 2009, and promulgated the Decree of People with Disabilities of Lao PDR in 2014, the Ministry of Public Health in Lao PDR had initiated IE in Lao PDR, and special schools with technical support from the MOES have been in place since 1993. Since then, many children with disabilities have greatly benefited (Save the Children Norway, 2009). Key government institutions have adopted policies and action plans that value the rights of children with disabilities as equal to others, and 
these policies are now regularly being adjusted and reformed. In 2008, the Inclusive Education Centre was created by the MOES. The National Policy on Inclusive Education, National Strategy and Action Plan on Inclusive Education 2011-2015 has been developed and implemented. These actions are in line with the UNCRC 1989, UNCRPD 2006, UNESCO Salamanca Statement and Framework for Action 1994, World Declaration on Education for All (1990), Dakar Framework for Action 2000 and MDGs 2000 (Tremblay, 2007).

In addition, this study found that the Lao IE policies appeared to be at least partially in line with the principles of inclusion. Inclusion means an ongoing process of transforming school cultures and environments to meet student's needs, instead of trying to rehabilitate students to fit into the existing school practices and settings (UNICEF, 2011). Documents indicate that the Lao IE policies aimed not only to achieve its EFA goals, but also to reform the education system to more appropriately accommodate children with a wide range of different abilities (MOES, 2011).

However, in relation to the principle of inclusion, the findings reveal that children with complicated types of impairments are still subject to being rehabilitated and trained in special schools, prior to attending state mainstream schools. This does not follow the principle of inclusion, understood to mean that all students, regardless of their abilities, should be attending the mainstream schools located close to the student's home (UNICEF, 2011). This is why the number of special schools tends to increase. Mostly, Lao special schools tend to focus on rehabilitating and educating students to comply with the mainstream school standards, rather than reforming all mainstream schools' cultures, policies, practices and environment to meet the ongoing changing needs of all learners, regardless of their impairments and abilities (Tremblay, 2007; UNICEF, 2011). The promotion of IE practice in schools should theoretically require a reduction in the number of special schools, because these mainly follow the medical approach to disabilities, which is less useful than the social approach to disabilities (Norwich, 2014).

\subsubsection{Data on children with disabilities}

Maintaining accurate and consistently updated data regarding children with disabilities is pivotal in order to implement the inclusion of children with disabilities in mainstream education (UNICEF, 2011). The findings revealed that there is only very limited data available regarding people with disabilities in Lao PDR, especially 
children with disabilities. Lao PDR also uses estimated figures to support their development plans. Many organisations have conducted disabilities surveys to collect data, but each organisation has tended to use different questionnaires which produce different results (Grimes, 2009). Such results have not been comprehensive and have only served organisational specific purposes. This finding is in line with the existing literature reviewed, where despite many attempts, there was no comprehensive data available regarding people with disabilities globally (WHO, 2015; UNICEF, 2011). Many statistics and data regarding children with disabilities have been collected only from very specific samples, which are not representative of the situation overall. This has hindered both governments and development organisations from taking a collective approach to address the educational needs of children with disabilities (UNICEF, 2012). Developing appropriate plans of action to address the needs of children with disabilities attending primary school is challenging because of the inadequate data available.

\subsubsection{Funding}

Ensuring that all children with disabilities are able to enjoy full development and equal participation with non-disabled peers often requires an increased financial commitment from all stakeholders, especially the government. Lao PDR, as a lower middle income country, still depends largely on external organisations to support its IE policy implementation and evaluation. Save the Children and the Swedish International Development Cooperation Agency provided long-term funding and technical support for an IE project implementing from 1993 to 2009. This project resulted in a centralised, national approach to the development of policy and practice in IE. Services began in 1993, when a pilot school opened in the capital, Vientiane. According to the World Report on Disability (World Health Organisation \& The World Bank, 2011), there are now 539 schools across 141 districts providing IE, with specialised support for more than 3,000 children with disabilities across the country. These schools, however, have not been supported in a sustainable way and after the projects ended in 2009, all schools experienced financial shortage, and struggled to maintain services for children with disabilities (Grimes, 2009). It seems that the government had achieved a great success in implementing IE schools, but from observations and the views of many IE teachers, many primary school students with disabilities gained poor quality education. 
The importance of government commitments to sufficient funding and resources to support mainstream schools to be inclusive is evident in the literature (Mambo, 2011; World Health Organisation \& World Bank, 2011). In Thailand for example, IE strategies have been implemented for over two decades, but most mainstream schools have experienced continuous funding shortages (Vorapanya \& Dunlap, 2014). If sufficient funding is not provided, it is likely to be difficult for school principals to make services available to children with significant disabilities. Required services may include purchasing braille language printers, providing hearing support devices, and delivering physiotherapy or psychological support.

This research revealed that insufficient funding is available in Lao PDR to effectively improve the education of children with disabilities. The findings show that the block grant of about 50,000 Kip per student annually, given by the government to each primary school, is insufficient to support the continuous improvement of the school environment, and to train teachers with disabilities skills. In addition, each primary school has collected a non-formal school fee of 100,000 Kip per students per year, but interviews and observations show that the combined block grant plus the non-formal school fee is still insufficient. Although schools have also requested inkind contributions from parents, private individuals, businesses and other charity organisations, this support is rarely received or is not sustained.

\subsubsection{The development of inclusive mainstream primary schools}

The findings reveal that many mainstream primary schools appeared to be in doubt regarding the demarcation between their own roles and responsibilities, and the roles of the Centre on Medical Rehabilitation (CMR) under the Ministry of Health (MOH). This is because the CMR initially started educational programmes to improve the literacy and numeracy of people with severe impairments since 1990s. One of the CMR divisions, namely the Division on Inclusive Education and Special Schools, is responsible for providing teacher training, producing teaching and learning materials, and giving advice on how the facilities of mainstream schools should be improved to better serve the needs of learners with disabilities. However, many interviewees claimed that the CMR should instead focus on its main responsibilities concerning medical examination, therapy and rehabilitation. Many advised that the Division on Inclusive Education and Special Schools should be managed by concerned departments of the MOES because the provision of education 
to any group of people is outside the role and responsibilities of $\mathrm{MOH}$. Negotiations have been initiated to transfer this division under the responsibility of MOES, but the Memorandum of Understanding between MOH and MOES has not yet been signed. The current confusion of roles and responsibilities has resulted in many mainstream primary schools still being uncertain about what exact actions should be taken by them, and how these should be prioritised in order to best reflect the principles of inclusion.

The above confusion between the responsibilities of CMR and MOES to provide education for children with disabilities seems to undermine the implementation of IE in Lao PDR. This is in line with findings from Ineland (2015), in that the implementation of IE can be confusing for many implementers, despite the Salamanca Statement and Framework for Action adopted by the World Conference on Special Education in 1994. One of the confusions is about prioritising the needs of the majority over the minority (children with disabilities). Moreover, the IE vision is not only about the inclusion and placement of pupils with disabilities in a mainstream class; it is also about the reform of the whole school system, including organisation structures, teaching expectations, curriculum, leadership and teachers' attitudes and values (D'Alessio, 2012). According to the Salamanca Statement 1994, UNCRPD 2006 , inclusive practice in education is necessary to combat negative attitudes by the wide community towards disabled people and promote a more inclusive society. As this is an extensive and society-wide goal, IE becomes the responsibility of everyone, and thus very challenging to implement.

\subsection{Participants' perceptions}

\subsubsection{Knowledge of the inclusive education strategy}

The effective implementation of IE policy cannot be achieved successfully by the education sector alone, because guaranteeing an education system that is inclusive and non-discriminatory with regard to students' abilities requires broader society to have an accurate, shared understanding of what IE principles are, and why inclusive educational practice is necessary. If most people in society have an understanding of IE policy, it is more likely that they will participate and show ownership and support to maintain all-inclusive practices. Ahmmed and Mullick (2014) found that IE practice in Bangladesh faced a lot of difficulties because of the lack of community participation and ownership that they attributed to the low level of understanding in 
the concept of IE. It is therefore useful to discuss the participants' perceptions of IE policy. It is important to bear in mind that the majority of participants had heard about the MOES's IE policy but had not seen or read the actual documents. Not many interviewees had seen and read the MOES's IE policy, so that they did not fully understand what an inclusive school is. It was even harder for many other interviewees who had never seen or been informed about the existing of Lao IE policy.

This present research found that participants had at least two different views towards the concept of IE. Some participants viewed IE strategy as a way of transforming the educational system to be a non-discriminatory environment that promotes equal opportunities for all students to learn together, with a focus on girls, ethnic minorities, disabled people and socio-economically disadvantaged children. However, the majority of participants who had limited experience of IE project activities had a more narrow understanding, believing that IE is a concept which enables children with disabilities to have an equal opportunity to study together with other non-disabled students in mainstream schools. They added that a school that does not accept a student with disabilities cannot be called an inclusive school. The first and broader view is in line with the obligations required by many international documents, especially the World Declaration on EFA 1990 and UNCRPD 2006 (Mambo, 2011).

\subsubsection{Children with disabilities and their education}

By law, schools in Lao PDR should welcome all children without discrimination on the basis of ability, race, religion or other attributes. However, when education law is translated into practice, children with severe disabilities, including physical, sensory, hearing and cognitive impairments, are required to go to special schools or attend special classes. This seems to conflict with the principle of inclusion, where all students regardless of their disabilities can learn together with other non-disabled students in the school of their choice, and in a school that is located in the children's own communities (UNICEF, 2011). However, many primary school staff and teachers explained that it is still a challenge for them to implement the concept of IE into practice as they are not inadequately prepared to take children with disabilities. 


\subsubsection{The education of children with disabilities in mainstream schools}

The study revealed that there are limited educational options in Lao PDR for a child with a complicated impairment such as being mute, deaf or blind. There are only three regional special schools and very few mainstream schools able to teach children with such impairments. These schools are available only in some provinces and especially in the Vientiane prefecture. Furthermore, both the literature and the findings from interviews and observations agreed that children with disabilities tend to face greater risks in pursuing further education in mainstream formal school. From literature, despite the development and implementation of IE in many countries globally, children with disabilities still remain largely out of formal school (Landsdown, 2013). Children with disabilities clearly have limited opportunity to attend the school located within their community.

This study also found almost all participants to be aware that there are lower expectations and weaker academic requirements placed on students with significant levels of impairment, while students with moderate levels of impairment are generally treated the same as other non-disabled students. It is an exception for a student with a severe disability to pass to a new grade each year although they do not have to repeat the same learning materials each year. This seems to be more in line with the EFA strategy than with the principles of IE (Singal \& Miles, 2010). Singal and Miles argue that the principles of EFA focus more on accessibilities and outcomes of attendance at school, while IE tends to emphasise transforming the cultures, attitudes and values within the school environments, and the process of producing quality education outcomes. Moreover, simply allowing students with disabilities to pass easily from one grade to another is insufficient in itself to bring about an inclusive society, which is the main aim of inclusion.

\subsubsection{Perceptions on disabilities}

Overall all participants viewed disabilities more in terms of the medical model than a social constructionist approach. Almost 99 percent of the total study participants perceived disability as a partially malfunctioning body due to sickness, physical weakness and psychological disorder. This is in line with the views of Barnes (1998) and UNICEF (2011) that disability is commonly viewed as bodily dysfunction as a result of individuals having impairments which give rise to health limitations. This is why in Lao PDR, medical treatment and rehabilitation activities 
have been strongly promoted to address the needs of people with disabilities (Crow, 1996). For example, the provision of IE and special education for children with disabilities has been implemented by the Division of Inclusive Education and Special School of the CMR, Ministry of Health.

In addition, participants showed no evidence of associating disabilities with dysfunction of the society itself, even though Lao PDR ratified the UNCRPD in 2009 and produced the National Decree on Persons with Disabilities in 2014. Oliver and Barnes (2006) argue that disability is a socially constructed prejudice, which excludes, alienates from the majority, and discriminates against people with impairments. This implies that the attitudes of many Lao people still view disability in terms of individual health issues rather than social issues.

People's perception of disabilities plays a vital role in determining instruments to promote the education of children with disabilities (Mambo, 2011). On the one hand, if disability is understood as an individual shortcoming (Crow, 1996, UNESCO, 2009), children with disabilities will be rehabilitated and receive medical treatment in order to prepare them to comply with existing universal education standards that are considered normal for non-disabled students. On the other hand, if disability is interpreted in terms of social restriction (United Nations, n.d.), any restrictions or barriers faced by children with impairments should, ideally, be eliminated in order to promote individual potential instead of focusing on individual deficiency.

One of the sensitive issues that was not discussed during interviews is how Lao people, under Buddhist principles, construct the discourse of disability in a negative way. In Lao PDR, especially in Vientiane, the majority of people follow Buddhism and it has been argued that Buddhist principles play a very important role in the way many people perceive disability (Vorapanya \& Dunlap, 2014). Vorapanya and Dunlap (2014) conclude that Karma is one of the most important beliefs in Buddhism, and the belief in Karma has a significant impact on the attitudes towards people with disabilities.

'In Buddhist thinking, being born with a disability came from having bad karma in a previous life. Social status was viewed as important, and someone born with a disability was perceived as having lower status' (Vorapanya \& Dunlap, 2014, p.1020).

This means that for people who believe in Karma, if you are either born or have an impairment which prevents you from having full and effective participation 
in all aspects of life, you are being punished for your past life and any sinful actions undertaken by anyone in your family. As such, many children with disabilities' rights to primary education have not been addressed adequately because many people do not view disability as a human rights issue but as a personal issue.

\subsection{Factors affecting the implementation of the inclusive education strategy}

\subsubsection{Physical environmental facilities}

Basic facilities in the wider community should also be improved, because access by disabled pupils to school would definitely be enhanced by improving the physical infrastructure, including roads, electricity, clean water supply and public transport networks (UNESCO, 2015). Poor school environmental conditions and similar issues in general public facilities are two of the most crucial factors that hinder children with disabilities from accessing primary schools. Findings reveal that most mainstream primary schools still do not have supportive, friendly and safe environments for children with a wide range of impairments. In many mainstream primary schools, facilities such as adjustable tables and chairs, ramps, toilets and other supportive facilities are rarely found, even though since 2009 there has been school construction guidelines developed by MOES.

\subsubsection{Education stakeholders participation}

Participation by all primary school stakeholders in promoting the rights of children with disabilities to basic education is very important to this study because such children require more than just being present in a classroom. Deluca, et al., (2014) assert that positive impacts on the education of children with disabilities can be realised if school teachers, parents, children's caregiver and the government all show strong commitment to supporting knowledge, human resources and financial assistance to the school. Weak coordination among primary school stakeholders might result in children being placed in the schools that can exacerbate the existing conditions of children with disabilities.

In addition, the effective implementation of IE also depends on the support of many external stakeholders: especially in a lower-middle income country like Lao PDR. As identified from the findings, these stakeholders include local disabled people organisations, INGOs and Development Partners (donors). These stakeholders play a 
great role supporting the MOES, especially the IEC. Without external influence in terms of both technical advice and funding, the many mainstream primary schools in Vientiane might have stopped taking children with disabilities after Save the Children ended its funding in 2009. Thus, it is clear that to achieve effective implementation of IE strategies, all the stakeholders in society should be involved (Poon-McBrayer \& Wong, 2013).

Both the research findings and literature suggests that there should be a special organisation with the explicit responsibility to focus on the minority needs rather than those of the majority. Given a too broad and unenforced national IE policy, schools tend to face challenges in prioritising their program activities to include children with disabilities (Kratochvilova \& Havel, 2014). When IE policy is directed on a broad basis simply to all children, children with severe impairments are, for many reasons, often taken for granted and ignored.

\subsubsection{The inclusive education strategy of mainstream primary schools}

Translating the national IE policy framework into policy functioning at the school level remains a critical concern. While it is acknowledged that it is hard to find a perfect model of an inclusive school or of inclusive standards (Singal \& Miles, 2010), all parties concerned should, ideally, be supportive of the inclusion of children with disabilities. That support should apply at both the national and the school levels of planning processes, and in the implementation of action plans. The study found very little documented evidence that the national IE framework has been translated into the development policy and action plans of provincial, district and school education organisations. Specifically, many primary school development plan reports did not even mention IE, or record the responsiveness of the school and any adjustment of its activities to better involve students with disabilities. The only reference was found in collected numerical data regarding students with disabilities. In addition, schools had an unclear organisational structure to support the incorporation of disability rights into their plan. This is likely to be because the majority of participants still think that persons with severe impairment should attend special schools, without considering the tailoring of mainstream schools to the needs of children with disabilities.

The literature reviewed suggests that more IE and disability rights training should be given at the grass-roots level, in order to better prepare local schools and 
communities for a decentralised IE implementation approach. There is no doubt that successful implementation of IE policy at a local level requires governmental commitment to supporting this strategic direction, including the provision of financial and other resources (Kearney, 2009; World Health Organisation \& World Bank, 2011). However, to achieve a responsive IE practice, the principles of inclusion also need be clarified and communicated to grassroots stakeholders through ongoing training in the concepts of disability and inclusion, with the aim of changing negative attitudes and mind-sets that see children with disabilities as disabled people, and instead viewing them as humans with equal rights (Singal \& Miles, 2010; Sakiz \& Woods, 2015). The bottom-up approach to implementing IE strategies implies that both the community and concerned school teachers need to be empowered with the skills and knowledge to identify the needs of children with disabilities, and to determine the most effective ways to bring about an IE setting that is legally and socially responsible.

\subsection{Chapter summary}

This discussion chapter concluded that despite the fact that the Lao IE strategy appeared to be a promising principle that is in line with human rights principles, its impacts to date have been largely ineffective in ensuring all children with disabilities are being included in all mainstream primary schools. This research identified some of the most critical issues that determined the extent of responsiveness of the all mainstream primary schools. One of the most important issues is the broadness of the focus of the IE strategy, which is based on a broad human rights approach which does not specifically emphasise the transformation of school institutions and environments to encompass children with all kinds of impairments. A further issue is the lack of enforceable legislation, requiring the provision of both adequate financial support and other resources that is essential to implement IE policy at the primary school level. The final issue is that people with different backgrounds mostly do not share the same understanding on the principles of inclusion and disability. These are some of the reasons why the implementation of the Lao IE strategy on primary school students continues to experience challenges. 


\section{CHAPTER SEVEN \\ CONCLUSIONS}

\subsection{Introduction}

This study was conducted with the aim of examining the responsiveness of the Lao public mainstream primary schools to meet the needs of primary school students with disabilities. This study provided an analysis on the quality and meaningful study environment of primary school students with all kinds of impairments, in regard to the effects of the implementation of the IE principles. Taking a qualitative research approach, this study examined both secondary literature and the opinions of participants from diverse professional backgrounds. This study was conducted in Vientiane, which is considered to be one of the most modernised cities in Lao PDR. Data collection was carried out over a two month period from April to June 2015. I was able to collect documents, conduct semistructured interviews and observe over ten public primary schools from four different districts in Vientiane. The backgrounds of participants includes representatives of government ministries, development partners, INGOs, local civil society, village authorities, communities, parents, disabled people, school principals, teachers and educational staff from both provincial and district education and sports offices.

In this conclusion chapter, I will summarise some of the most important issues identified through the findings. It will also provide some recommendations for future research.

\subsection{The inclusive education strategy and primary school students with disabilities}

The development of IE policy and practices in Lao PDR has been progressing at a relatively slow pace because there are many issues that have not yet been properly addressed. One of the positive signs for the progressive transformation of Lao IE is that there is ongoing development of national action plans regarding IE. These plans include the National IE policy, National Strategy and Action Plan on IE 2011-2015, The Draft Plan of Action on Education for Learners with Disabilities 2016-2020, and establishment of the Children with 
Special Educational Needs Division in the IE Centre of the MOES. Thus at the national level, IE policy and practice appears to be improving.

However, despite the improvement of IE policy at the national level, many of Lao public mainstream primary schools' policy and practices have not rigorously followed the principles of IE. The overall national IE policy framework states that children with complex impairments will be required to attend the regional special IE centre. In this centre, if students perform well, they will be sent to a nominated state mainstream school.

A fundamental principle of inclusion requires that children, regardless of their abilities, should begin their education in the local schools which other nondisabled students attend. In addition, even though Lao IE policy specifies that children with disabilities constitute one group of target beneficiaries, almost all public mainstream primary schools do not have a disabilities policy or special provisions in place that meet the needs of students with disabilities. If these issues persist, students with sever impairments will continue to experience all sorts of barriers in learning and socialising.

Furthermore, while IE policies and plans have been discussed amongst different stakeholders at the national level, there has been little impact on most state mainstream primary schools. Virtually none of the state mainstream primary schools has an IE policy, a disabilities unit, or facilities and services that will support and enable the education of children with complex types of impairments. Children with disabilities are not being prioritised, in part because of the lack of comprehensive, accurate and relevant data, and because of inadequate funding. IE policy still conforms to the medical model of disabilities which has been critiqued. Participants in this study still perceive disability as a malfunction of the body. This is in turn aligned with the national IE policy that requires children with complex impairments to be sent to an IE special centre to be 'rehabilitated' in order to comply with mainstream school standards. In practice, children with complex impairments are still far from being able to experience an equal and nondiscriminatory mainstream primary educational environment. 


\subsection{Suggestions for future research}

Based on questions raised by this thesis, a few useful suggestions were discovered. In the light of my experience with the present research I suggest that future research should utilise both quantitative and qualitative approaches. This is because this thesis was not able to quantify the opinion of all interviewees in percentage. The present research was limited to students with disabilities, and concentrated on only four districts within Vientiane capital. However, it would be valuable to explore the impacts of the IE principles in others. Results gathered from Vientiane, the most industrialised city, cannot be generalised to others that have poorer infrastructure and services. In addition, this study took a wide range of perspectives, so the investigation was not limited to only one or two particular types of disability. Future research that focusses on one or two types of disability, and looks at them in greater detail would also be valuable as children with either similar or different types of impairment may not share different experiences in accessing mainstream primary schools. The researcher should also spend sufficient time observing the education of students with these specific disabilities, such as students with visual impairment, or students with speaking or hearing difficulties. These are only a few recommendations that might bring about a more comprehensive view to build on this existing study. 


\section{REFERENCES}

Ahmmed, M., \& Mullick, J. (2014). Implementing inclusive education in primary schools in Bangladesh: recommended strategies. Educational Research for Policy and Practice, 13(2), 167-180. doi: 10.1007/s10671-013-9156-2

Asia Development Bank. (2015). Lao PDR: Economy. Retrieved 1 December 2015, from http://www.adb.org/countries/lao-pdr/economy

Association for Autism. (2015). Annual report 2014. Vientiane: Association for Autism.

Barnes, C. (1998). The social model of disability: A sociological phenomenon ignored by sociologists. The disability reader: Social science perspectives, 65-78.

Bouthakhanh, K. (2013). Inclusive education teachers' perception on educating children with special needs in primary schools in Vientiane capital. (Master), Osaka University, Kyoto.

Bowen, G. A. (2009). Document analysis as a qualitative research method. Qualitative research journal, 9(2), 27-40.

Carter, M. R., \& Barrett, C. B. (2006). The economics of poverty traps and persistent poverty: An asset-based approach. The Journal of Development Studies, 42(2), 178-199.

Chacko, E. (2004). Positionality and Praxis: Fieldwork Experiences in Rural India. Singapore Journal of Tropical Geography, 25(1), 51-63. doi: 10.1111/j.01297619.2004.00172.x

Chanthalanouvong, T. (2010). Country presentation: Measurement of gender dimensions of persons with disabilities in Lao PDR. 3rd Global Forum on Gender Statistics. Manila.

Chounlamany, K. (2014). School education reform in Lao PDR: good intentions and tensions?. Revue internationale d'éducation de Sèvres. Retrieved 10 December 2015, from https://ries.revues.org/3766

Conquergood, D. (1988). Health theatre in a Hmong refugee camp: Performance, communication, and culture. TDR (1988-), 32(3), 174-208.

Creswell, J. W. (2009). Research design: Qualitative, quantitative, and mixed methods approaches: SAGE Publications, Incorporated.

Creswell, J. W. (2013). Research design: Qualitative, quantitative, and mixed methods approaches: Sage publications. 
Cross, W. E. (2013). The Semi-Structured Interview as a Repertoire of Possibilities. In A. Galletta (Ed.), Mastering the Semi-Structured Interview and Beyond (pp. 4572): NYU Press.

Crow, L. (1996). Including all of our lives: Renewing the social model of disability. Encounters with strangers: Feminism and disability, 206-226.

D’Alessio, S. (2012). Inclusive Education in Italy (Vol. 10): Springer Science \& Business Media.

Daveta, M. L. (2009). Inclusive education for children with disabilities in Fiji: Teacher perspectives and attitudes. The University of Waikato.

de Boer, A., Pijl, S. J., \& Minnaert, A. (2011). Regular primary schoolteachers' attitudes towards inclusive education: A review of the literature. International Journal of Inclusive Education, 15(3), 331-353.

Deluca, M., Tramontano, C., \& Kett, M. (2014). Including children with disabilities in primary school: the case of Mashonaland, Zimbabwe. Retrieved 28 November 2015, from https://www.ucl.ac.uk/lcccr/centrepublications/workingpapers/WP26_IE_Zimbabwe.pdf

Dyson, A. (2003). Working towards Inclusive Education: Social Contexts. European Journal of Special Needs Education, 18(1), 125-128. doi: $10.1080 / 0885625032000042357$

Education Review Office. (2015). Inclusive practices for students with special needs in schools. Wellington, New Zealand.

Elkins, J., Van Kraayenoord, C. E., \& Jobling, A. (2003). Parents' attitudes to inclusion of their children with special needs. Journal of Research in Special Educational Needs, 3(2), 122-129.

Freire, P. (2000). Pedagogy of the oppressed: Bloomsbury Publishing.

Friedmann, J. (1992). Empowerment: the politics of alternative development: Blackwell.

Fuchs, D., \& Fuchs, L. S. (1994). Inclusive schools movement and the radicalization of special education reform. Exceptional children, 60(4), 294.

Government. (2014). Decree on persons with disabilities. Vientiane: The government of Lao PDR.

Grimes, P. (2009). A quality education for all: A history of the Lao PDR inclusive education project 1993-2009. Vientiane: Save the Children Norway. Retrieved 27 November 2015, from 
http://www.eenet.org.uk/resources/docs/A_Quality_Education_For_All_LaoPD R.pdf

Grimes, P., Sayarath, K., \& Outhaithany, S. (2011). The Lao PDR Inclusive Education Project 1993-2009: reflections on the impact of a national project aiming to support the inclusion of disabled students. International Journal of Inclusive Education, 15(10), 1135-1152.

Global Facility for Disater Reduction Recovery. (2014). Country Case Study Series: Disaster Recovery Framework Guide. Retrieved 20 November 2015 from http://gfdrr.org/sites/gfdrr/files/New\%20Folder/Lao\%20April\%202014.pdf.

Hamilton-Merritt, J. (1993). Tragic mountains: The Hmong, the Americans, and the secret wars for Laos, 1942-1992: Indiana University Press.

Hassanein, E. E. A. (2015). Inclusion, Disability and Culture: Springer.

Ineland, J. (2015). Logics and ambivalence - professional dilemmas during implementation of an inclusive education practice. Education Inquiry, 6(1). doi: http://dx.doi.org/10.3402/edui.v6.26157

JICA. (2002). Country profile on disability Lao PDR. Vientiane: Japan International Cooperation Agency Retrieved 1 December 2015, from http:/gwweb.jica.go.jp/km/FSubject0601.nsf/3b8a2d403517ae4549256f2d002e 1dcc/54a619bb76fd92034925727d0008246b/\$FILE/LaoPDR\%282002\%29.pdf Kavale, K. A., \& Forness, S. R. (2000). History, rhetoric, and reality analysis of the inclusion debate. Remedial and Special Education, 21(5), 279-296.

Kearney, A. C. (2009). Barriers to school inclusion: An investigation into the exclusion of disabled students from and within New Zealand schools. (Doctor of Philosophy), Massey University, Wellington. Retrieved 30 November 2015 from http://mro.massey.ac.nz/handle/10179/876

Kim, Y.-W. (2014). Inclusive education in South Korea. International Journal of Inclusive Education, 18(10), 979-990. doi: 10.1080/13603116.2012.693402

Kimmel, M. S. (2004). Masculinity as homophobia: Fear, shame, and silence in the construction of gender identity. Race, Class, and Gender in the United States: An Integrated Study. Ed. Paula S. Rothenberg. New York: Worth, 81-93.

Kratochvílová, J., Havel \&, J. (2014). Terms of Inclusive Education in Primary Schools-National and School Curriculum. Procedia-Social and Behavioral Sciences, 141, 337-341. 
Landsdown, G. (2013). Children with disabilities. Schulze, M. \& Sabatello, M. (Eds.). Human Rights and Disability Advocacy (pp.97-112). Philadelphia: University of Pennsylvania Press.

Lao Disabled People's Association. (2011). Sign language development project report, 6 months period (1 January - 30 June 2011). Vientiane, Lao PDR: Lao Disabled People's Association.

Lim, L., \& Thaver, T. (2014). Inclusive education in the Asia-Pacific region. International Journal of Inclusive Education, 18(10), 975-978.

MacQuarrie, A. \& Laurin-Bowie, C. (2013). Our lives, our voices: People with intellectual disabilities and their families. Schulze, M. \& Sabatello, M. (Eds.). Human Rights and Disability Advocacy (pp.25-44). Philadelphia: University of Pennsylvania Press.

Mambo, J. A. (2011). Exploring Teachers' perceptions of the Implementation of Inclusive Education in a Regular Primary School: A Papua New Guinea Study. (Master), Victoria University of Wellington, Wellington. Retrieved 30 November 2015 from http://researcharchive.vuw.ac.nz/bitstream/handle/10063/2496/thesis.pdf?sequen ce $=2$

Maout, C. (2014). Disability Inclusive Education in Lao PDR: Situational Analysis Report for Handicap International. Vientiane, Lao PDR.

McMichael, P. (2011). Development and social change: A global perspective: Sage Publications.

Ministry of Education and Sports (MOES). (2009). School construction guidelines. Vientiane, Lao PDR.

MOES. (2011). National strategy and action plan on inclusive education 2011-2015. Vientiane, Lao PDR.

MOES. (2014). Special and inclusive education guideline (draft). Department of Pre and Primary Education. Inclusive Education Center. Vientiane, Lao PDR.

MOES. (2015). The Plan of Action on Education for Learners with Disabilities 20162020 (draft). Department of Pre and Primary Education, Inclusive Education Center. Vientiane, Lao PDR.

MOH. (2011). Approval on the implementation and organisation of the Centre of Medical Rehabilitation No.1241, date 04 August 2011. Vientiane: Ministry of Health. 
MOPW. (2015). Draft regulation on public housing control. Department of Public Housing and Urban Plannning. Ministry of Public Works and Transportation. Vientiane, Lao PDR

Norwich, B. (2014). Recognising value tensions that underlie problems in inclusive education. Cambridge Journal of Education, 44(4), 495-510. doi: 10.1080/0305764X.2014.963027

National Assembly of Lao PDR. (2011a). 9th party congress of the Lao people's revolutionary party opens. Retrieved 30 November 2015, from http://na.gov.la/index.php?option=com_content \&view=article\&id=139:9thparty-congress-of-the-lao-peoples-revolutionary-party-opens-\&catid=64:theassociation-of-lao-parliamentarians\&lang=en

National Assembly of Lao PDR. (2011b). Constitution of Lao PDR: Chapter II The socio-economic system. Retrieved 4 January 2016, from http://www.na.gov.la/index.php?option=com_content $\& v i e w=\operatorname{article} \& i d=28 \% 3 \mathrm{~A}$ chapter-1l-the-socio-economic-system \&catid=35\%3Aconstitution-of-laopdr\&Itemid $=52 \&$ lang $=$ en

National Reguatory Authority. (n.d). National Regulatory Authority for the UXO/Mine Action Sector in the Lao PDR ( NRA). Retrieved 10 September 2015, from http://www.nra.gov.la/

National Statistics Centre. (2011). Disability statistics of Lao PDR. Vientiane, Lao PDR: National Statistic Center.

Natioanl Statistics Center. (2015). Population and housing survey 2015. Department of Social Statistics. National Statistics Centre. Vientiane.

Oliver, M., \& Barnes, C. (2010). Disability studies, disabled people and the struggle for inclusion. British Journal of Sociology of Education, 31(5), 547-560.

Opoku, M. P., Badu, E., Amponteng, M., \& Agyei-Okyere, E. (2015). Inclusive Education at the crossroads in Ashanti and BrongAhafo regions in Ghana: Target not achievable by 2015. Disability, CBR \& Inclusive Development, 26(1), 63-78.

Organisation for Economic Co-operation and Development. (2000). Inclusive education at work: Students with disabilities in mainstream schools. Paris: OECD Publishing. 
Pijl, S., Minnaert, A., \& de Boer, A. (2011). Regular primary schoolteachers' attitudes towards inclusive education: a review of the literature. International Journal of Inclusive Education, 15(3), 331-353. doi: 10.1080/13603110903030089

Polonsky, M. J., \& Waller, D. S. (2014). Designing and managing a research project: A business student's guide: Sage Publications.

Poon-McBrayer, K. F., \& Wong, P.-m. (2013). Inclusive education services for children and youth with disabilities: Values, roles and challenges of school leaders. Children and Youth Services Review, 35(9), 1520-1525.

Price, P., \& Takamine, Y. (2003). The Asian and Pacific decade of disabled persons 1993-2002: What have we learned? Developmental Articles, 14(2), 115-127.

Rist, G. (2002). The history of development: from western origins to global faith: Zed books.

Sabatello, M. (2013). A short history of the international disability rights movement. Schulze, M. \& Sabatello, M. (Eds.). Human Rights and Disability Advocacy (pp.13-24). Philadelphia: University of Pennsylvania Press.

Save the Children Norway. (2009). Lao PDR inclusive education project: Internal final evaluation report. Vientiane, Lao PDR.

Saythany District Education and Sports Services. (2015). Report of the education development plan implementation 2014-2015 and education development plan 2015-2016. Saythany District Education and Sports Services. Vientiane, Lao PDR.

Scior, K., \& Werner, S. (2015). Changing attitudes to learning disability: A review of the evidence Retrieved 30 November 2015, from https://www.mencap.org.uk/sites/default/files/documents/Attitudes_Changing_R eport.pdf

Sen, A. (2001). Development as freedom: Oxford University Press.

Shakespeare, T. (2006). The social model of disability. The disability studies reader, 2 , 197-204.

Shaw, B. (2014). Inclusion or choice? Securing the right to inclusive education for all. Human rights \& disability advocacy. University of Pennsylvania Press, Philadelphia, 58-63.

Silverman, D. (2001). Interpreting qualitative data: Methods for analysing talk, text and interaction: Sage London. 
Singal, N., \& Miles, S. (2010). The Education for All and inclusive education debate: conflict, contradiction or opportunity? International Journal of Inclusive Education, 14(1), 1-15. doi: 10.1080/13603110802265125

Singal, N., \& Muthukrishna, N. (2014). Introduction: Education, childhood and disability in countries of the South-Re-positioning the debates. Childhood, 0907568214529600.

Terzi, L. (2004). The social model of disability: A philosophical critique. Journal of applied philosophy, 21(2), 141-157.

The World Bank. (2015). Overview: context. Retrieved 1 December 2015, from http://www.worldbank.org/en/country/lao/overview

The World Bank \& OECD. (2013). Human rights into development: Donor approaches, experiences and challenges (2nd ed.). Washington DC: The World Bank and Organisation for Economic Co-operation and Development.

Thomas, P. (2011). Implementing disability - inclusive development in the Pacific and Asia. The Development Bulletin. Retrieved 29 November 2015, from http://www.vision2020australia.org.au/uploads/page/83/db-74.pdf

Tremblay, P., \& Tivat, M. (2007). Special Needs Education Basis: Historical and Conceptual Approche. Special Needs Education Basis: Historical and Conceptual Approach.

UNDP. (1991). Human development report 1991. Retrieved 30 November 2015, from http://hdr.undp.org/sites/default/files/reports/220/hdr_1991_en_complete_nostat s.pdf

UNDP. (2013). The MDGs and Lessons Learnt for the Post-2015 Period: A Summary Review. Retrieved 2 January 2016, from http://www.la.undp.org/content/lao_pdr/en/home/library/mdg/mdgs-summaryreview/

UNDP. (2014). Human development report 2014. Retrieved 30 November 2015, from http://hdr.undp.org/sites/default/files/hdr14-report-en-1.pdf

UNICEF. (2016). Human rights-based approach to programming. Retrieved 5 March 2016, from http://www.unicef.org/policyanalysis/rights/index_62012.html

United Nations. (n.d(a)). Convention on the rights of persons with disabilities and optional protocol. Retrieved 28 November 2015, from http://www.un.org/disabilities/documents/convention/convoptprot-e.pdf United Naitons. (n.d(b)). Factsheet on persons with disabilities. Retrieved 30 November 2015, from http://www.un.org/disabilities/default.asp?id=18 
United Nations Educational, Scientific and Cultural Organisation (UNESCO). (2009).

Teaching children with disabilities in inclusive setting. Retrieved 29 November 2015, from http://unesdoc.unesco.org/images/0018/001829/182975e.pdf

UNESCO. (2012). Lao PDR UNESCO country programme document 2012-2015.

Retrieved 28 November 2015, from

http://www.uis.unesco.org/Library/Documents/lao-pdr-unesco-countryprogramming-document-education-2012-2015-en.pdf

UNESCO. (n.d). Education for all flagship initiatives The right to education for persons with disabilities: Towards inclusion Retrieved 28 November 2015, from http://www.unesco.org/education/efa/know_sharing/flagship_initiatives/persons _disabilities.shtml

UNESCO. (2014). Education for all 2015 national review: Country report of Lao PDR. Retrieved 2 January 2016, from http://unesdoc.unesco.org/images/0023/002314/231489e.pdf.

UNICEF. (n.d). Our representative. Laos. Retrieved 30 November 2015, from http://www.unicef.org/laos/about_23215.html

UNICEF. (2007). Promoting the rights of children with disabilities. Retrieved 30 November 2015 from http://www.un.org/esa/socdev/unyin/documents/children_disability_rights.pdf

United Nations Children's Fund (UNICEF). (2011). The right of children with disabilities to education: A rights-based approach to inclusive education in the CEECIS Region. Retrieved 27 November 2015, from http://www.unicef.org/ceecis/Background_NoteFINAL\%281\%29.pdf

UNICEF. (2014). Global initiative on out-of-school children: South Asia regional study covering Bangladesh, India, Pakistan and Sri Lanka. Retrieved 28 November 2015, from

http://www.unicef.org/education/files/SouthAsia_OOSCI_Study_Executive_Su mmary_26Jan_14Final.pdf

United States Census Bureau. (2014). American community survey. Retrieved 27 November 2015, from https://www.census.gov/people/disability/methodology/acs.html?cssp=SERP Vientiane Capital Education and Sports Bureau. (2014). Statistics of schools, teachers and class room, primary schools in 9 districts in 2014-2015 (Both public and 
private school). Vientiane Capital Education and Sport Bureau. Vientiane, Lao PDR.

Vorapanya, S., \& Dunlap, D. (2014). Inclusive education in Thailand: practices and challenges. International Journal of Inclusive Education, 18(10), 1014-1028. doi: 10.1080/13603116.2012.693400

Woods, C., \& Sakız, H. (2015). Achieving inclusion of students with disabilities in Turkey: current challenges and future prospects. International Journal of Inclusive Education, 19(1), 21-35. doi: 10.1080/13603116.2014.902122

World Health Organisation, \& The World Bank. (2011). World report on disability. Geneva. 


\section{APPENDICES}

Appendix A: Ethic approval

TE WHARE WÃNANGA O TE OPOKO O TE IKA A MĀUI

5 F

UNIVERSITY OF WELLINGTON

MEMORANDUM

Phone $\quad 0-4-4635676$

Fax $\quad 0-4-4635209$

Email Allisonkirkman\&vuw.acnz

\begin{tabular}{l|l}
\hline TO & Nor Heu \\
\hline COPY TO & John Overton \\
\hline FROM & Dr Allison Kirkman, Convener, Human Ethics Committee \\
\hline
\end{tabular}

\begin{tabular}{l|l}
\hline DATE & 22 April 2015 \\
\hline PAGES & 1 \\
\hline
\end{tabular}

\section{SUBJECT $\quad$ Ethics Approval: $\mathbf{2 1 6 7 0}$}

The Impact of the Inclusive Education Strategy on the Education of Primary School Students with Disabilities in Vientiane, Lao PDR

Thank you for your application for ethical approval, which has now been considered by the Standing Committee of the Human Ethics Committee.

Your application has been approved from the above date and this approval continues until 26 February 2016. If your data collection is not completed by this date you should apply to the Human Ethics Committee for an extension to this approval.

Best wishes with the research.

Allison Kirkman

Human Ethics Committee 


\section{Appendix B: Letter of support}

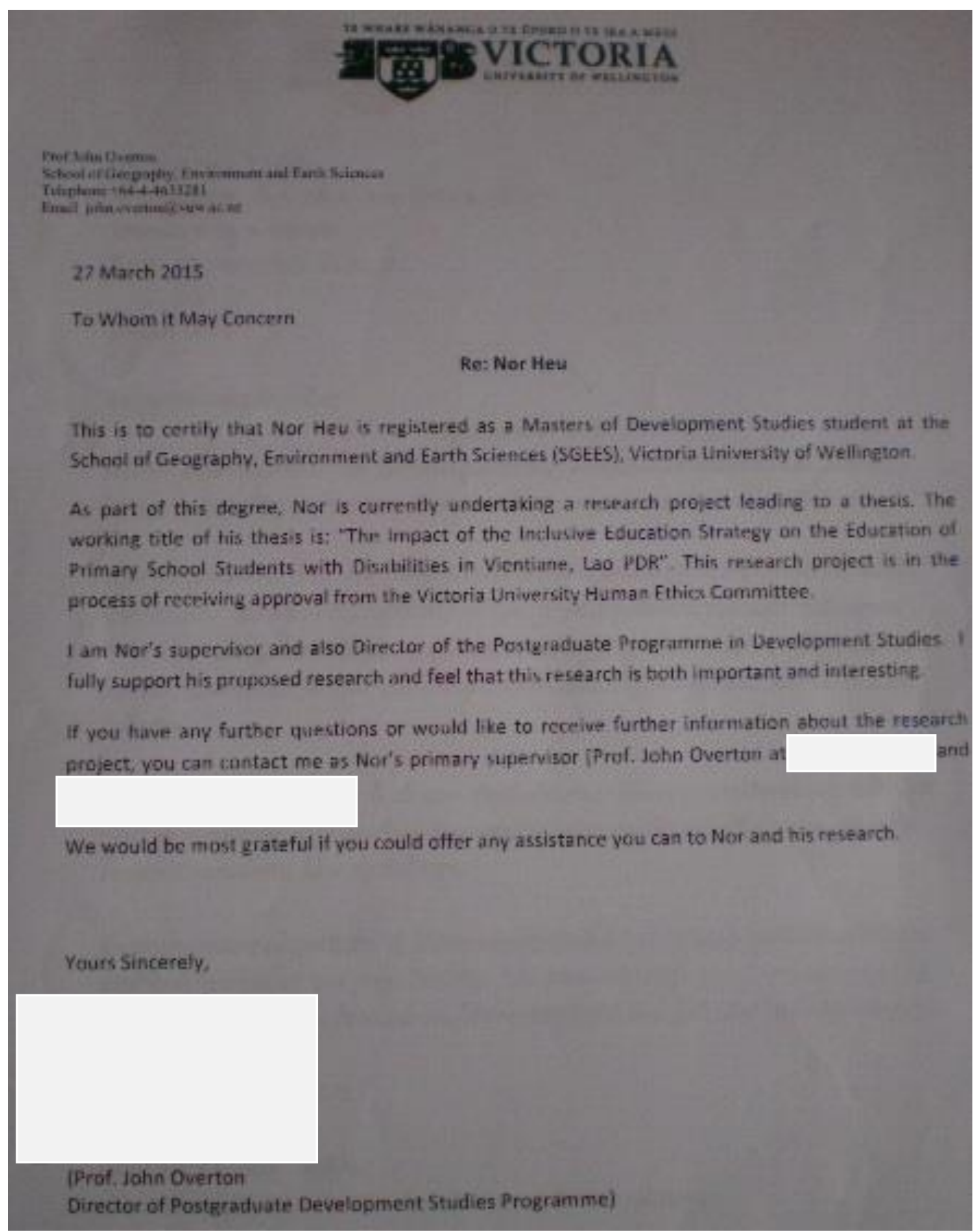




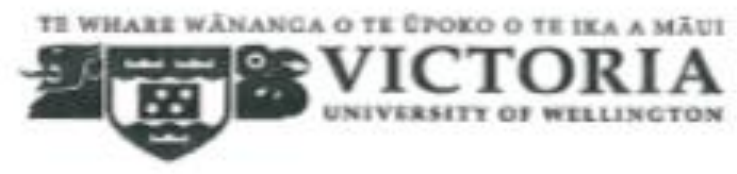

\section{Participant Information Sheet}

Research Title: The Impact of the Inclusive Education Strategy on the Education of Primary School Students with Disability in Vientiane, Lao PDR.

Sabaidee! I, Nor HEU, am a Master of Development Studies student at Vietoria University of Wellington, New Zealand. As part of my degree, I am writing a thesis on the impact of the Inclusive Education Initiatives on improving the education of primary school students with disability in Lao PDR. The main objective of this research is to analyse lessons from the Inclusive Education Strategy in order to ensure that in the future more children with disability will be able to complete meaning ful and good quality basic oducation in the same ofucational setting as others children across the country.

I would like to invite you, as a representative of your organisation to participate in an interview in which you will be able to share your experiences and stories of bow your organisation has participate in the government's inclusive education programme to improve primary school facilities and policies to include students with disability. The discussion we have will be conducted through semi-structured questions related to this topic. It will take around 40 minutes.

Victoria University requires all students conducting research with people to undergo ethics assessment and approval. As part of this process there are several things that you need to be aware of before you consent to participate in this rescarch:

If you give me your permission, the interview will be reconded to support the researcher's notes in case any ideas have been missed. Following our discussion, you have the right to check the interview notes. Written and electronically recorded material made during the interview will be safely stored and will only be seen by my supervisor and myself. The researcher will take all necessary steps to kecp interview information safe during time in the field. All interview materials will be destroyed upon completion of the thesis.

It will be your decision as to whether you and your organisation will be identified or will remain confidential in the published thesis. As a participant, you do not have to answer all questions. If you agree to take part in the interview you are free to withdraw at any stage without having to give a reason. You are free to withdraw any information you have provided before data collection and analysis of the research is complete on $1^{\text {it }}$ October 2015.

Upon completion of my thesis, a copy of this thesis will be lodged in the Victoria University Wellington. The summary findings will be made available to you, if you are interested. The final research may also be published in academic or professional journals and/or disseminated at academic or professional conferences as the opportunity arises.

I hope you will agree to participate in this research and I look forwand to speaking with you

Nor HEU,

Professor John Overton (Supervisor) 
Appendix D: Semi-structured interview questions

\section{Semi-Structured Interview Questions}

I. Understanding of Inclusive Education (IE) approach

1. Could you explain the aim of the IE approach?

2. Who are the target beneficiaries for IE? Why?

3. For primary school education, how does IE relate to what types of Students with Disabilities (SWDs)? What indicators that IE determines access to education of SWDs?

II. Understanding of disability

1. How do you understand disability? What are types of disability?

2. Thinking about the primary school you know, what type of children with disability can participate in the regular public primary school? Why and why not?

3. If children with disability cannot attend or complete primary school, what are the effects? What could be improved in IE policy?

III. To what extent have public primary schools being adapted to be responsive to the needs of PSDs?

1. How do schools and others create awareness raising for a friendly environment (values, belief, practice, words, traditions and others within school?)

2. What is the policy toward the welfare and wellbeing of PSD in terms of accommodation, transport, foods, registration and tuition fees, study materials, and other social event fees?

3. How do you address not attending, repetition and drop out of PSDs at primary schools?

4. How do you provide mobile teachers or extra support teacher to PSD? (resources and money)

5. How do you reform curricula and provide teaching and learning materials, including supportive devices that is appropriate the needs of students with learning difficulties?

6. How do you guarantee making sure schools provide appropriate assistance (facilities and services) to PSDs? How is this issues being addressed if school do not meet the requirements to include PSD?

7. How do you promote the recruitment and development of teacher and civil staff to

8. The collection, analysis and dissemination of disability data including children with disabilities

9. Promote the participation and coordination of other stakeholders

10. Increase budget and investment of both public and private education on PSDs' education

VI. Recommendations for improvement:

1. How to address barriers to education of PSDs? (attitudes, environment and institutions)

2. How to minimize repetitive challenges? (ownership, coordination, administration others expenses)

3. What/how can you offer to help expand the IE to all primary schools across the country? 
Appendix E: Transcriber confidentiality form

\section{Transcriber Confidentiality Form}

Project Title: The Impact of the Inclusive Education Strategy on the Education of Primary School Students with Disability in Vientiane, Lao PDR.

\section{Principal Investigator: Nor HEU}

I, Nor HEU, agree to ensure that the audiotapes transcribed will be remained confidential to my supervisor and myself.

I agree to take the following precautions:

1. I will ensure that no person, other than my research supervisor, hears the recording.

2. I will ensure that no other person has access to my PC.

3. I will delete the files from my pc once the transcription has been completed.

4. I will not discuss any aspect of the recording with anyone except my supervisor.

Signature:

Date: $11-03-2015$ 
Appendix F: Letter of proposal

Lao People's Democratic Republic

Peace Independence Democracy Unity Prosperity

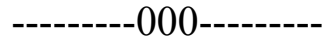

Vientiane, Lao PDR

21 April 2015

\section{$\underline{\text { Letter of Proposal }}$}

To:

Subject: Request permission to conduct interview(s) and collect both hard and soft copy of data concerning the impact of the Inclusive Education strategy on the education of primary school students with disability.

- According to the letter of support dated 27 March 2015.

I, Nor HEU, am a student of New Zealand Aid Programmes Scholarship 2014 - 2016 to undertake a Master of Development Studies at Victoria University of Wellington (VUW), New Zealand. This year I am writing a research project on 'the impact of the Inclusive Education strategy on the education of primary school students with disabilities in Vientiane, Lao PDR'. Confidentiality and privacy issues will be strictly protected under VUW research ethics policy since this project has approval from the VUW Human Ethics Committee.

This project involves interviewing and collect relevant data. These data is very crucial to support me writing my final thesis. Therefore, I would like to request your permission to recruit an appropriate person for interviewing and discuss my project in more details. Any question, please contact me at (Lao PDR) or email:

I hope that you will provide me appropriate assistance and allow your organisation to participate in this project.

Yours Sincerely,

Approved by:

Requested by:

Attachment:

- Letter of Support (Lao and English)

- Interview questions (Lao and English) 
Appendix G: Participant consent form

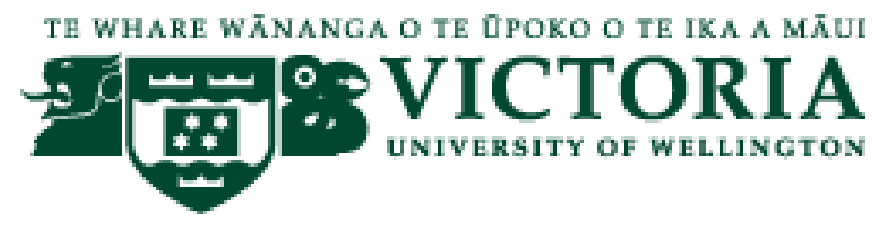

Consent to Participation in Research

Title of project: The Impact of the Inclusive Education Strategy on the Education of Primary School Students with Disability in Vientiane, Lao PDR.

Researcher: Nor HEU, School of Geography, Environment and Earth Sciences, Victoria University of Wellington

$\checkmark \quad$ I have read the Participant Information Sheet and understand the purpose of this research project.

$\checkmark \quad$ I understand the interview will be electronically recorded and any notes or recorded material from interviews will be destroyed at the end of the research process.

$\checkmark \quad$ I understand that all information I provide will be safely stored accessed only by the researcher and research supervisor.

$\checkmark \quad$ I understand I will have an opportunity to see a summary of the interview.

$\checkmark$ I understand I may withdraw myself, and any information I have provided, from this research project without explanation at any time before $1^{\text {st }}$ October 2015.

$\checkmark \quad$ I understand the results of this research will be included in a thesis and may be used for publication in academic or professional journals, and for dissemination at academic or professional conferences.

$\checkmark$ I agree to take part in this research.

\section{Please tick as appropriate:}

I would like to check the interview note before ending the interview process.

I would like to receive a summary of the results of this research when it is completed.

I consent to my name being used when my comments or opinions are used in this research.

I request that my name be omitted and a pseudonym assigned by the researcher be used if my comments or opinions are included in this research.

I consent to the name of the organisation I work for being used in this research.

I request the name of the organisation I work for to be omitted from this research.

Name: Date:

Organisation: ..Phone:

Email:

\section{Signature:}

